National Library

of Canada

Acquisitions and

Bibliographic Services Branch

395 Wellington Streel

Ottawa. Ontario

KIA ON4
Bibliotheque mationale

du Cánada

Direction des acquisitions el

des senvices bibliographiques

395. ne Wellinglon

Onawa (Ontario)

KIA ON4

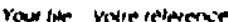

The quality of this microform is heavily dependent upon the quality of the original thesis submitted for microfilming. Every effort has been made to ensure the highest quality of reproduction possible.

If pages are missing, contact the university which granted the degree.

Some pages may have indistinct print especially if the original pages were typed with a poor typewriter ribbon or if the university sent us an inferior photocopy.

Reproduction in full or in part of this microform is governed by the Canadian Copyright Act, R.S.C. 1970 , c. C-30, and subsequent amendments.
La qualité de cette microforme dépend grandement de la qualité de la thèse soumise au microfilmage. Nous avons tout fait pour assurer une qualité supérieure de reproduction.

S'il manque des pages, veuillez communiquer avec l'université qui a conféré le grade.

La qualité d'impression de certaines pages peut laisser à désirer, surtout si les pages originales ont été dactylographiées à l'aide d'un ruban usé ou si l'université nous a fait parvenir une photocopie de qualité inférieure.

La reproduction, même partielle, de cette microforme est soumise à la Loi canadienne sur le droit d'auteur, SRC 1970, c. C-30, et ses amendements subséquents. 


\section{THE EFFECTS OF LONGGAVE RADIATION \\ IN A SMALL CUMULUS CLOUD}

\section{By}

Hong Guan
SUBMITTED IN PARTIAL FULFILMENT OF THE ... REQUIREMENTS FOR THE DEGREE OF DOCTOR OF PHILOSOPHY AT MCGILL UNIVERSITY MONTREAL, QUEBEC August, 1995

(c) Copyright by Hong Guan, 1995 
Acquisitions and

Bibliographic Services Branch

395 Wellington Street

Ottawa, Ontario

KIA ON4
Bibliothèque nationale

du Canada

Direction des acquisitions et des services bibliographiques

395, rue Wellington

Ottawa (Ontario)
The author has granted an irrevocable non-exclusive licence allowing the National Library of Canada to reproduce, loan, distribute or sell copies of his/her thesis by any means and in any form or format, making this thesis available to interested persons.
L'auteur a accordé une licence irrévocable et non exclusive permettant à la Bibliothèque nationale du Canada de reproduire, prêter, distribuer ou vendre des copies de sa thèse de quelque manière et sous quelque forme que ce soit pour mettre des exemplaires de cette thèse à la disposition des personnes intéressées.

L'auteur conserve la propriété du droit d'auteur qui protège sa thèse. Ni la thèse ni des extraits substantiels de celle-ci ne doivent être imprimés ou autrement reproduits sans son autorisation. 
This work is dedicated to my parents 


\section{Abstract}

The effects of longwave radiation on the development of a small cumulus cloud were investigated by a combination of three-dimensional radiative transfer model as well as slabsymmetric and axially symmetric cloud ciynamics models.

A longwave radiation model was developed. The model was first applied to the case of an isolated cumuliform cloud in the form of a cylinder, the results of which illustrate the importance of cloud side cooling. We proposed that the radiatively forced sinking of air at the sides of cumuliform clouds would lead to lower-level convergence and thereby enhances the upward motion in the interior of the cloud.

A study of cloud top cooling rate in stratiform clouds with positive (lifting) or negative (sinking), axially symmetric perturbations shows that a lifting of the cloud top does not increase the cooling rate, whereas the peak cooling rate decreases rapidly in depressions. For small perturbation, $\approx 10 \mathrm{~m}$, this may tend to inhibit the growth of negative perturbations. For larger perturbations, $\approx 100 \mathrm{~m}$, changes to the radiative cooling rates within the positive perturbations and next to the negative perturbations may act to sustain the perturbation and promote its growth.

Using a three-dimensional longwave radiation model and a slab-symmetric cloud 
dynamics model, we demonstrated that longwave radiative cooling substantially enhances the maximum cloud water content. The maximum increase reaches $96 \%$. The total cloud water was aiso increased somewhat (maximum 20\%).

In the initial stage of the development, the augmentation of cloud water content near the cloud top and sides is traced mainly to ihe direct effect of longwave radiative cooling on cloud microphysics (i.e. radiative cooling reduces the local temperature and hence the saturation water vapour pressure, which leads to additional condensation).

In the mature stage of cloud, the increase of total cloud water content comes from a combination of the effects of radiation on microphysics and dynamics. The cooling from radiation and evaporation produces additional downward motion at the sides of the cloud. The enhanced low-level convergence invigorates the updraft promoting fuither cloud development.

In the decaying stage, the negative buoyancy produced by cloud top radiative cooling and a higher liquid water load speeds up the decay process in the LW run.

In a sheared environment, shear suppresses convection. In conjunction with horizontal momentum transport, radiative cooling also results in a more negative temperature perturbation and a stronger downdraft on the downshear flank relative to the upshear side.

In an axially symmetric simulation, longwave cooling produces a weaker updraft in the cloud core. This phenomena was attributed to the shorter lifetime of the axially symmetric cloud, and the fact that the cloud side sinking motion can spread around the cloud core instead of being confined to a vertical plane. As a result, a weaker secondary circulation develops which is offset by the negative effects of the cloud top radiative cooling and the higher liquid water load. 


\section{Résumé}

Nous étudions les effets du rayonnement de grandes longeurs d'onde sur le développement des petits cumulus en utilisant un modele de transfert radiatif tri-dimensionel ainsi que des modèles dynamiques à symétrie axiale et planaire.

Un modele de rayonnement de grandes longeurs d'onde est présenté dans cette thèse. Nous appliquons ce modèle au cas d'un nuage cumulus isolé ayant la forme d'un cylindre. Ce cas démontre l'importance du refroidissement des côtés du nuage dû au rayonnement. Nous suggérons que les courants descendants en bordure des cumulus, formés par ce refroidissement résultent en une convergence d'air dans les niveaux inférieurs du nuage. Cette convergence peut ensuite renforcé le courant ascendant au centre du nuage.

Avec ce même modèle nous étudions le taux de refroidissement au sommet d'un nuage stratiforme sur lequel nous superposons, selon une symétrie axiale, des perturbations positives (pics) et négatives (dépressions). Nous constatons que le taux de refroidissement n'augmente pas dans les régions des pics mais que le taux maximum decroît rapidement dans les dépressions. Ceci a pour effet que dans le cas ou les perturbations ont $\approx 10 \mathrm{~m}$ de dimension la croissance des perturbations négatives est inhibee. Par contre, dans le cas ou les perturbations ont $\sim 100 \mathrm{~m}$ de dimension la croissance des perturbations est augmentée.

De plus, nous démontrons dans cette thèse que le refroidissemnent dû au rayonnement de grandes longeurs d'onde est responsable d'une augmentation importante de la valeur maximale du contenu en eau nuageuse. Cette augmeniation va jusqu’à $96 \%$. Le contenu total en eau nuageuse subit une augmentation moins importante, allant jusqu'à $20 \%$. Pour ce faire, nous utilisons le 
modèle de transfert radiatif tri-dimensionel avec le modèle dynamique à symétrie planaire.

Dans les premiers stades de développement du nuage, l'augmentation du contenu en eau nuageuse s'explique par l'effet directe du refroidissemnet radiatif, e'est-à-dire, lorsque la témperature locale baisse, la pression de vapeur d'eau à saturation décroît aussi et s'ensuit plus de condensation. Lorsque le nuage a atteint sa maturite, l'augmentation s'explique à la fois par l'effet directe et l'effet indirect via la dynamique du nuage. Ce dernier effet est relié au fait que le refroidissement dû au rayonnement ainsi qu'à l'évaporation est cause de courants descendants en bordure du nuage. Ces courants descendants augmente la convergence au niveau inférieur du nuage et ainsi accroît les courants ascendants en son centre. Nous remarquons aussi que la dissipation du nuage est accélérée lorsque l'on tient compte du refroidissement radiatif. Ceci est dû à la création de zones où la force de flottabilité est négative.

Nous présentons aussi des résultats qui montrent que le cisaillement du vent réduit la convection. Dû au refroidissemnet radiatif ainsi qu'au transport de quantité de mouvement horizontal nous trouvons que du côté du nuage en aval du vecteur de cisaillement, les courants descendants ainsi que les perturbations négatives de températures sont plus importants.

Dans une simulation avec le modèle dynamique à symétrie axiale, nous trouvons que le refroidissement radiatif produit un courant ascendant plus faible dans le centre du nuage. Nous expliquons ce résultat par le fait qu'avec un tel modèle la durée de vie du nuage est plus courte et aussi par le fait que dans cette géométrie les courants descendants sur les cotés du nuage peuvent se répandre autour du centre du nuage au lieu d'être confiné dans un plan vertical. Il en resulte une circulation secondaire moins importante qui est dominêe par les effets dynamiques du refroidissement radiatif au sommet du nuage. 


\section{Acknowledgements}

First and foremost, I would like to thank my supervisor, Dr. M. K. Yau for his constint encouragement, and expert guidance throughout this work. I would also like to thank Dr. Roger Davies for his enthusiastic supervision in the study of the radiation part. I am grateful to Drs. Roger Davies, and Henry Leighton for their helpful suggestion and comments during the progress of my work.

I acknowledge Alan Schwartz for his help in solving computer problems and Paul Vaillancourt for translating the abstract to French.

This research was supported in part by grants from FCAR (Quebec), the Natural Science and Engineering Research Council, the Atmospheric Environment Service (Canada), and the U.S. Office of Naval Research grant N00014-87-G-0171.

Finally, I would like to express gratitude to my husband, Wei, and my son, Andy, for their understanding and support. 


\section{Statement of Originality}

The original results contained in this thesis are as follows:

1) The distribution of longwave radiative cooling rate in an axially symmetric cloud has been calculated. The possibility of sustained cloud side cooling leading to low-level convergence and enhanced cloud development is noted for the first time.

2) Longwave radiative feedbacks in the maintenance of conical perturbations in stratiform cloud tops was discovered.

3) A three-dimensional longwave radiation model has been incorporated into a slabsymmetric cloud dynamics model for the first time. Longwave radiation dramatically increases the maximum cloud water content in a small cumulus cloud. The effects of longwave cooling in different stages of development of the simulated cloud and the physical mechanisms responsible for these effects were identified.

4) The effects of longwave cooling on the development of a small cumulus cloud in a sheared environment has been investigated. Shear suppresses convection. Longwave cooling enhances the asymmetric characteristics of the simulated cloud. The physical mechanism responsible for this phenomenon was identified.

5) The effects of longwave radiation on the development of a small cumulus cloud in an 
axially symmetric model and a slab-symmetric model were compared. The weaker updralt in the axially symmetric cloud core was found and explained.

6) The distributions of the longwave radiative cooling rate in the slab-symmetric and axially symmetric clouds were compared and explained.

( Chapter 2 is based on the paper published in J. Geophys. Res.. The paper was mostly written by Roger Davies. I did all calculations.) 


\section{Contents}

$\begin{array}{lll}\text { Abstract } & \text { i }\end{array}$

Résumé $\quad$ iii

$\begin{array}{lll}\text { Acknowledgments } & \text { v }\end{array}$

Statement of Originality vi vi

Contents $\quad$ viii

List of Figures $\quad$ xi

List of Plates $\quad$ Xv

List of Tables $\quad$ xvi

1 Introduction $\quad 1$

1.1 Longwave radiative cooling rates in clouds

1.2 The role of longwave radiation on cloud development 3

$\begin{array}{ll}1.3 \text { Statement of problem and outline of thesis } & 6\end{array}$

$\begin{array}{lll}2 & \text { Longwave radiative cooling rates in axially symmetric clouds } & 8\end{array}$

2.1 Introduction $\quad 8$

2.2 Radiative cooling rates in isolated axially symmetric clouds 9

2.2.1 Model description 9

2.2.2 Results for an isolated cylindrical cloud 13

2.3 Cloud top inhomogeneity effects on radiative cooling rates 20 
2.3.1 Simplified axially symmetric model $\quad 20$

2.3.2 Results 23

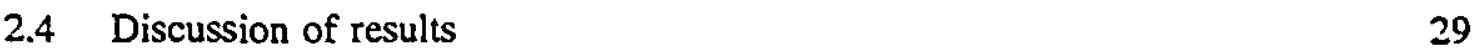

2.4.1 Cumuliform clouds $\quad 30$

2.4.2 Stratiform clouds $\quad 30$

3 The effects of longwave radiation on the development of a small cumulus cloud: slab-symmetric model simulation 33

3.1 Introduction 33

3.2 Description of cloud dynamics model 34

3.2.1 Major assumptions 34

3.2.2 Model equations 35

3.2.3 The numerical methods 37

3.2.4 Boundary conditions 38

3.2.5 Domain size, grid size, and time step 40

3.3 The longwave radiation model in the slab-symmetric cloud 41

3.3.1 Model 41

3.3.2 Test of spatial resolution 43

$\begin{array}{lll}3.4 & \text { Experiments and results } & 47\end{array}$

3.4.1 Control run -- no longwave radiation process 47

3.4.2 Total effect - 50

3.4.3 Positive feedback of longwave radiative cooling on condensation $\quad 52$

3.4.4 Secondary circulation induced by longwave radiative cooling 58

3.4.5 Rapid decay of cloud induced by longwave radiation 68

$\begin{array}{ll}3.5 & \text { Conclusions and discussions } \\ \end{array}$

$4 \quad$ The effects of wind shear $\quad 74$

$\begin{array}{lll}4.1 & \text { Introduction } & 74\end{array}$

4.2 Initial condition 76

$\begin{array}{lll}4.3 & \text { Results } & 76\end{array}$

4.3.1 The effects of wind shear on cloud development 77

4.3.2 Including the effects of longwave radiation 81

4.3.3 The asymmetric effects of longwave radiation on downdrafts 91

4.4 Conclusions 94

5 The effects of axially symmetric geometry 95

5.1 Introduction 95

5.2 Longwave radiative cooling rate between the slab-symmetric and axially
symmetric geometries

5.3 Comparisons between the results of experiment AC and the slab CONTROL run 
5.4 Including the effects of longwave radiation

5.5 Conclusions

110

6 Summary and conclusions

111

References

115 


\section{LIST OF FIGURES}

Figure 2.1: Radiative heating (positive) and cooling (negative) rates in a cylindrical cloud as a function of height above the cloud base. Dotted curve, at the cloud center. Solid curve, $1 \mathrm{~m}$ from the cloud side. Dashed curve, horizontal average.

Figure 2.2: Contours of radiative heating (dashed) and cooling (solid) rates in a cylindrical cloud. Contour interval is $5 \mathrm{~K} \mathrm{~h}^{-1}$. Cross-sectional view through the cloud center. (a) Entire view of the cloud from center to side. (b) Expanded view of top corner. (c) Expanded view of bottom corner.

Figure 2.3: Schematic of (a) convex and (b) concave cloud top perturbations. Each perturbation is an axially symmetric cone of height $h$, half-angle $A$, and perturbation angle 22 p.

Figure 2.4: peak cooling rates $1 \mathrm{~m}$ below the center of a conical perturbation as a function of perturbation angle $p$. Numbers on each line give the perturbation amplitude $h(m) . \quad 28$

Figure 3.1: Contours of radiative cooling rates in a circular cloud. Contour interval is $1 \mathrm{~K} \mathrm{Ii}^{-1}$. a) Spatial resolution is $25 \mathrm{~m}$. b) Spatial resolution is $10 \mathrm{~m}$.

Figure 3.2: Radiative cooling (positive ) rates at the center of the circular cloud as a function of height above the cloud base. Solid curve, spatial resolution is $25 \mathrm{~m}$. Dashed curve, spatial resolution is $10 \mathrm{~m}$.

Figure 3.3: Initial temperature $(T)$, potential temperature $(\theta)$, and specific humidity $(q)$ profiles.

Figure 3.4: Vertical section of a) vertical velocity (W), b) horizontal velocity (U), c) cloud water mixing ratio (CL), and d) temperature perturbation (TP) at $35 \mathrm{~min}$. The contour intervals for $\mathrm{W}, \mathrm{U}, \mathrm{CL}$, and $\mathrm{TP}$ are $0.5 \mathrm{~m} \mathrm{~s}^{-1}, 0.5 \mathrm{~m} \mathrm{~s}^{-1}, 0.1 \mathrm{~g} \mathrm{~kg}^{-1}$, and $0.2 \mathrm{~K}$ respectively.

Figure 3.5: Vertical section of a) vertical velocity (W), b) horizontal velocity (U), c) cloud water mixing ratio (CL), and d) temperature perturbation (TP) at $55 \mathrm{~min}$. The contour intervals for $\mathrm{W}, \mathrm{U}, \mathrm{CL}$, and $\mathrm{TP}$ are $0.5 \mathrm{~m} \mathrm{~s}^{-1}, 0.5 \mathrm{~m} \mathrm{~s}^{-1}, 0.1 \mathrm{~g} \mathrm{~kg}^{-1}$, and $0.2 \mathrm{~K}$ respectively. 51 
Figure 3.6: Evolution of maximum cloud water content for the Control and LW runs. Solid curve, Control run. Dashed curve, LW run.

Figure 3.7: Evolution of total cloud water content for the Control and LW runs. Solid curve, Control run. Dashed curve, LW run.

Figure 3.8: Vertical section of cloud water content at $40 \mathrm{~min}$. Contour interval is $0.1 \mathrm{~g} \mathrm{~kg}^{-1}$. a) Control run. b) LW run.

Figure 3.9: Same as Figure 3.8 but at $55 \mathrm{~min}$. 56

Figure 3.10: Same as Figure 3.8 but at $60 \mathrm{~min} . \quad 57$

Figure 3.11: Vertical section of vertical velocity at $40 \mathrm{~min}$. Solid contours, upward motion. Dashed contours, downward motion. Contour interval is $0.5 \mathrm{~m} \mathrm{~s}^{-1}$. a) Control run. b) LW run.

Figure 3.12: Vertical section of radiative cooling rates at $40 \mathrm{~min}$. Contour interval is $1 \mathrm{~K} \mathrm{~h}^{-1}$. The cloud boundary is shown in thin solid curve.

Figure 3.13: Same as Figure 3.12 but at $55 \mathrm{~min}$.

Figure 3.14: Vertical section of temperature perturbation at $55 \mathrm{~min}$. Contour interval is $0.1 \mathrm{~K}$. a) Control run. b) LW run.

Figure 3.15: Same as Figure 3.11 but at $55 \mathrm{~min}$.

Figure 3.16: Vertical section of the difference of horizontal velocity between the $\mathrm{LW}$ and Control runs at $55 \mathrm{~min}$. Contours are $-5000,-500,0,500,5000 \times 10^{-4} \mathrm{~m} \mathrm{~s}^{-1}$.

Figure 3.17: Vertical velocity at the 1st grid near the center of the domain at $55 \mathrm{~min}$. Solid curve, Control run. Dashed curve, LW run.

Figure 3.18a: Evolution of cloud water content. Solid curve, Control run. Dashed curve, LW run.

$\begin{array}{ll}\text { Figure 3.18b: Same as Fig.3.18a but for vertical velocity. } & 70\end{array}$

Figure 3.18c: Same as Fig.3.18a but for temperature perturbation.

Figure 4.1: Vertical section of a) vertical velocity (W), b) cloud water mixing ratio (CL), and c) temperature perturbation (TP) at $40 \mathrm{~min}$ for experiment S0.5C. The contour intervals for $\mathrm{W}, \mathrm{CL}$, and TP are $0.5 \mathrm{~m} \mathrm{~s}^{-1}, 0.1 \mathrm{~g} \mathrm{~kg}^{-1}$, and $0.2 \mathrm{~K}$ respectively 
Figure 4.2: Vertical section of a) vertical velocity (W), b) cloud water mixing ratio (CL), and c) temperature perturbation (TP) at $60 \mathrm{~min}$ for experiment S0.5C run. d) Vertical section of vertical velocity at 60 min for CONTROL run. The contour intervals for $W, C L$, and TP are $0.25 \mathrm{~m} \mathrm{~s}^{-1}, 0.1 \mathrm{~g} \mathrm{~kg}^{-1}$, and $0.2 \mathrm{~K}$ respectively.

Figure 4.3: Evolution of total cloud water content for the CONTROL (solid) and S0.5C (dashed) runs.

Figure 4.4: Evolution of maximum cloud water content for the S0.5C (solid) and S0.5LW (dashed) runs.

Figure 4.5: Evolution of total cloud water content for the S0.5C (solid) and S0.5LW (dashed) runs.

Figure 4.6: Vertical section of cloud water content at $40 \mathrm{~min}$ for a) S0.5C run, b) S0.5LW run. Contour interval is $0.1 \mathrm{~g} \mathrm{~kg}^{-1}$.

Figure 4.7: Same as Figure 4.6 but at $55 \mathrm{~min}$.

Figure 4.8: Same as Figure 4.6 but at $60 \mathrm{~min}$.

Figure 4.9: Vertical section of temperature perturbation at 55 min for a) S0.5C run, b) S0.5LW run. Contour interval is $0.1 \mathrm{~K}$.

Figure 4.10: Vertical section of vertical velocity at $55 \mathrm{~min}$ for a) S0.5C run, b) S0.5LW run. Solid contours denote upward motion and dashed contours denote downward motion. Contour interval is $0.5 \mathrm{~m} \mathrm{~s}^{-1}$.

Figure 4.11: Vertical distribution of maximum vertical velocity at $55 \mathrm{~min}$ for SO.5C aun (solid) and S0.5LW run (dashed).

Figure 4.12: Vertical section of horizontal velocity for S0.5LW run at $55 \mathrm{~min}$. Contour interval is $0.5 \mathrm{~m} \mathrm{~s}^{-1}$. Solid line denote the motion along positive $\mathrm{x}$-direction. Dashed line represent the motion along negative $x$-direction. Thin solid line denote longwave radiative cooling rate.

Figure 4.13: Vertical section of difference of temperature perturbation between the SO.5LW and S0.5C runs. Contour interval is $0.1 \mathrm{~K}$.

Figure 5.1: Radiative cooling rates in the idealized slab-symmetric cloud. Contour interval is $1 \mathrm{~K} \mathrm{~h}^{-1}$.

Figure 5.2: Same as Figure 5.1 except in the idealized axially symmetric cloud. 
Figure 5.3: Vertical section of a) vertical velocity (W), b) horizontal velocity (U), c) cloud water mixing ratio (CL), and d) temperature perturbation (TP) at $35 \mathrm{~min}$ for the $A C$ run. The contour intervals for $W, U, C L$, and $T P$ are $0.5 \mathrm{~m} \mathrm{~s}^{-1}, 0.5 \mathrm{~m} \mathrm{~s}^{-1}, 0.1 \mathrm{~g} \mathrm{~kg}^{-1}$, and $0.2 \mathrm{~K}$ respectively.

Figure 5.4: Evolution of maximum cloud water content for the CONTROL and AC runs. Solid curve denotes CONTROL run and dashed curve the $\mathrm{AC}$ run.

Figure 5.5: Evolution of maximum cloud water content for the AC and ALW runs. Solid curve denotes $\mathrm{AC}$ run and dashed curve the ALW run.

Figure 5.6: Vertical section of cloud water content at $39 \mathrm{~min}$. Contour interval is $0.1 \mathrm{~g} \mathrm{~kg}^{-1}$. a) $A C$ run, and $b$ ) ALW run.

Figure 5.7: Vertical section of vertical velocity at $39 \mathrm{~min}$. Solid contours represent upward motion and dashed contours, downward motion. Contour interval is $0.5 \mathrm{~m} \mathrm{~s}^{-1}$. a) AC run. b) ALW run.

Figure 5.8: Vertical section of temperature perturbation at $39 \mathrm{~min}$. Contour interval is $0.1 \mathrm{~K}$. a) AC run. b) ALW run.

Figure 5.9: Vertical velocity at the central axis at $39 \mathrm{~min}$. Solid curve denotes AC run and dashed curve the ALW run. 


\section{LIST OF PLATES}

Plate 2.1: False color representation of radiative cooling rates in (a) convex or positively perturbed cloud tops and (b) concave or negatively perturbed cloud tops. Only the top $100 \mathrm{~m}$ of the semi-infinite cloud is shown. 
xvi

\section{LIST OF TABLE}

Table 5.1: Some characteristics of the cloud evolution in experiment CONTROL and AC. 


\section{Chapter 1}

\section{Introduction}

\subsection{Longwave radiative cooling rate in clouds}

The atmosphere is continuously emitting longwave radiation to space in order to balance the solar heating of the earth-atmosphere system. A typical value for this longwave cooling in a cloud-free atmosphere is about $2-4 \mathrm{~K}$ day $^{-1}$ (Roewe and Liou, 1978). When clouds are present, however, the situation changes rather dramatically. Because a large amount of longwave radiation is emitted from the cloud top, cooling rates larger by about two orders of magnitude may occur in a relatively thin layer near the tops of clouds. The air above the cloud top is a poor absorber of longwave radiation, and therefore the amount of energy re-radiated downward from the cloudfree atmosphere is very small. As a result, the cloud layer near the cloud top experiences a net loss in radiation and air is cooled near that level. However, at the base of the cloud, more energy is gained from the upwelling radiation at the earth's surface than is lost from downward radiation from the cooler cloud base. As a result, longwave radiation causes a warming near the base of the cloud. For regions far away from the cloud boundaries, the cooling rate is negligible because 
of the condition of radiative equilibrium. The strong cooling near the cloud top and weak warming near the cloud base are thought to be very important in affecting the dynamics and microphysics of the clouds.

Considerable theoretical research on longwave radiative cooling rates for horizontally homogeneous clouds has been carried out (Yamamoto et al., 1971; Stephens, 1978; Khvorostyanov, 1981; Slingo et al., 1982; Twomey, 1983; Curry and Herman, 1985; Davies and Alves, 1989). It was found that local radiative cooling rates for liquid-water clouds usually peak near the cloud top with values reaching $m 50 \mathrm{~K} \mathrm{~h}^{-1}$ when there is a sharp isothermal transition separating the cloudy and clear air. This result is known to depend on the vertical profile of temperature and humidity in the air immediately above the cloud top as well as on the gradient of liquid water within $\sim 50 \mathrm{~m}$ of the cloud top. Because of these effects the peak radiative cooling rate in stratiform clouds $\left(-5 \mathrm{~K} \mathrm{~h}^{-1}\right)$ is typically less than at the top of cumuliform clouds. Considering that radiative net flux changes rapidly with distance near the cloud boundary, it is apparent that high spatial resolution is important in the calculation of net flux divergence and longwave radiative cooling rates. As pointed out by Davies and Alves (1989), coarser resolution models have a natural tendency to average the radiative flux divergence over the layer thickness, thereby reducing the maximum value.

A three-dimensional approach to radiative transfer may be needed whenever the shapes of clouds become too complex for conventional (i.e., plane parallel) treatments. For example, the limited horizontal extent of cumuliform clouds can, at times, result in a greater interaction of radiation with the cloud sides than with the top and the base. Even when side effects are negligible, as for horizontally extensive stratiform clouds, convective cells at the cloud top may 
cause significant departures from the flat surface assumed in many models. In the past, little attention has been given to the distribution of longwave radiation in horizontally finite or inhomogeneous clouds. A need exists for a systematic study of the effects of three-dimensional cloud geometry on the interaction of clouds with longwave radiation. To our knowledge, only Liou and Ou (1979) and Harshvardhan et al. (1981) have studied the longwave radiative cooling rates in horizontally finite clouds. Liou and Ou (1979) used a four-term spherical harmonics approach to calculate the $10-\mu \mathrm{m}$ wavelength cooling rates for finite clouds. They noted that cubic clouds exhibit stronger cooling than comparable plane-parallel clouds. Harshvardhan et al. (1981) used a modified two-stream approximation to demonstrate the existence of enhanced radiative cooling at the sides of isolated clouds. Neither of these pioneering techniques are noted for their accuracy (Stephens and Preisendorfer, 1984), and they cannot be adapted to noncuboidal cloud shapes very easily.

\subsection{The role of Longwave radiation on cloud development}

Radiative effects are thought to play a key role in the evolution of various clouds like small cumuli (Sommeria, 1976; Veyre et al., 1980), stratus (Moeng and Schumann, 1991; Moeng et al., 1992), stratocumulus (Chen and Cotton, 1983; Nicholls, 1984; Driedonks and Duynkerke, 1989; Duynkerke, 1989; Koracin and Rogers, 1990; Rogers and Koracin, 1992), altocumulus (Gedzelman, 1988), cirrus (Starr and Cox, 1985; Lilly, 1988), and thunderstorm anvils (Webster and Stephens, 1980; Ackerman et al., 1988; Chen and Cotton, 1988; Tripoli and Cotton, 1989; Dudhia, 1989; Tao et al., 1991, 1993; Xu and Randall, 1995; Fu et al., 1995). Various mechanisms have been proposed to account for the effects of radiation on clouds based on the 
gradient and/or magnitude of radiative heating rates in the presence of clouds $(\mathrm{Xu}$ and Randall, 1995). They include (i) horizontal differential heating between cloudy and clear regions (Gray and Jacobson, 1977; Tao et al., 1991; 1993), (ii) horizontal differential cooling between cloud sides and the cloud center which produces a secondary circulation to alter the airflow in the clouds and enhances cloud development (Guan et al., 1995), (iii) vertical differential heating between cloud base and top, which leads to a destabilization of the cloud layers to augment convective overturning (Veyre et al., 1980; Webster and Stephens, 1980; Chen and Cotton, 1988; Tripoli and Cotton, 1989; Dudhia, 1989; Koracin and Rogers, 1990; Rogers and Koracin, 1992; Tao et al., 1991,1993; Fu et al., 1995), (iv) in-cloud radiative heating and radiative destabilization, which generate buoyant turbulence in the clouds (Sommeria, 1976; Lilly, 1988), and (v) radiation induced condensation (Sommeria, 1976; Heymsfield and Miloshevich, 1991).

Up to now, numerous quantitative studies on the interaction between clouds and longwave radiation have mainly focused on the anvil regions of thunderstorms, stratiform clouds, or other horizontally homogenous clouds. For these types of clouds, vertical differential heating is very important. The mechanism of the horizontal differential heating between the cloudy and clear air regions was first proposed by Gray and Jacobson (1977) and was further supported by calculations from Tao et al. (1991; 1993). However, very recent numerical simulations (Xu and Randall, 1995) clearly showed that the Gray-Jacobson mechanism is not very important compared to vertical differential heating, because the magnitudes of the horizontal differential heating between cloudy and clear air regions is much smaller than the vertical differential heating between the top and base of the cloud.

Studies on the interaction between horizontally finite clouds, such as small cumuli, and 
longwave radiation are few in number.

Earlier work carried out by Sommeria (1976) showed that longwave radiative cooling rate has the same importance as condensation heating rate in a small tropical cumulus. He also proposed that longwave radiative cooling affects the development of a cloud layer by fivouring condensation and reducing buoyancy. However, no quantitative estimates of the effects of longwave radiative cooling upon cloud dynamics and microphysics have been presented. Heymsfield and Miloshevich (1991) noted that the latent heat release as a result of condensition caused by radiative cooling partially offsets the pure effect of radiation on cloud temperature.

Veyre et al. (1980) quantitatively studied the effect of longwave rndiation on small tropical cumuli. However, their longwave radiation $\mathrm{r}$ del is only uni-dimensional and the contribution of horizontal net flux divergence on longwave radiative cooling rate is neglected. Their result shows that longwave radiation enhances the average cloud water content by $25 \%$. They attributed the enhancement to vertical differential heating between the cloud base and the cloud top, which destabilizes the cloud layer.

It is known that the horizonal scale is comparable to the vertical scale in a small cumulus cloud. The calculation of longwave radiative cooling rate in a 3-dimensional framework (Liou and Ou, 1979; Guan et al., 1995) revealed that cloud side cooling is of the same order of magnitude as cloud top cooling for a horizontally finite cumuliform cloud. Therefore, horizontal differential heating between the sides and the center of the cloud may significantly affect cloud development. We hypothesize that the longwave radiative cooling at the cloud sides produces enhanced downward motion, which in turn strengthens the convergence near the cloud base. The upward motion near the center of the cloud therefore intensifies and a stronger development of 
the cloud results.

\subsection{Statement of problem and outline of thesis}

This thesis is directed towards a study of the interaction between longwave radiation and horizontally finite or horizontally inhomogeneous clouds. Specifically, we would explore the validity of the hypothesis that for a small tropical cumulus longwave radiative cooling at the cloud sides produces enhanced downward motion, which in turn strengthens the convergence near the cloud base. The upward motion near the center of the cloud therefore intensifies and a stronger development of the cloud results. Our approach would be through the development and application of an interactive three-dimensional radiative transfer model, a slab-symmetric cloud model, and an axially symmetric cloud model. The organization of the six chapters comprising the thesis is as follows.

Chapter 1 provides some background of the problem and motivation for our study.

Chapter 2 describes a three-dimensional axially symmetric longwave radiative transfer models and its application to an isolated cumuliform cloud and a stratiform cloud with a perturbed top. We would present calculations of longwave radiative cooling rates at the cloud tops and the sides. The effect of cloud top inhomogeneities on longwave radiative cooling rate is also examined. The possible effects of cooling rate on cloud dynamics are proposed.

In Chapter 3, we introduce an interactive slab-symmetric cloud dynamics model and a three-dimensional longwave radiative transfer model. We examine the effect of spatial resolution on longwave radiative cooling rate and investigate the effects of longwave radiation on cloud development in a calm environment. 
Chapter 4 is devoted to a study of the effect of longwave radiation on cloud development in an environment with uni-directional wind shear.

Chapter 5 discusses the effects of longwave radiation on cloud development in an axially symmetric cloud. A comparison will be made between the results of slab-symmetric and axially symmetric geometries.

Chapter 6 summarizes the results and provides the final conclusions of our research. 


\section{Chapter 2}

\section{Longwave radiative cooling rates in axially}

\section{symmetric clouds}

\subsection{Introduction}

As discussed in Chapter 1, the application of plane parallel theory to clouds of limited horizontal extent and clouds with inhomogeneous top surfaces can lead to errors. In this chapter, we will examine the insight that a three-dimensional approach brings to the determination of longwave radiative cooling rates at or near the surface of idealized cumuliform and stratiform liquid-water clouds.

The outline of this chapter is as follow. Section 2.2 describes a simple axially symmetric longwave radiative transfer model, which is then applied to an isolated cumuliform cloud. The model is simplified further in Section 2.3 and then applied to a stratiform cloud with a perturbed 
top. The results obtained for these two types of axially symmetric cloud are summarized and discussed in Section 2.4 .

\subsection{Radiative cooling rates in isolated axially symmetric clouds}

\subsubsection{Model description}

Our goal is to obtain representative longwave radiative cooling rates as functions of position in horizontally inhomogeneous clouds. The general radiative transfer problem could be solved using Monte Carlo simulation (Harshvardhan et al., 1981), or by the use of twodimensional Fourier transforms followed by a variety of one-dimensional solution techniques (Davies, 1978; Stephens and Preisendorfer, 1984). Here, however, we can choose a much simpler approach since we are not concerned with the solution for radiances, just for cooling rates. This takes advantage of the finding by Davies and Alves (1989) that omission of scattering alters the local net flux divergence of longwave radiation by less than $\approx 5 \%$. Geometrical and spectral factors affect the results more than this. Following Stephens (1978), we also take the cooling rates integrated over 8 to $13.4 \mu \mathrm{m}$ to be representative of the broadband cooling rates, recognizing that this limits our results to isothermal conditions at the cloud boundaries as explained by Davies and Alves. To highlight the main geometric dependence of the cooling rates, we focus on axially symmetric situations and ignore internal inhomogeneity in the distribution of cloud liquid water.

The longwave radiative cooling rate at any point within the cloud may be expressed in 
terms of the three-dimensional divergence of the net flux density of longwave radiation, $F_{n e t}$ as

$$
\frac{\partial T}{\partial t}=-\frac{\nabla \cdot F_{n e t}}{\varrho C_{p}}
$$

where $T$ is temperature, $t$ is time, $Q$ is air density, and $C_{p}$ is the specific heat of air at constant pressure. We can simplify the general three-dimensional problem by invoking azimuthal symmetry about a vertical axis, $z$.

The net flux divergence can then be expressed in cylindrical coordinates $\mathrm{r}$ and $\mathrm{z}$ as

$$
\nabla \cdot F_{\text {net }}=\frac{1}{r} \frac{\partial\left(r F_{\text {netr }}\right)}{\partial r}+\frac{\partial F_{\text {nets }}}{\partial z},
$$

An axially symmetric integral model of longwave radiative transfer was therefore developed to calculate radiances, net flux densities, and radiative cooling rates. We use the conventional zenith and azimuthal angles, $\theta$ and $\phi$, for calculating the vertical flux components. To calculate the horizontal flux components, it is convenient to define an additional pair of angles, $\theta^{\prime}$ and ' $\phi^{\prime}$, where $\theta^{\prime}$ is the angle the radiance makes with the $\mathrm{r}$ axis and $\phi^{\prime}$ ' is the angle that the projection of the radiance onto a plane orthogonal to the $r$ axis makes with the $z$ axis. In such a model, clouds are symmetrical about the vertical axis and are given some vertical position within a horizontally homogeneous atmosphere with plane-parallel boundaries. Here we consider only cylindrical clouds and stratiform clouds with a conical bump or depression on the top surface, but this model could also be applied to more complicated axially symmetric cloud shapes.

The spectral radiance at any point $(r, z)$ in the model in direction $\Omega$ is expressed in terms of emission and absorption as 


$$
I_{\lambda}(r, z, \Omega)=I_{b_{\lambda}}(\Omega) \operatorname{Tr}_{\lambda}[S(r, z, \Omega)]+\int_{0}^{s\left(r_{2} \Omega\right)} B_{\lambda}\left(T\left(s^{\prime}\right)\right) T_{\lambda}\left[S(r, z, \Omega)-s^{\prime}\right] k_{\lambda}\left(s^{\prime}\right) d s^{\prime}
$$

Here

$\mathrm{B}_{\lambda}(\mathrm{T}) \quad$ Planck function;

$S(r, z, \Omega) \quad$ total distance in direction $\Omega$ between the point $(r, z)$ and the boundary of the domain, which is an isothermal ground of temperature $T_{8}$ for upwelling radiances, or cold atmosphere with $\mathrm{T}=0 \mathrm{~K}$ for downwelling radiances;

$s^{\prime} \quad$ similarly the distance between an intermediate point $\left(r^{\prime}, z^{\prime}\right)$ and the boundary;

$I_{b \lambda} \quad$ radiance emitted from the domain boundary, $I_{b \lambda}=B_{\lambda}\left(T_{g}\right)$ for upwelling radinnce, $I_{b \lambda}=0$ for downwelling radiances;

$\operatorname{Tr}_{2}[s]$ transmission function through an absorber path of distance $s$, for monochromatic absorption, $\operatorname{Tr}_{\lambda}\left[S-s^{\prime}\right]=\exp \left[-k_{\lambda}\left(S-s^{\prime}\right)\right]$

$k_{\lambda} \quad$ volume absorption coefficient obtained from a combination of droplet absorption and water vapour absorption (we ignore emission and absorption by other gases).

The vertical component of net flux is then found as

$$
F_{\text {netz }}(r, z)=\int_{8}^{13.4} \int_{0}^{2 \pi} \int_{-1}^{1} I_{2}(r, z, \mu, \phi) \mu d \mu d \phi d \lambda
$$

where $\mu=\cos \theta$. 
The horizontal component (in the $+r$ direction) is similarly found as

$$
F_{\text {netr }}(r, z)=\int_{8}^{13.4} \int_{0}^{2 \pi} \int_{-1}^{1} I_{\lambda}\left(r, z, \mu^{\prime}, \phi j \mu^{\prime} d \mu^{\prime} d \phi^{\prime} d \lambda,\right.
$$

where $\mu^{\prime}=\cos \theta^{\prime}$.

Standard midlatitude summer atmosphere temperature and humidity profiles were used above the cloud top. Within the cloud, moist adiabatic temperature and saturated water vapour profiles were used, and the liquid water content and drop size distribution were kept constant. Below the cloud base, the water vapour distribution was again that of a midlatitude summer atmosphere, but the temperature profile was dry adiabatic.

The spectral absorption coefficients for cloud liquid water were evaluated as

$$
k_{\text {droplet } 2}=\int_{0}^{\infty} \pi r^{2} Q_{a b s}(\tilde{m}, r) n(r) d r
$$

where $r$ is the droplet radius, $n(r)$ is the number droplet concentration, and $Q_{\text {abs }}(\bar{m}, r)$ is the Mie efficiency factor for absorption, which in the present work is determined using Wiscombe's (1979) Mie code. The required refractive index $(\overline{\mathrm{m}})$ were taken from Hale and Querry (1973) and Irvine and Pollack (1968). Water vapour absorption was included, following Houghton (1977), by setting $k_{\text {vepore }}=e k_{2}$ where $e$ is water vapour pressure and $k_{2}=10^{-2}\left(\mathrm{~g} \mathrm{~cm}^{-2}\right)^{-1} \mathrm{mbar}^{-1}$ is a constant.

Since gaseous attenuation and the attenuation due to droplets are uncorrelated, the total 
cloud transmission function is thus determined by the product of the individual transmission function. The "multiplication property" of band transmission function is discussed by Goody (1964).

The integrals of (2.3)-(2.5) were evaluated numerically, using steps of $0.2 \mu \mathrm{m}$ in wavelength, and $\approx 10^{\circ}$ in angle. For the cloudy region, a spatial resulution of $1 \mathrm{~m}$ was used near the cloud boundaries and a coarser resolution elsewhere. Each atmospheric layer was assumed to be homogeneous with the same thermodynamic and microphysical properties for the middle point of the layer. Tests of the numerical precision were made to ensure that the results were insensitive to further improvements in the spatial or angular resolution. At the chosen resolution the numerical precision of the cooling rates was better than $1 \%$ (where this precision would have deteriorated in places to $20 \%$ if 5-m spatial resolution and $20^{\circ}$ angular resolution had been used).

\subsubsection{Results for an isolated cylindrical cloud}

The above model was first applied to a cylindrical cloud of radius $500 \mathrm{~m}$. The cloud top was at $2 \mathrm{~km}$ and the base at $1.5 \mathrm{~km}$ above a black surface of temperature $302 \mathrm{~K}$. The temperatures of the cloud top and base were 285.2 and $287.5 \mathrm{~K}$. The Deirmendjian modifiedgamma size distribution was used for the cloud droplets, with a resulting liquid water content of $1.034 \mathrm{~g} \mathrm{~m}^{-3}$ ("nimbostratus top" distribution of Welch et al. (1980)). Deirmendjian modifiedgamma distribution function is given by the expression

$$
n(r)=a r^{\eta} \exp \left[-\frac{\eta}{\gamma}\left(\frac{r}{r_{m}}\right)^{\eta}\right]
$$

where $r_{m}$ is the modal radius of the distribution, and $a, \eta$, and $\gamma$ are other empirically derived 
parameters.

Detailed effects of various droplet size distributions were studied by Stephens (1978) and Alves (1987), who concluded that the specific cloud microphysical structure is not important to the determination of the droplet absorption coefficient, hence the radiative flux divergence. They noted that the changes of cloud LWC distribution introduces considerably larger variation in cooling and heating rates.

Figure 2.1 shows the radiative cooling (negative) and heating (positive) rates at the cloud center, side, and horizontally averaged over the entire cloud, each as a function of height above the cloud base. The horizontally averaged results are qualitatively similar to those of Harshvardhan et al. (1981) but show larger values at the top and base, due in part to the higher liquid water content. Peak cooling rates of $-34 \mathrm{~K} \mathrm{~h}^{-1}$ occur at the cloud top, and a modest warming of $8 \mathrm{~K} \mathrm{~h}^{-1}$ occurs at the base. The center profile would be very similar to that of a plane-parallel cloud and shows that much of the interior is, as expected, in radiative equilibrium. There is therefore very little difference between the horizontally averaged profile and the planeparallel profile for this example of a thick, wet cloud.

Note by contrast the profile $1 \mathrm{~m}$ from the cloud side, which cools at $-14 \mathrm{~K} \mathrm{~h}^{-1}$ over much of its height. The difference between the side and the center cooling rate profiles is the greatest at the cloud base, fairly constant with height for much of the cloud, and tends to zero at the cloud top. The cloud side continues to cool all the way down to the cloud base, albeit at a slightly lower rate than higher up. Other examples covering a range of cloud temperatures down to $275 \mathrm{~K}$ and ground temperatures up to $310 \mathrm{~K}$ were also considered, but the results were very similar, changing in magnitude by less than $=20 \%$. 


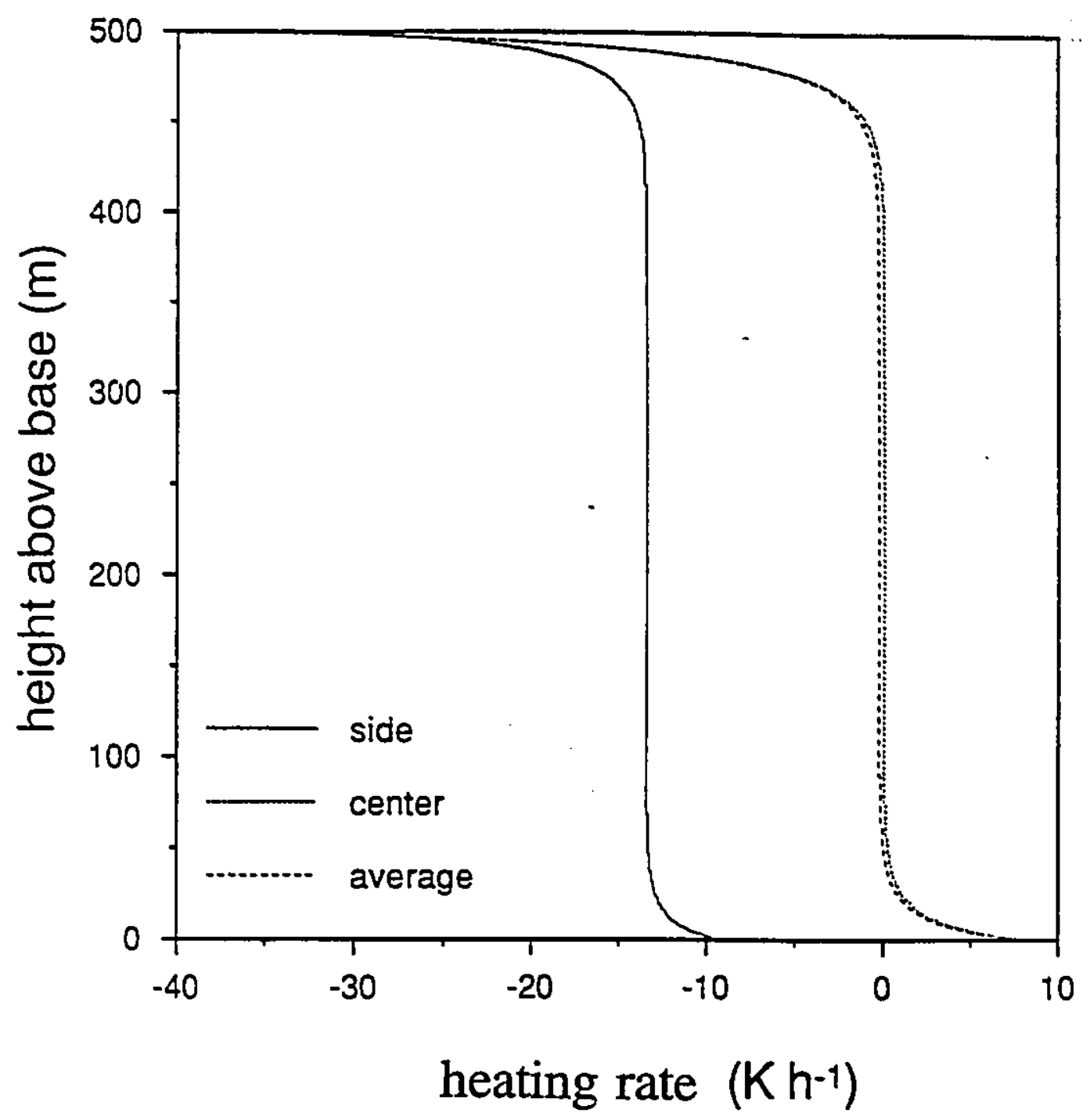

Figure 2.1: Radiative heating (positive) and cooling (negative) rates in a cylindrical cloud as a function of height above the cloud base. Dotted curve, at the cloud center. Solid curve, $1 \mathrm{~m}$ from the cloud side. Dashed curve, horizontal average. 
Figure 2.2a provides contours of the radiative cooling rates over the entire cloud, shown in vertical cross section through the cloud center. The most interesting feature are the sharp gradients of cooling rate at the top and sides. Since most radiative cooling from the top and sides occurs within $20 \mathrm{~m}$ of the boundary, these regions are shown in more detail in Figure $2.2 \mathrm{~b}$ (top corner) and Figure 2.2c (bottom comer).

Our results extend those of Davies and Alves (1989), who showed peak cooling at the tops of stratiform clouds restricted to the upper $\approx 20 \mathrm{~m}$, by illustrating the presence of a similar effect at the cloud sides. However, cloud side cooling will have a very different effect on cloud development compared to cloud top cooling. An air parcel that is radiatively cooled at the cloud top will tend to sink back into the cloud where it rapidly becomes shielded from further cooling. By contrast, an air parcel that starts cooling radiatively at the top corner can sink down the side of the cloud without being shielded and continue to cool radiatively as it descends. One is left with the prospect of thin $(-20 \mathrm{~m})$ skin effect of cold air subsiding down the sides of cumuliform clouds, possibly serving to enhance vertical development within the cloud through low-level convergence.

While the above example is for an isolated cumuliform cloud, the results may also be applied to a field of widely spaced cumuliform clouds. The cloud top cooling rates and cloud base heating rates are very insensitive to cloud-cloud spacing provided the clouds have similar cloud base and cloud top altitudes. However, the typical cloud side cooling rates will be reduced by about $10 \%$ when the mean cloud-cloud spacing becomes comparable to the height of the clouds, and this reduction will be greater for lower portions of the cloud side. For even closer cloud-cloud spacing, the cooling rates from adjacent cloud sides will rapidly tend to the 
(a)

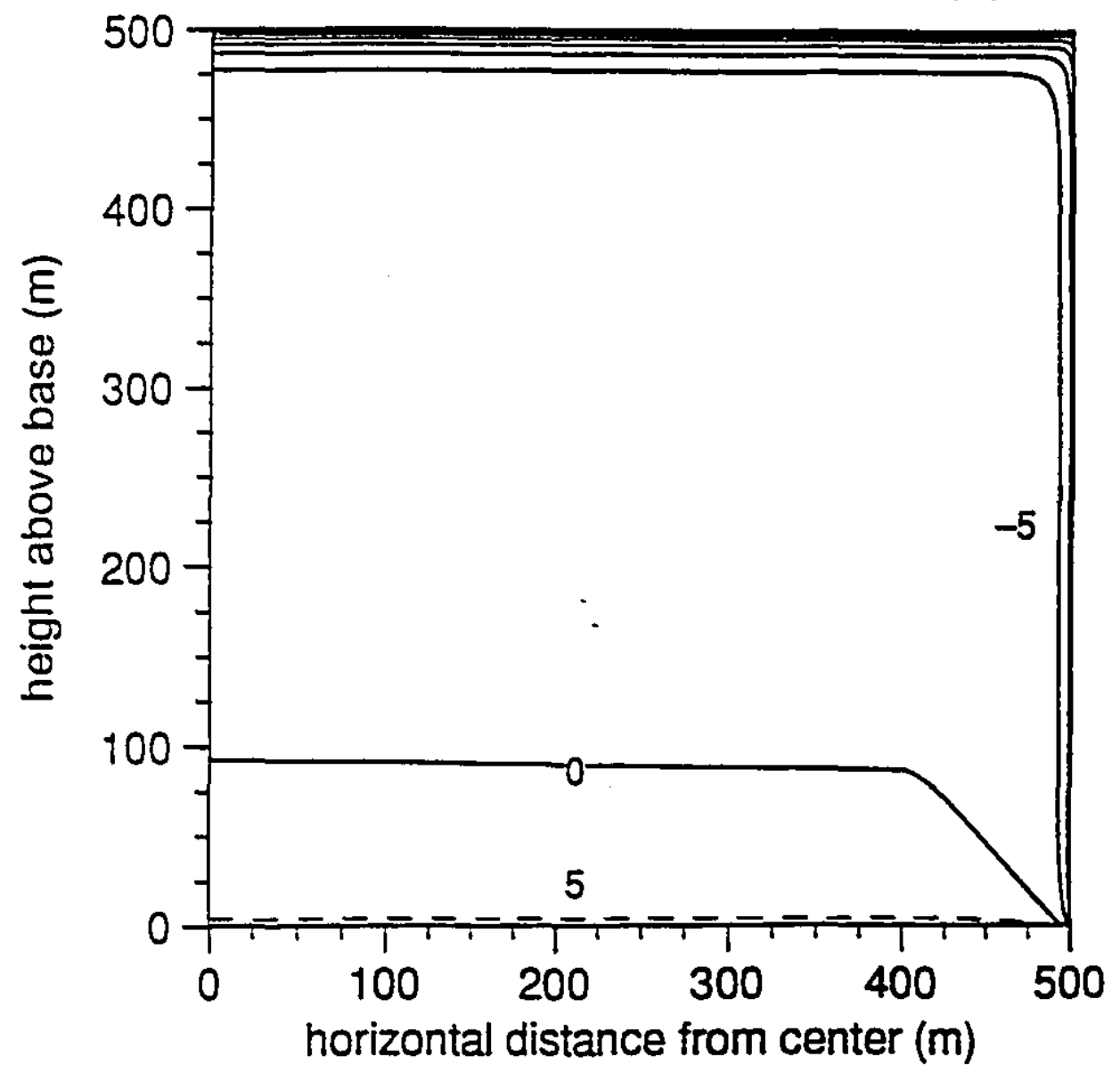

Figure 2.2: Contours of radiative heating (dashed) and cooling (solid) rates in a cylindrical cloud. Contour interval is $5 \mathrm{~K} \mathrm{~h}^{-1}$. Cross-sectional view through the cloud center. (a) Entire view of the cloud from center to side. (b) Expanded view of top corner. (c) Expanded view of bottom comer. 
(b)

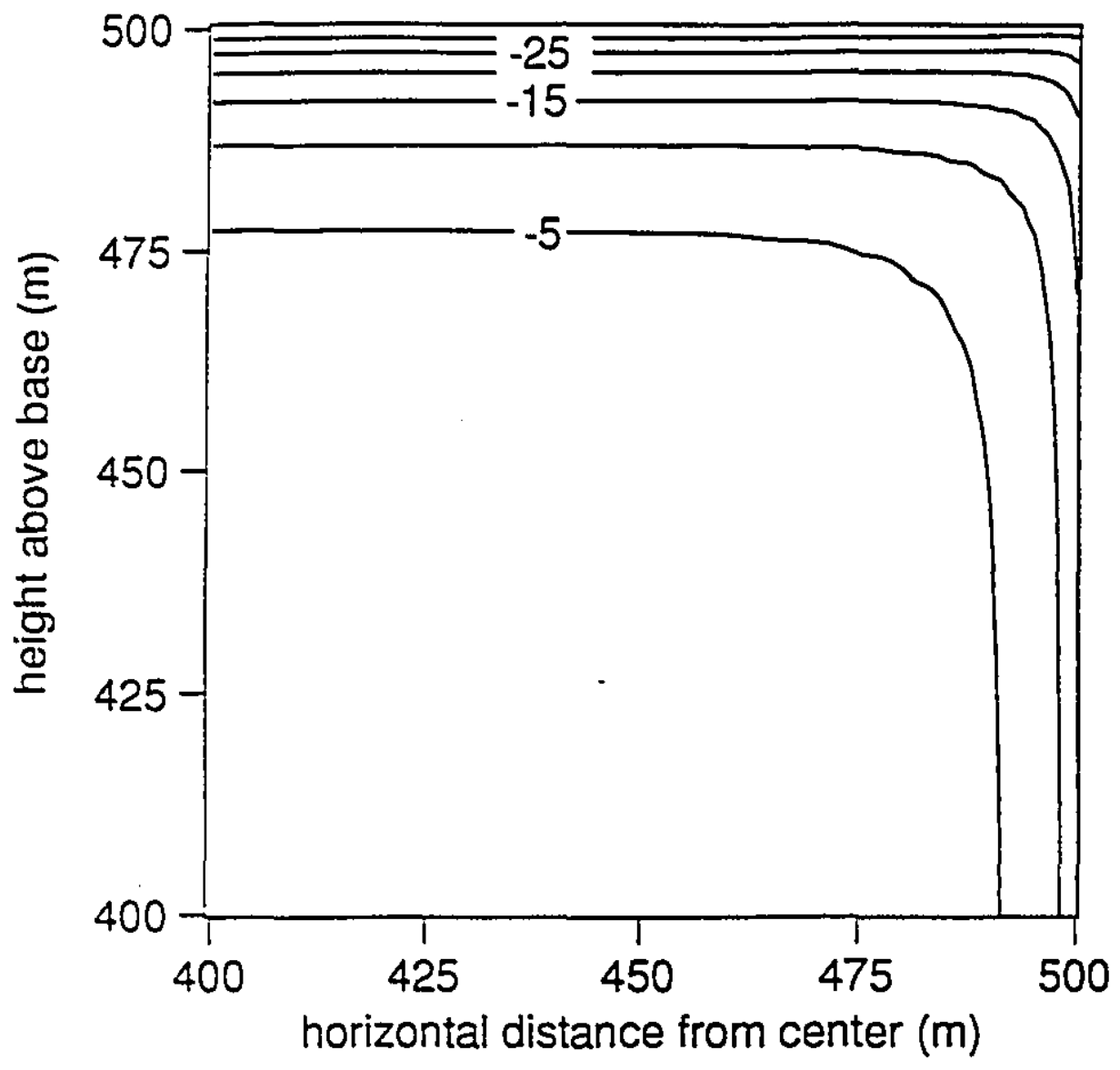


(c)

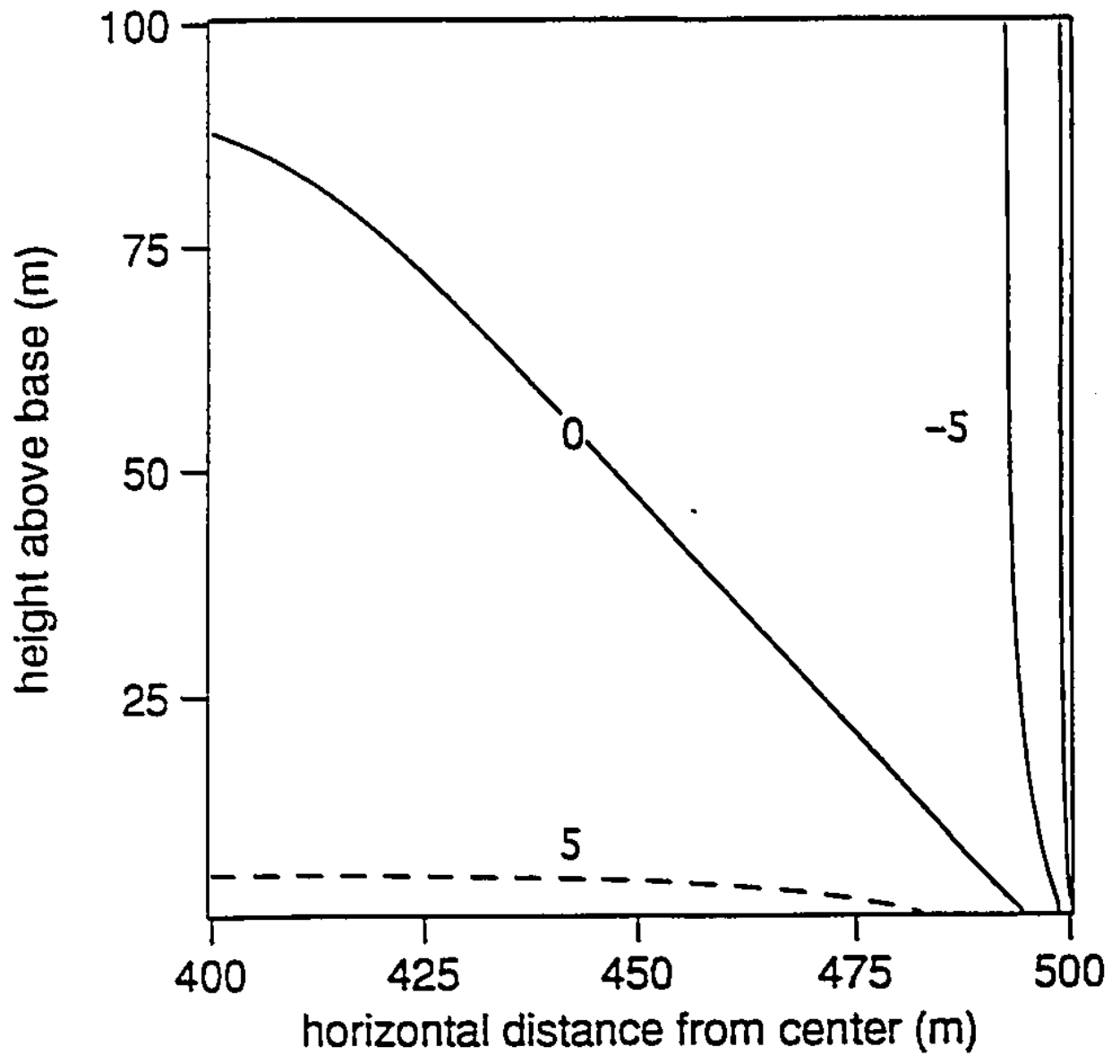


corresponding stratiform solution.

\subsection{Cloud top inhomogeneity effects on radiative cooling rates}

\subsubsection{Simplified axially symmetric model}

Real cloud tops seldom have the flat horizontal surfaces typical of modelling simulations. They display a wide variety of billowed structures that can be characterized by local height departures from some mean cloud top height with varying degrees of convex and concave curvature. Especially for stratiform clouds these billows are largely a result of the turbulence that is generated by radiative cooling at the cloud top. Since the cooling rate may be affected by the curvature of the surface, there arises the interesting possibility of a feedback mechanism between turbulent billows and radiative cooling. We therefore introduce a simplified version of the axially symmetric radiation model to efficiently explore the curvature effect in more detail. This model is then used to produce cooling rates for a variety of convex and concave perturbations to a flat stratiform cloud top.

Because we are dealing only with perturbations to the top of a stratiform cloud, a number of simplifications to the previous model are possible. We assume the cloud is isothermal (286.2 K) with a constant effective absorption coefficient, $k_{w}$. The source function due to emission, $B_{w}(T)=40 \mathrm{~W} \mathrm{~m} \mathrm{~m}^{-2} \mathrm{sr}^{-1}$, is also assumed constant within the cloud. We ignore downwelling radiation to the cloud top. The combined errors due to these assumptions are removed by "tuning" the value of $\mathrm{k}_{\mathrm{w}}\left(\infty 6.7 \mathrm{~km}^{-1}\right)$ to give the same value of unperturbed cloud top cooling (-5 $\mathrm{K} \mathrm{h}^{-1}$ ), as found by the detailed calculations of Davies and Alves (1989).

The local radiative cooling rate may then be expressed (Goody and Yung, 1989,p.23) as 


$$
\frac{\partial T}{\partial t}=\frac{4 \pi k_{w}\left(\bar{I}_{w}-B_{w}(D)\right)}{\rho C_{p}}
$$

where

$$
\bar{i}_{w}=\frac{1}{4 \pi} \int_{0}^{2 \pi} \int_{-1}^{1} I_{w}(\mu, \phi) d \mu d \phi
$$

is the spherically averaged radiance in the window region.

The integrals over angle are found by Gaussian quadrature as before. The integral for $\mathrm{I}_{w}$ can be solved analytically, however, giving

$$
\begin{array}{cc}
I_{w}(r, z, \mu, \phi)=B_{w}\left(1-\exp \left(-k_{w} S(r, z, !, \phi)\right)\right) & \text { for } \mu<0 \\
I_{w}(r, z, \mu, \phi)=B_{w} \quad \text { for } \mu>0 &
\end{array}
$$

where $S(r, z, \mu, \phi)$ is the total pain from point $(r, z)$ to the cloud boundary in direction $(\mu$, ф). Results for local radiative cooling rates are then calculated, again at a spatial resolution of $1 \mathrm{~m}$.

Perturbations to the cloud top structure were chosen to be either cuncave conical depressions or convex conical bumps, as shown in Figure 2.3. The perturbations are characterized by amplitude and angle, as defined in the figure. The clouds are plane parallel beyond the perturbation. Since the cooling rates are insensitive to cloud conditions below $-100 \mathrm{~m}$ from the 


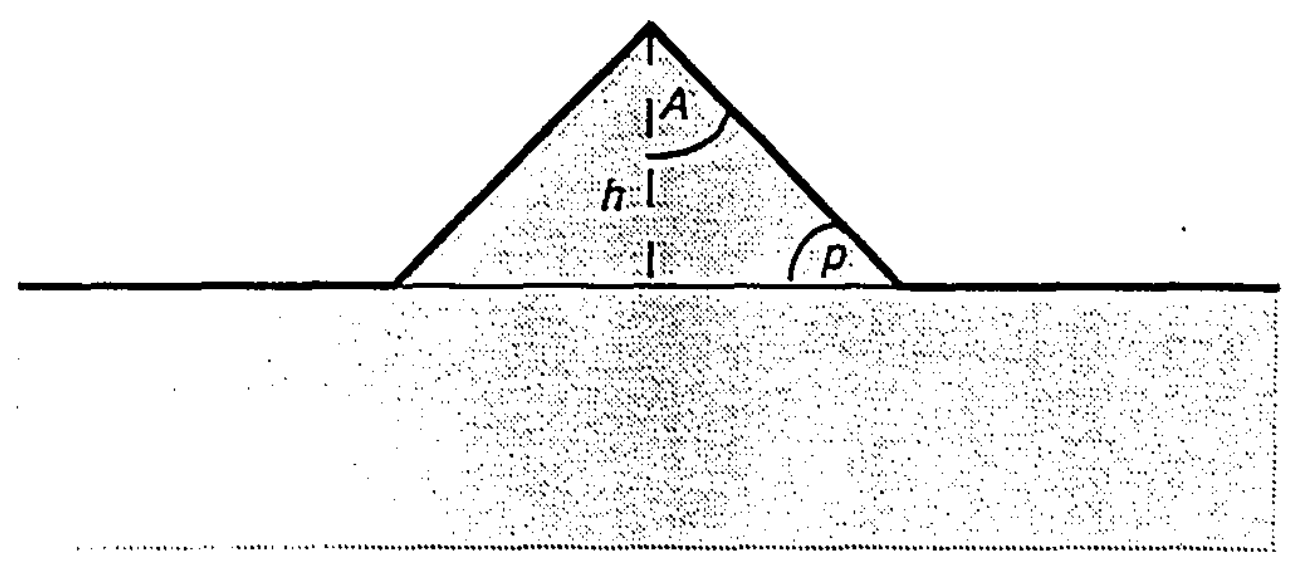

(a)

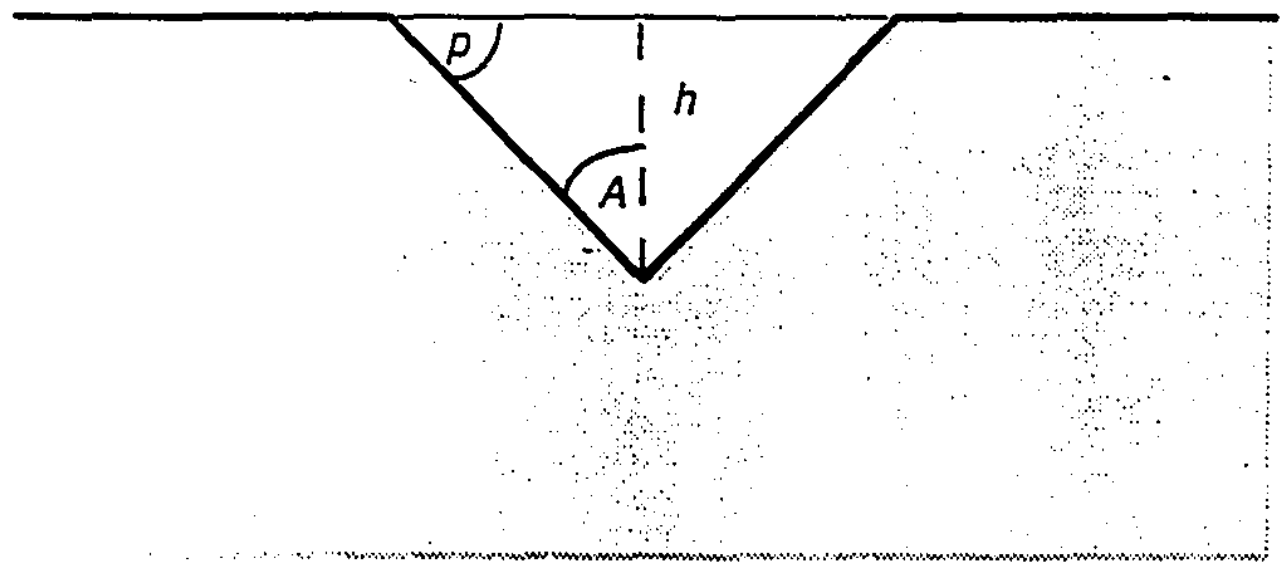

(b)

Figure 2.3: Schematic of (a) convex and (b) concave cloud top perturbations. Each perturbation is an axially symmetric cone of height $h$, half-angle $A$, and pertubation angle $p$. 
top, the cloud may be considered to be semi-infinite and the lower boundary condition ignored.

\subsubsection{Results}

Convex perturbations. Plate 1a illustrates the distribution of radiative cooling rates for a convex perturbation to the cloud top, somewhat illustrative of a billow that projects above the mean cloud top height. The half angle of the cone was $50^{\circ}$, and its height above the unperturbed cloud top was $100 \mathrm{~m}$.

The maximum cooling rate at the top of the conical perturbation is found to be identical to the maximum from the unperturbed cloud top. All other convex perturbations we simulated with different cone angles and heights gave the same results. In other words, a convex perturbation does not increase the maximum cooling rate at the top of a stratiform cloud.

The isothermal assumption made earlier means that all parts of the cloud, whether perturbed or not, emit the same amount of radiation. Similarly, the upwelling radiation absorbed by any region of the cloud near the top surface is the same everywhere, since this radiation must come from some other part of the cloud irrespective of direction within the lower hemisphere.

However, the convex perturbation does change the absorption of downwelling radiation. This absorption is a minimum for points unaffected by the perturbation, namely, at the top of the cone and on the top surface far from the cone. The downwelling radiation to the horiznntal cloud top close to the cone and to the surface of the cone (except for the top of the cone) is larger than before due to downward emission from the perturbation and reaches a local maximum at the base of the conical surface. The surface cooling rate is therefore a minimum at this point.

The difference in surface-cooling rates due to the perturbation is not large. If we define 

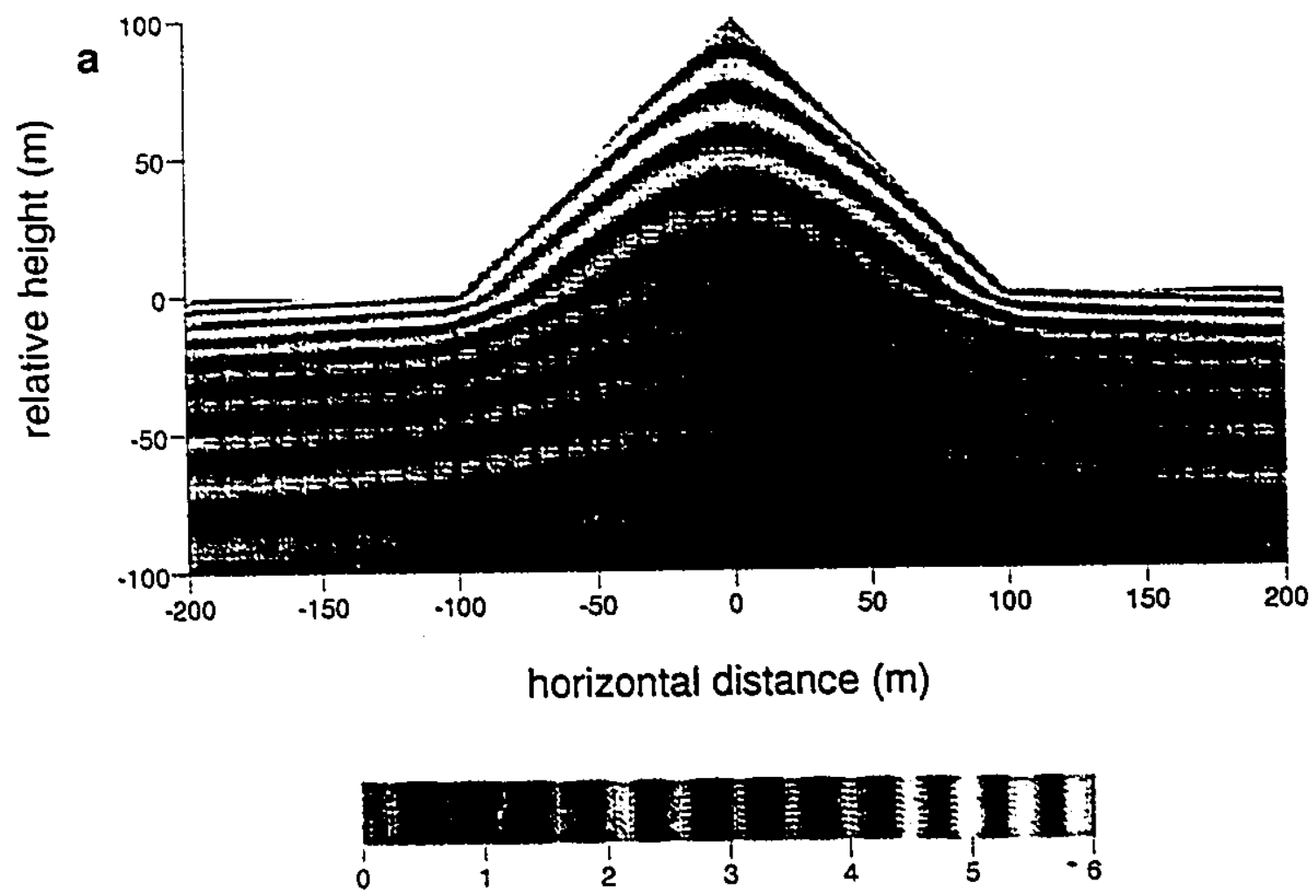

cooling rates $\mathrm{K} \mathrm{h}^{-1}$

PIate 2.1: False color representation of radiative cooling rates in (a) convex or positively perturbed cloud tops and (b) concave or negatively perturbed cloud tops. Only the top $100 \mathrm{~m}$ of the semi-infinite cloud is shown. 

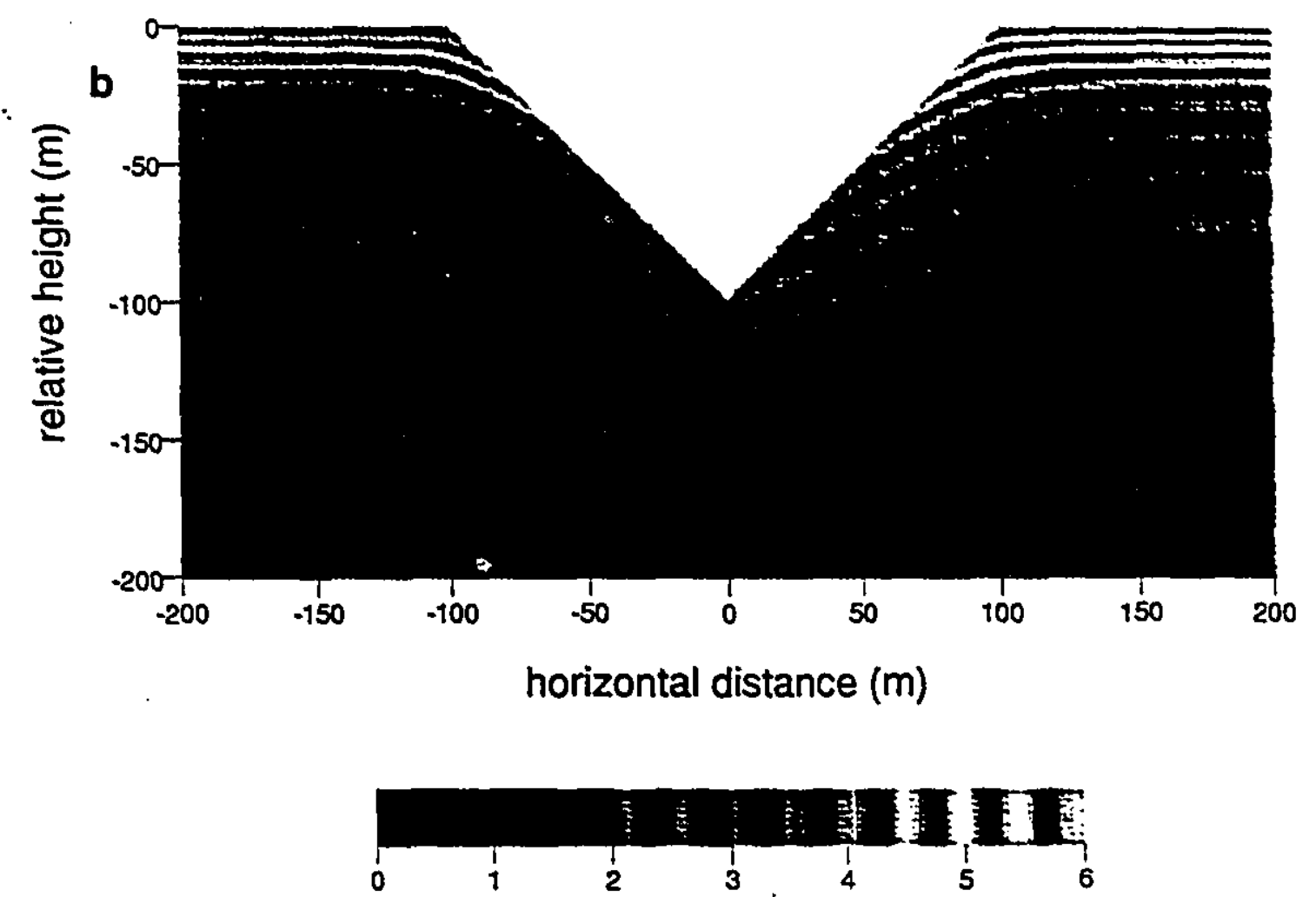

cooling rates $\mathrm{K} \mathrm{h}^{-1}$ 
a differential surface-cooling rate to be the difference between the maximum (at the apex of the cone) and minimum (at the base of the cone) surface-cooling rates, this turns out to be only about $-0.7 \mathrm{~K} \mathrm{~h}^{-1}$ for the example shown in Plate 1a. We can conclude that the maximum cloud top cooling rate is relatively insensitive to convex perturbations.

The interior cooling rates show greater differences, however, and we note that the perturbation generates a substantial horizontal gradient in cooling rates. With the exception of the region within $-10 \mathrm{~m}$ of the apex of the cone, the minimum cooling rate at all altitudes occurs on the cone axis, so that the sides of cone are cooling more rapidly than the center. At the altitude of the unperturbed cloud top, for example, the center of the perturbation is cooling at the rate of only $-3 \mathrm{~K} \mathrm{~h}^{-1}$ cumpared with the rate of $-5 \mathrm{~K} \mathrm{~h}^{-1}$ at a horizontal distance of $100 \mathrm{~m}$ from the center. This effect would appear to be more important than the small differences in surfacecooling rate for a convex perturbation. We are left with the prospect that the differences in radiative cooling rates due to a convex perturbation could act to sustain the perturbation.

This conclusions do pot appear to be very sensitive to the initial assumptions. However, should there be a strong temperature gradient in the vicinity of the cloud top, both the isothermal assumption and the window-emission assumption would be inappropriate, and a more detailed analysis would be required. Similarly, if the cloud is not horizontally extensive, then radiation emitted by the ground enters the problem, also requiring a more detailed analysis.

Concave perturbation. Plate $1 \mathrm{~b}$ shows the distribution of radiative cooling rates for a concave perturbation to the cloud top. This perturbation is a conical depression into the cloud, somewhat representative of the sinking motion that occurs whenever a portion of the cloud 
subsides below the mean cloud top height. No change is evident in the maximum cooling rate of the unperturbed portion of the cloud top. The cooling rate on the surface of the conical depression, however, decreases significantly with depth into the depression. This is due to emission from the sides of the depression which provides an increasing contribution of downwelling radiation with depth.

The differential cooling rate, from the start of the perturbation of the cloud top to the deepest point, reaches $-3.5 \mathrm{~K} \mathrm{~h}^{-1}$ for the case shown. This is substantially larger than for the convex example. Concave curvature thus acts to significantly reduce the peak cooling rate of the cloud surface. It appears to provide an element of negative feedback to the growth of the depression: as portions of the cloud top cool and begin to sink into the cloud, the radiative cooling rate for that portion is rapidly reduced so that other portions may catch up by cooling faster.

There may also be an element of positive feedback due to the horizontal gradient in cooling rate created by the perturbation. The cooling rate increases in the horizontal direction toward the perturbation at fixed altitude within the cloud. This effect would act to sustain the perturbation by cooling the perturbed region more rapidly than the unperturbed region. However, the gradient in internal cooling rate $\left(-1 \mathrm{~K} \mathrm{~h}^{-1}\right.$ over $\left.100 \mathrm{~m}\right)$ is weaker than the gradient in surface cooling rate, so the latter effect should be the dominant one.

Effect of angle and amplitude of the perturbation. We have already noted that the cooling rate at the tip of the conical perturbation (the calculation is for $1 \mathrm{~m}$ below the tip) does not change for convex perturbations and decreases for concave perturbations. Figure 2.4 


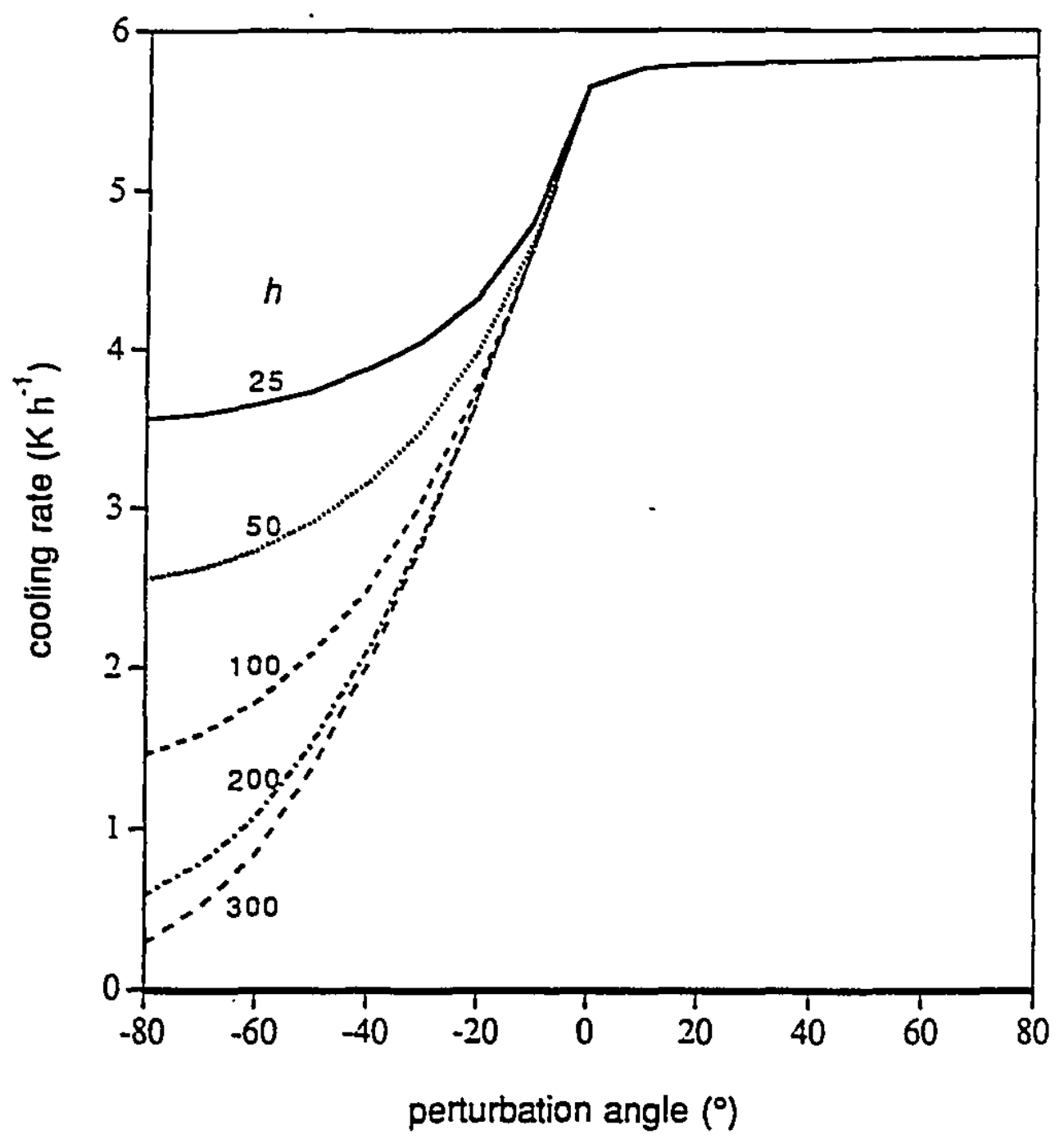

Figure 2.4: peak cooling rates $1 \mathrm{~m}$ below the center of a conical perturbation as a function of perturbation angle $p$. Numbers on each line give the perturbation amplitude $h(m)$. 
summarizes this effect as a function of the angle that the conical surface makes with the horizontal cloud top. Positive angles represent convex perturbations, negative angles concave perturbations. Results are shown for perturbation amplitudes (vertical distance from unperturbed cloud level to the tip of the cone) from 25 to $300 \mathrm{~m}$.

Concave cooling rates decrease with perturbation angle, at first rapidly, then less rapidly as the angle increases. They also decrease with perturbation amplitude, especially at larger perturbatoicn angles. These results are consistent with the hypothesis that concave perturbations may be self-limiting in terms of their local radiative forcing. As the perturbation grows, both the amplitude and the angle increase, and the cooling rate decreases.

\subsection{Discussion of results}

The models we have used here are fairly simple, and only two types of cloud inhomogeneity have been considered. The results are limited by the techniques of using "tuned" monochromatic calculations for homogeneous clouds and window cooling for internally inhomogeneous clouds, so that the cases considered are only of lower tropospheric clouds with no temperature inversion at the cloud top. However, these techniques allow us to ignore the effects of scattering on the cooling rates, and the results obtained are sufficiently clear that general conclusions may be drawn from this study. There is a significant dependence of longwave radiative cooling rates on the three-dimensional structure of the cloud. This dependence appears important for subsequent cloud development and should be considered in future dynamical models of clouds. 


\subsubsection{Cumuliform clouds}

For cumuliform clouds with exposed sides we show the existence of a "skin" effect, a narrow $(-50 \mathrm{~m})$ region of strong cooling at the cloud sides $\left(-14 \mathrm{~K} \mathrm{~h}^{-1}\right)$. This is analogous to the even stronger cooling rate $\left(\infty-34 \mathrm{~K} \mathrm{~h}^{-1}\right)$ that exist at the cloud top. Cloud side cooling may be more important dynamically, however, as vertically sinking air at the cloud side can continue to cool during descent, whereas the cloud top air rapidly becomes shielded from radiative cooling as it subsides. We hypothesize that the radiatively forced sinking of air at the sides of cumuliform clouds would lead to lower-level convergence and thereby enhance the upward motion in the interior of the cloud.

\subsubsection{Stratiform clouds}

The second type of inhomogeneity considered, that of perturbation to a stratiform cloud top, also appears to have important implications to cloud development. Here the cloud is horizontally extensive and the focus is on the radiative effect of perturbations to a horizontal cloud top. Convex perturbations, or pumps, do not increase the maximum cooling rate at the cloud top, so the local generation of turbulence kinetic energy is unaffected by a perturbation in this direction. However, once the perturbation is sufficiently large $(-100 \mathrm{~m})$, the interior of the perturbation cools less rapidly than its surface (analogous to the cumuliform example above), providing an element of positive feedback that would help to sustain its growth.

Concave perturbations, or dips, have a different effect. There is an immediate reduction in the maximum cooling rate on the surface of the perturbation as the dip forms. This provides an element of negative feedback to the initial growth of the perturbation. There is a weaker effect in the opposite direction, however, whereby a horizontal gradient in cooling rate is established 
in a region $(-100 \mathrm{~m})$ around the perturbation that gives greater cooling as the dip is approached. This gradient would help in the growth of the perturbation once it becomes large enough.

Since real stratiform clouds will have a combination of positive and negative perturbations to the mean cloud height, we distinguish two different types of overall radiative cooling effects due to the perturbations. These are distinguished by their scale of action.

A scale of $O(10 \mathrm{~m})$ orthogonal to the cloud surface, the surface cooling rates are most intense $\left(-5 \mathrm{~K} \mathrm{~h}^{-1}\right)$ and lead to much of the radiative generation of turbulent kinetic energy. Here the perturbations act asymmetrically. Convex perturbations do not change the peak cooling rate, whereas concave perturbations decrease it. Averaging over a combination of bumps and dips therefore reduces the initial rate of production of turbulent kinetic energy compared with the unperturbed state. Also, since the generation of radiatively driven convective eddies starts by this process, there is an element of negative feedback that acts to delay the onset of organized convection.

At horizontal scale of $\mathrm{O}(100 \mathrm{~m})$, differences in the internal cooling rates (still close to the top surface of course) of the cloud become evident. The interior of bumps cool less rapidly than their surfaces or the unperturbed cloud top. The interior of the cloud near dips cools more rapidly than unperturbed regions. These are similar effects in the sense that they contribute elements of positive feedback to the growth of either perturbation. The net effect of averaging over positive and negative perturbations at this scale does not therefore appear to produce the cancelation that would allow the perturbations to be ignored.

Our quantitative results for radiative cooling rates respond reasonably accurately to the inhomogeneities considered. They have an error of $-5 \%$ due to the omission of scattering and 
are limited to isothermal cloud top conditions. The discussion of the implication of these results to cloud development is purely qualitative, however, and certainly requires more rigorous analysis using models of cloud dynamics that include the generation and propagation of turbulent kinetic energy produced by longwave radiative cooling. 


\section{Chapter 3}

\section{The Effects of Longwave Radiation on the}

\section{Development of a Small Cumulus Cloud:}

\section{Slab-Symmetric Model Simulation}

\subsection{Introduction}

As was discussed in Chapter 2, significant longwave radiative cooling occurs in a thin layer near the tops and sides of cumuliform clouds. This strong cooling may be important in affecting the microphysics and dynamics of the clouds by favouring local condensation and inducing negative buoyancy. The effect of the latter can be twofold. Firstly, the negative buoyancy from cloud top cooling tends to decrease (increase) local upward (downward) motion. Secondly, radiatively forced sinking of air at the sides of clouds may lead to lower-level convergence and enhancement of the upward motion in the interior of the cloud. The goal of the 
present chapter is to examine these effects.

Our focus will be on a small tropical cumulus cloud. This choice is motivated by the following reasons. In the tropical boundary layer, small scattered cumuli are quite prevalent. For these weak cumuli, the rates of condensation heating and adiabatic cooling are relatively small. Radiative cooling may be of similar importance as other processes. For instance, Sommeria (1976) showed that the radiative effect is of approximately the same magnitude as the effect of condensation in affecting the mean putential temperature of the tropical boundary layer.

In this chapter, we will investigate the effects of longwave radiation on the dynamics and microphysics of a small tropical cumulus cloud in a calm environment using a slab-symmetric cloud model. The effects of wind shear and axially symmetric geometry will be explored respectively in chapter 4 and chapter 5 .

\subsection{Description of cloud äymamics model}

With the exception of incorporating the longwave radiation term in the thermodynamic equation, the model is essentially the same as the one used by Hedley and Yau (1988) and Reuter and Yau $(1987 \mathrm{a}, \mathrm{b})$.

\subsubsection{Major assumptions}

(1) We use the anelastic equations of Ogura and Phillips (1962) to filter out acoustic waves by setting the local time derivative of the air density to zero.

(2) The effect of the Earth's rotation is neglected since the lifetime of a cloud is expected to be short compared to the time scale of the Earth's rotation. 
(3) Friction at the Earth's surface is niglected.

(4) Water occurs only in the vapour and liquid phases. Condensation occurs whenever the water vapour mixing ratio exceeds the saturation value. Raindrops do not exist and the cloud water is assumed to move with the air.

\subsubsection{Model equations}

The deep anelastic continuity equation and the momentum equations in flux form are:

$$
\begin{aligned}
& \frac{\partial u}{\partial x}+\frac{1}{\varrho_{0}} \frac{\partial w Q_{0}}{\partial z}=0 \\
& \frac{\partial u}{\partial t}+\frac{\partial\left(u^{2}\right)}{\partial x}+\frac{1}{\varrho_{0}} \frac{\partial\left(Q_{0} u w\right)}{\partial z}=-\frac{1}{\varrho_{0}} \frac{\partial p^{\prime}}{\partial x}+D_{u} \\
& \frac{\partial w}{\partial t}+\frac{\partial(u w)}{\partial x}+\frac{1}{\varrho_{0}} \frac{\partial\left(w^{2} \varrho_{0}\right)}{\partial z}=-\frac{1}{\varrho_{0}} \frac{\partial p^{\prime}}{\partial z}+\beta+D_{w}
\end{aligned}
$$

Here $D_{u}$ and $D_{w}$ are subgrid scale friction due to eddy momentum exchange of the form

$$
\begin{aligned}
& D_{k}=\frac{\partial}{\partial x}\left(2 v_{m} \frac{\partial u}{\partial x}\right)+\frac{1}{\varrho_{0}} \frac{\partial}{\partial z}\left[\varrho_{0} v_{m}\left(\frac{\partial u}{\partial z}+\frac{\partial w}{\partial x}\right)\right] \\
& D_{w}=\frac{\partial}{\partial x}\left[v_{m}\left(\frac{\partial u}{\partial z}+\frac{\partial w}{\partial x}\right)\right]+\frac{1}{\varrho_{0}} \frac{\partial}{\partial z}\left(2 \varrho_{0} v_{m} \frac{\partial w}{\partial z}\right),
\end{aligned}
$$

and 


$$
\beta=8\left[\frac{T^{\prime}}{T_{0}}+0.61 q_{\nu}^{\prime}-q_{1 t}-\frac{p^{\prime}}{p_{0}}\right]
$$

is the total buoyancy with $q_{v}$ ' and $q_{l}$ being the water vapour and cloud water mixing ratios, respectively.

For the specification of the eddy diffusion coefficient of momentum, $v_{m}$, we use a firstorder closure scheme where the Reynolds stresses are assumed proportional to the velocity deformation. The scheme is analogous to that of Hill (1974) where the eddy diffusion coefficient depends on the buoyancy and shear time scales. However, no turbulence will be generated when ihe local Richardson number exceeds 0.25 . The eddy diffision coefficient for scalar quantities, $v_{v}$ is assumed to have the same value as that for momentum.

Conservation of water substance is described by

$$
\frac{\partial q}{\partial t}+\frac{\partial(u q)}{\partial x}+\frac{1}{Q_{0}} \frac{\partial}{\partial z}\left(\digamma_{0} w q\right)=\frac{\partial}{\partial x}\left(v_{s} \frac{\partial q}{\partial x}\right)+\frac{1}{Q_{0}} \frac{\partial}{\partial z}\left(v_{s} Q_{0} \frac{\partial q}{\partial z}\right)
$$

where $q=q_{v}+q_{1}$ is the total water mixing ratio.

The thermodynamic equation is given by the conservation of total specific entropy $\phi$,

$$
\frac{\partial \varphi}{\partial t}+\frac{\partial(u \varphi)}{\partial x}+\frac{1}{\ell_{0}} \frac{\partial}{\partial z}\left(\ell_{0} w \varphi\right)=\frac{\partial}{\partial x}\left(\nu_{s} \frac{\partial \varphi}{\partial x}\right)+\frac{1}{\ell_{0}} \frac{\partial}{\partial z}\left(\nu_{s} \ell_{0} \frac{\partial \varphi}{\partial z}\right)+\left.\frac{C_{p}}{\Gamma} \frac{\partial T}{\partial t}\right|_{\mathrm{rad}}
$$

where

$$
\varphi=C_{p d} \ln T-R_{d} \ln p+\operatorname{Lq}_{v} T^{-1}
$$

The rate of the change of total specific entropy due to longwave radiation is represented by the last term in (3.8). The calculation of longwave radiative cooling rate will be given in section 3.3. 
Saturation analysis required to obtain $T^{*}, q^{*}$ and $q_{1}$ is based on an extension of a scheme used for shallow convection (Ogura, 1963; Orville, 1965; Steiner, 1973) to the case of deep clouds. Reuter (1985) gives the details for the computations.

Because a perturbation pressure gradient term exists in the momentum equation, an additional pressure diagnostic equation has to be solved. This equation is obtained by combining the momentum equations and the continuity equation with the form

$$
\begin{gathered}
\frac{\partial}{\partial x} \frac{\partial}{\partial x} p^{\prime}+\frac{\partial}{\partial z} \frac{\partial}{\partial z} p^{\prime}=\frac{\partial}{\partial x} Q_{0} A_{u}+\frac{\partial}{\partial z} Q_{0} A_{w}+\frac{\partial}{\partial x} Q_{0} D_{u}+\frac{\partial}{\partial z} Q_{0} D_{w}+ \\
\frac{\partial \beta}{\partial z}-\frac{\partial}{\partial t}\left[Q_{0} \frac{\partial u}{\partial x}+\frac{\partial}{\partial z}\left(Q_{0} w\right)\right]
\end{gathered}
$$

where

$$
\begin{aligned}
& A_{u}=-\left[\frac{\partial\left(u^{2}\right)}{\partial x}+\frac{1}{Q_{0}} \frac{\partial}{\partial z}\left(Q_{0} u w\right)\right] \\
& A_{w}=-\left[\frac{\partial(u w)}{\partial x}+\frac{1}{\rho_{0}} \frac{\partial\left(\rho_{0} w w\right)}{\partial z}\right]
\end{aligned}
$$

The last term in (3.10) is retained for numerical reasons to ensure that the divergence of the mass flux in each grid box vanishes at the end of each time step.

\subsubsection{The numerical methods}

(1) A staggered grid is used in the $(x, z)$ plane. The wind velocities are placed at the sides of a grid box and the other variables at its center. A second-order non-diffusive leapfrog in time and centerd difference in space method is used to solve the prognostic equations. 
(2) To prevent splitting of solutions at even and odd time step, a Robert time filter (Asselin, 1972) is used every time step.

(3) The perturbation pressure p' is solved by the subroutine POISSX developed by Sweet (1973). This subroutine utilizes a direct solver and imposes no restriction on the number of points in the $\mathrm{x}$ and $\mathrm{z}$ directions. A unique solution for the pressure equation is obtained by setting the value of p' to zero at the top right hand comer.

\subsubsection{Boundary conditions}

(1) Lateral boundaries

The radiation boundary conditions given by Hedley and Yau (1988) are imposed at the lateral boundaries.

(2) Upper boundary

The upper boundary is assumed rigid and free-slip. Also, all vertical gradients of the scalar quantities vanish.

(3) Lower boundary

Except for the fields of total specific entropy and water vapour, the same conditions as those at the upper boundary are applied. Diffusion of heat and moisture from the ground to the lowest grid point is allowed to act as an initialization mechanism for convective activity.

(4) Heat and moisture fluxes

Heat and moisture diffuse from the surface into the lowest grid point. The fluxes of total specific entropy and moisture were computed as

total specific entropy flux: 


$$
\begin{array}{ll}
v_{H} \frac{\partial \phi}{\partial z}, & \frac{\partial \theta}{\partial z}<0 \\
0, & \text { otherwise }
\end{array}
$$

moisture flux:

$$
\begin{array}{cc}
v_{H} \frac{\partial q_{\nu}}{\partial z}, & \frac{\partial \theta}{\partial z}<0 \\
0, & \text { otherwise }
\end{array}
$$

where,

$$
v_{H}=c \Delta^{2}\left(\frac{g}{T}\right)^{\frac{1}{2}}\left(\gamma_{\text {venv }}-\gamma_{a d}\right)^{\frac{1}{2}}
$$

Here $\mathrm{T}$ is the mean temperature between the surface and lowest grid point, $\mathrm{c}$ is a constant which was taken as 1.6, $\Delta=(\Delta \mathrm{x} \Delta \mathrm{z})^{1 / 2}$ is the scale of the grid spacing and the value of $\gamma_{\text {veav }}$ was computed from the temperatures and moistures at the lowest grid point and the surface.

A constant water vapour mixing ratio of $16.5 \mathrm{~g} \mathrm{~kg}^{-1}$ is specified at the surface. Surface heating was applied by prescribing a time-dependent surface temperature $T_{a}$ with maximum amplitude at the central axis. The form of the surface heating is almost identical to that of Clark (1984) and Reuter (1987). Similar to Liu et al. (1969), cloud shadow effect was included. Specifically, the expression for $T_{\mathbf{a}}$ is 


$$
T_{s}(x, t)=T_{s 0}+A \exp \left[-(\ln 2) \frac{\left(x(I)-x_{0}\right)^{2}}{B^{2}}\right] t_{c}-C \exp \left[-(\ln 2) \frac{\left(x(I)-x_{0}\right)^{2}}{B^{2}}\right]\left(t-t_{c}\right), \text { for } t>t_{c}
$$

$$
T_{s}(x, t)=T_{s 0}+A \exp \left[-(\ln 2) \frac{\left(x(I)-x_{0}\right)^{2}}{B^{2}}\right] t, \quad \text { for } t \leq t_{c}
$$

where $A$ and $C$ are heating rate constants (1.6 and $1.4 \mathrm{~K} \mathrm{~h}^{-1}$ respectively). The distance $x(\mathrm{I})$ at grid point $I$ is measured from the center of the ciomain located at $x_{0}$. The time when cloud forms is denoted by $t_{c}$. The parameter B gives a measure of the width of the Gaussian heating function and is $130 \mathrm{~m}$. When $\mathrm{x}(\mathrm{l})-\mathrm{x}_{0}$ equals $\mathrm{B}$, the heating rate is half of its maximum value. Eqs. (3.18) and (3.19) show that before (after) the cloud forms, the surface temperature increases (decreases) linearly with time.

\subsubsection{Domain size, grid size, and time step}

The domain sizes in the $x, z$ directions are $20 \mathrm{~km}$ and $3 \mathrm{~km}$ respectively. It is subdivided into 800 equally spaced grid intervals in the $x$ direction and 120 equally spaced grid intervals in the $\mathrm{z}$ direction. The constant grid length $\Delta$ is therefore $25 \mathrm{~m}$.

With a high resolution grid, strong surface heating, and large turbulence close to the ground, a small time step is required for numerical stability. The time step is $0.5 \mathrm{~s}$ for simulation times less than about $27 \mathrm{~min}$, and $0.05 \mathrm{~s}$ thereafter. Typically, we needed more than 49200 time iterations to cover a simulation time of $65 \mathrm{~min}$. 


\subsection{The longwave radiation model in the slab-symmetric}

\section{cloud}

\subsubsection{Model}

The model equations for the slab-symmetric model are very similar to those of the axially symmetric model described in Chapter 2 except for the calculation of the net flux divergence. In the slab-symmetric model, it is assumed that no property varies in the y direction and the $y$ direction is infinite. Thus, the net flux divergence can be expressed in Cartesian coordinates $x$ and $\mathrm{z}$ as

$$
\nabla \cdot F_{n e t}=\frac{\partial F_{n e t, x}}{\partial x}+\frac{\partial F_{n e t, z}}{\partial z}
$$

Similar to the axially symmetric model described in Chapter 2 , a three-dimensional appronch to the calculation of the radiance has been used. As pointed out as in Chapter 1, the cumulus cloud is of limited horizontal extent, and the plane parallel theory is not suitable. In order to evaluate fluxes, the angular integration is performed using Gaussian quadrature. In the present study, the angular resolution was taken as $18^{\circ}$. The cooling rates with a angular resolution of $9^{\circ}$ were also calculated. The results are very similar for both angular resolutions. The cooling rates were calculated every $30 \mathrm{~s}$ using the temperature, water vapour and cloud water contents from the cloud model. Preliminary test runs, using a grid size of $50 \mathrm{~m}$, have shown that the evolutions of the simulated clouds when the radiative cooling rates were calculated every $5 \mathrm{~s}$ or $30 \mathrm{~s}$ are very similar.

Another new feature is that the spectral absorption coefficient calculation for cloud water 
was simplified. In chapter 2 , the method used to calculate the spectral absorption coefficient for cloud water was cumbersome and made large demands on computer time. Therefore in chapter 3, chapter 4 and chapter 5 , we used a simple expression for the absorption coefficient which has been used extensively by many researchers (e.g., Platt, 1975, 1976; Pinnick et al., 1979; Chýlek et al., 1982; Stephens, 1984; Chýlek et al., 1992).

The approximation was based on the observation that at wavelergths around $\lambda=10 \mu \mathrm{m}$, the Mie absorption coefficient $\mathrm{Q}_{\mathrm{abs}}$ can be reasonably well approximated by a linear function of the radius for all droplet radii $\mathrm{r}<12 \mu \mathrm{m}$, i.e. $\mathrm{Q}_{\mathrm{abs}}=(2 \pi \mathrm{r} / \lambda) c(\lambda)$. In this case the cloud spectral absorption coefficient given in (2.6) becomes

$$
k_{\lambda}=\int_{0}^{\infty} \pi r^{2} c(\lambda) \frac{(2 \pi r)}{\lambda} n(r) d r
$$

or

$$
k_{\lambda}=\frac{3 \pi Q_{a t r} c(\lambda)}{2 \lambda Q_{\text {water }}} q_{l}
$$

where $c(\lambda)$ is some wavelength factor. $c(\lambda)$ is taken from Pinnick et al. (1979). Equation (3.22) shows that, in this regime where $Q_{\text {abs }}$ increases linearly with droplet radius, the absorption coefficient for a given wavelength is a function of a single parameter, the cloud liquid water content.

It is noted that the radius of most of the droplets in a cloud is smaller than about $12 \mu \mathrm{m}$ (Best, 1951; Carrier et al., 1967; Stephens, 1978). The limit of $12 \mu \mathrm{m}$ does not mean that the cloud cannot contain larger droplets. All that is required is that the dominant contribution toward 
the absorption comes from droplets smaller than $12 \mu \mathrm{m}$ (Chylek and Ramaswamy, 1982).

\subsubsection{Test of spatial resolution}

It is well known that the radiative cooling rate is sensitive to spatial resolution especially when the liquid water content and its gradient are large (Alves, 1987). Alves pointed out that computations of radiative cooling using a coarse resolution tends to underestimate the peak cooling rate. A primary question confronting our study is whether a grid size of $25 \mathrm{~m}$ is sufficient to resolve the peak cooling rate in our simulated cloud. To answer this question, we calculated longwave radiative cooling rate in an idealized small cumulus with resolutions of $25 \mathrm{~m}$ and 10 $m$ respectively. A comparison between the two sets of results would indicate whether a resolution of $25 \mathrm{~m}$ is adequate.

A circular cloud was assumed with a constant LWC of $0.4 \mathrm{~g} \mathrm{~kg}^{-1}$. The cloud was positioned between 650 and $1050 \mathrm{~m}$ in the tropical boundary layer. The atmospheric sounding is the same as that used in Section 3.4 (see Fig. 3.3). The longwave radiative cooling rates for both resolutions were calculated by using the longwave radiation model introduced in Section 3.3.1. Fig 3.1a and Fig. 3.1b show the distributions of longwave radiative cooling rate in the cloud for the two resolutions. It can be seen that both distributions and peak cooling rates are quite similar. The vertical profiles of cooling rate at the center of the cloud for the two resolutions are also given in Fig. 3.2. In general, the agreement is good with the peak cooling rate for the $10 \mathrm{~m}$ resolution case larger by at most $10 \%$. Since the liquid water content gradient at of top of real clouds is finite, a more realistic estimate of the difference in the cooling rate between the two resolutions should be less than $10 \%$. 


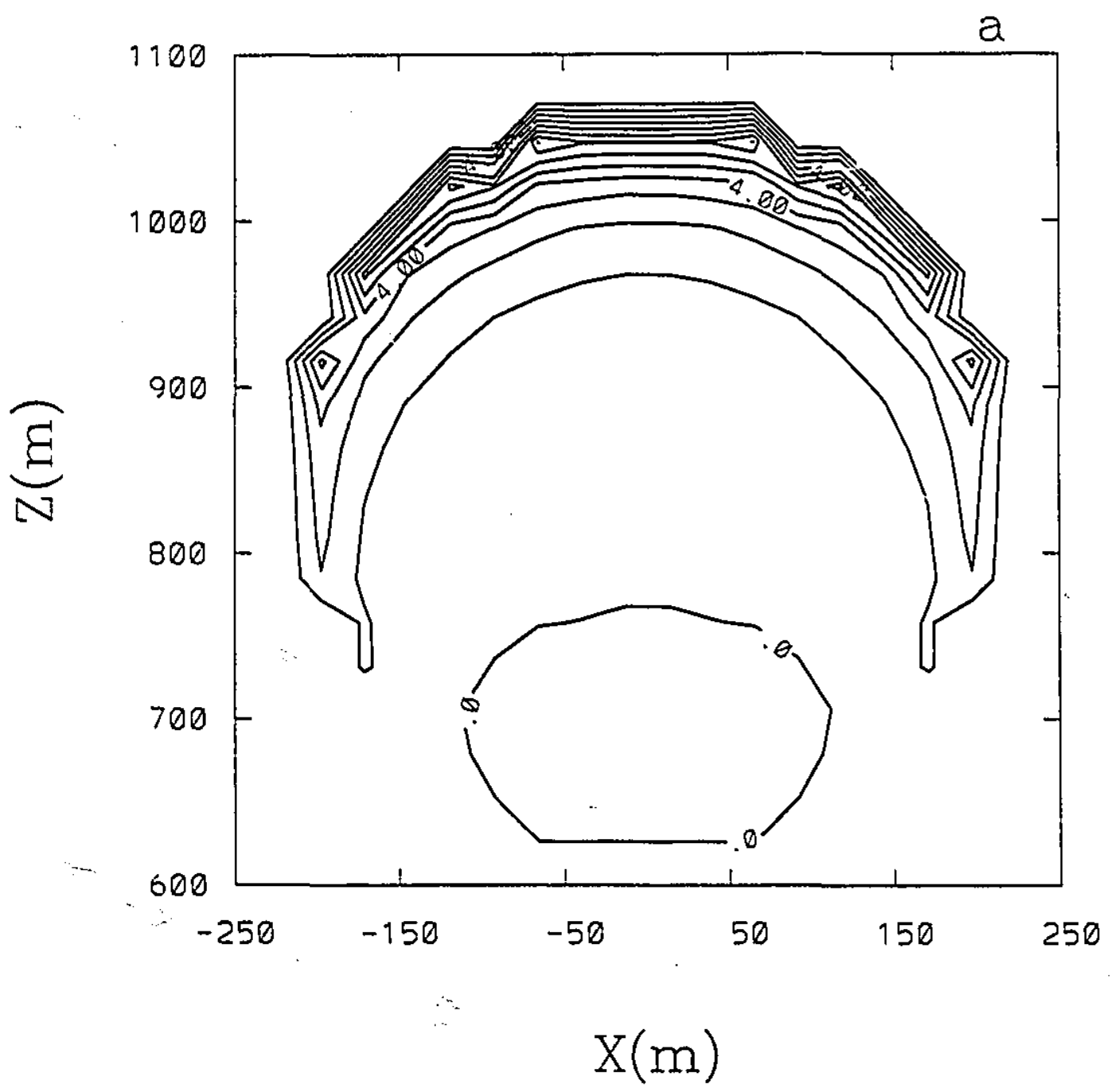

Figure 3.1: Contours of radiative cooling rates in a circular cloud. Contour interval is $1 \mathrm{~K} \mathrm{~h}^{-1}$. a) Spatial resolution is $25 \mathrm{~m}$. b) Spatial rèsolution is $10 \mathrm{~m}$. 


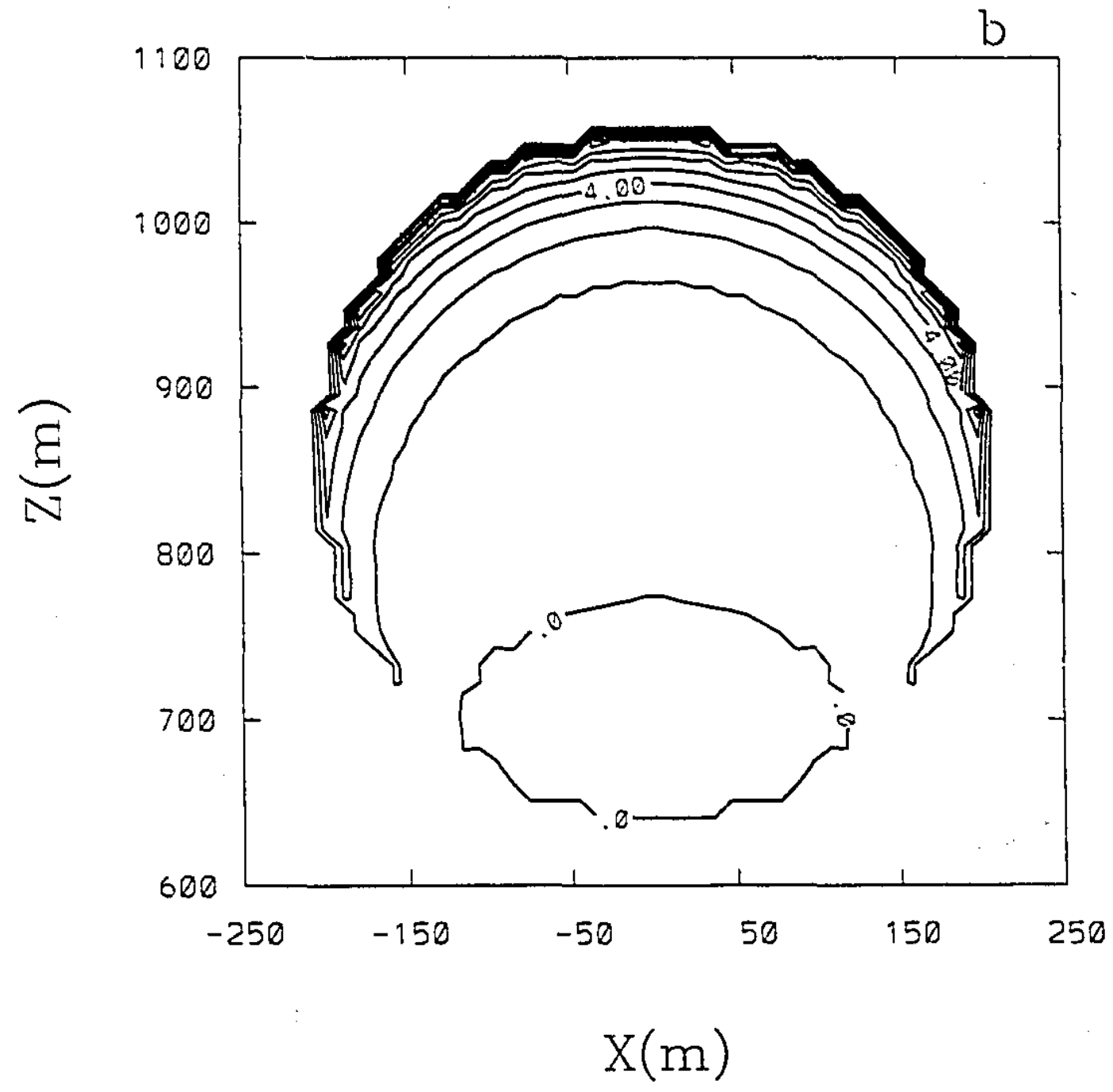




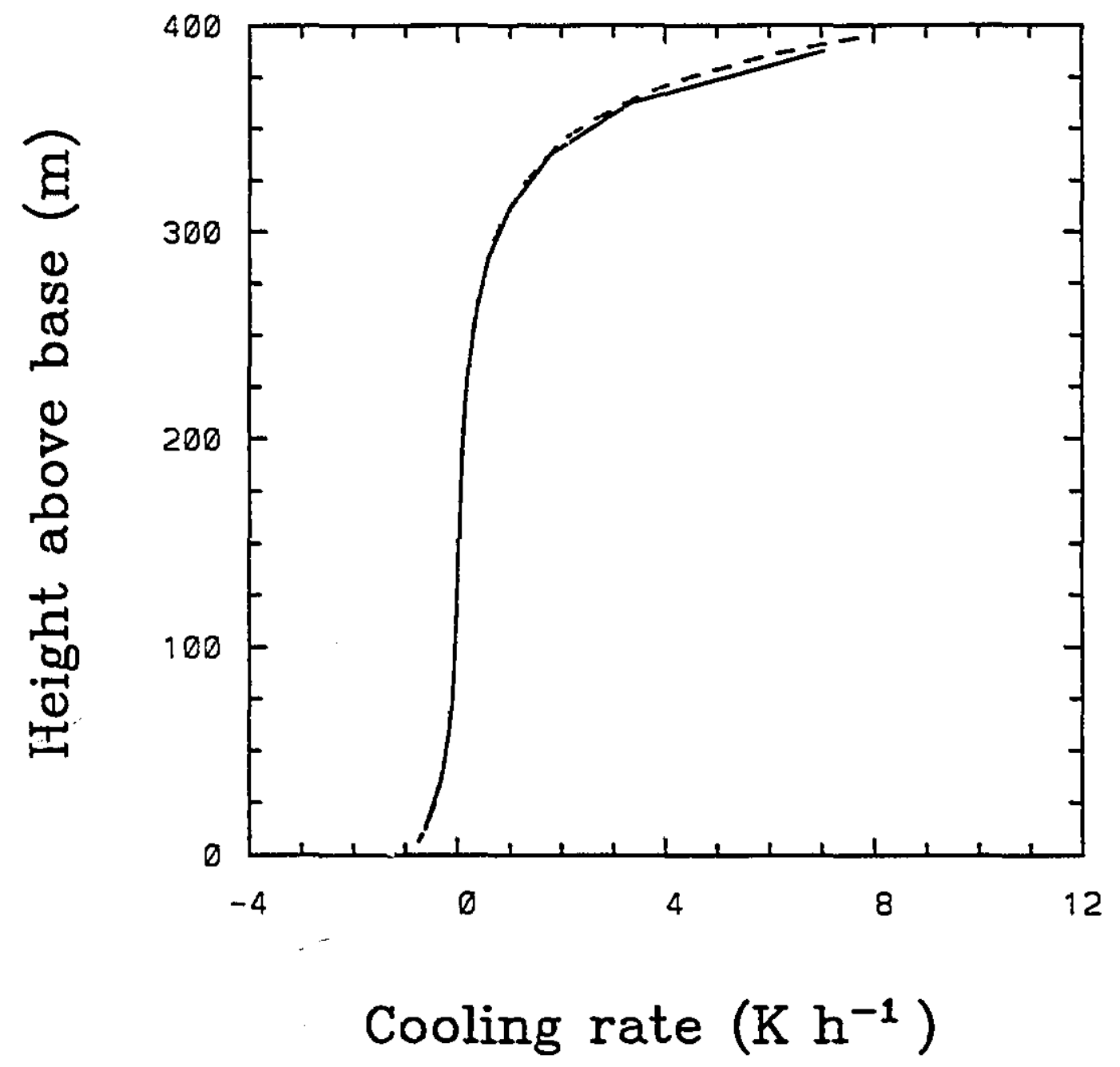

Figure 3.2: Radiative cooling (positive) rates at the center of the circular cloud as a function of height above the cloud base. Solid curve, spatial resolution is $25 \mathrm{~m}$. Dashed curve, spatial resolution is $10 \mathrm{~m}$. 


\subsection{Experiments and results}

The initial sounding is almost the same as that used by Veyre et al. (1980) which is representative of the environment in Puerto Rico when small cumuli (300-500 $\mathrm{m}$ in thickness) occur (Pennell and LeMone, 1974). Figure 3.3 shows a mixed layer with almost constant potential temperature and water vapour mixing ratio to a height of $525 \mathrm{~m}$. From $525 \mathrm{~m}$ to 1050 $\mathrm{m}$, the mixed layer is surmounied by a moist layer which will become the cloud layer. The moist layer is capped by a stable layer aloft. A thin superadiabatic layer is found close to the surfice. The convective condensation level (CCL) is about $600 \mathrm{~m}$.

Two experiments have been pertormed. In the "CONTROL run", longwave radiation is turned off (the last term in Eq. (3.S) was set to zero). In the "LW run", longwave radiation is included. A comparison between the two runs gives indication of the effect of longwave radiation on small cumulus cloud development. Before discussing the differences between the two runs, the main features of the evolution of the "CONTROL" cloud will tirst be described.

\subsubsection{CONTROL run -- no longwave radiation process}

The cloud was initiated after $27 \mathrm{~min}$ from surface heat and moisture fluxes. The properties of the cloud at $35 \mathrm{~min}$ and $55 \mathrm{~min}$ are depicted in Fig. 3.4 and Fig. 3.5.

(a) Structure at $35 \mathrm{~min}$

Fig. 3.4 shows the cloud at its initial stage of development. For clarity and economy, only a limited region of the domain is plotted. A core of updraft (Fig. 3.4a) is found near the central axis (maximum $1.9 \mathrm{~m} \mathrm{~s}^{-1}$ ). The horizontal velocity (Fig. 3.4b) indicates outflow (maximum 1.3 $\mathrm{m} \mathrm{s}^{-1}$ ) above $400 \mathrm{~m}$. Below this level, there is a weak inflow region. The distribution of cloud 


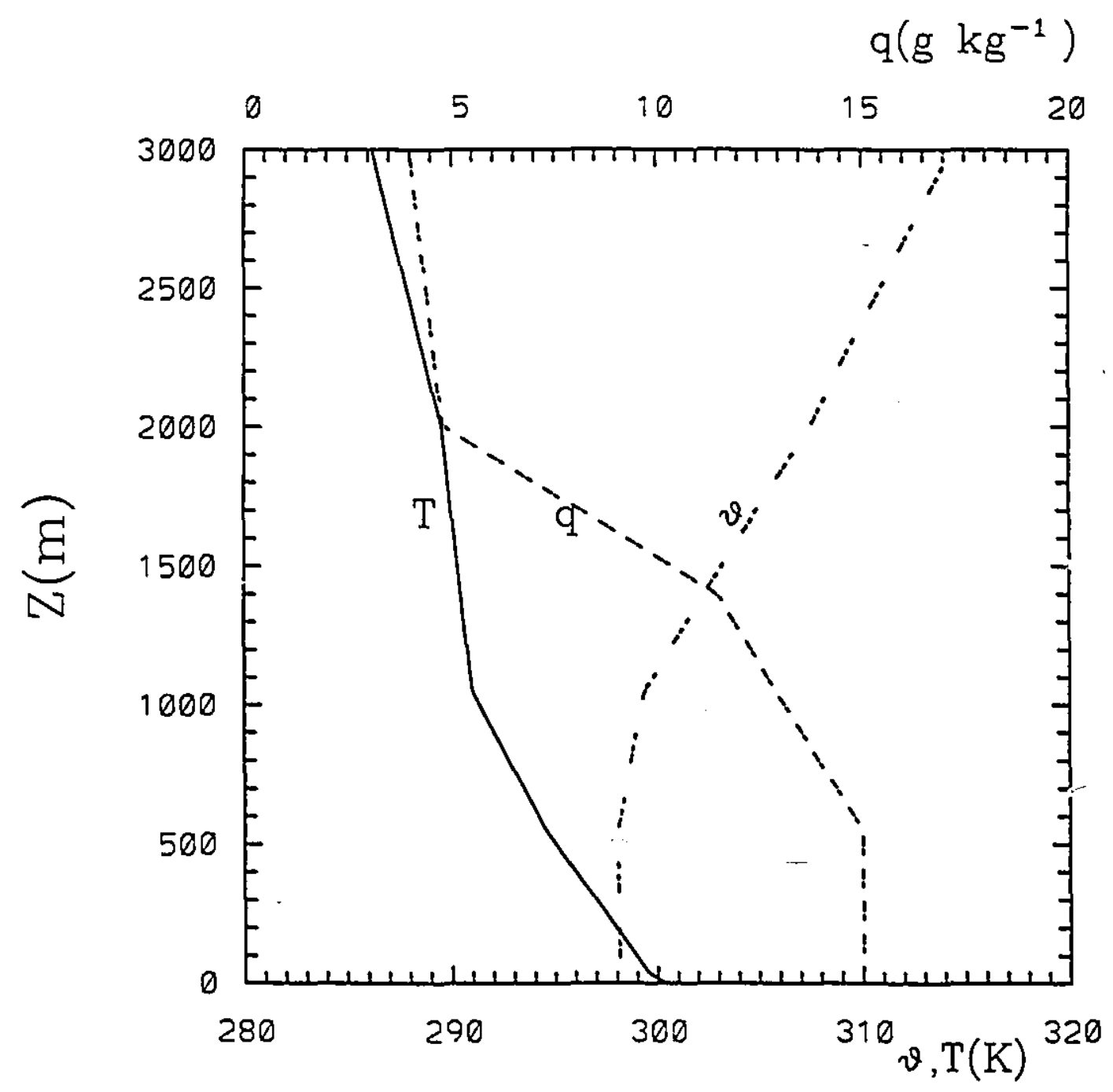

Figure 3.3: Initial temperature $(T)$, potential temperature $(\theta)$, and specific humidity ( $($ ) profiles. 

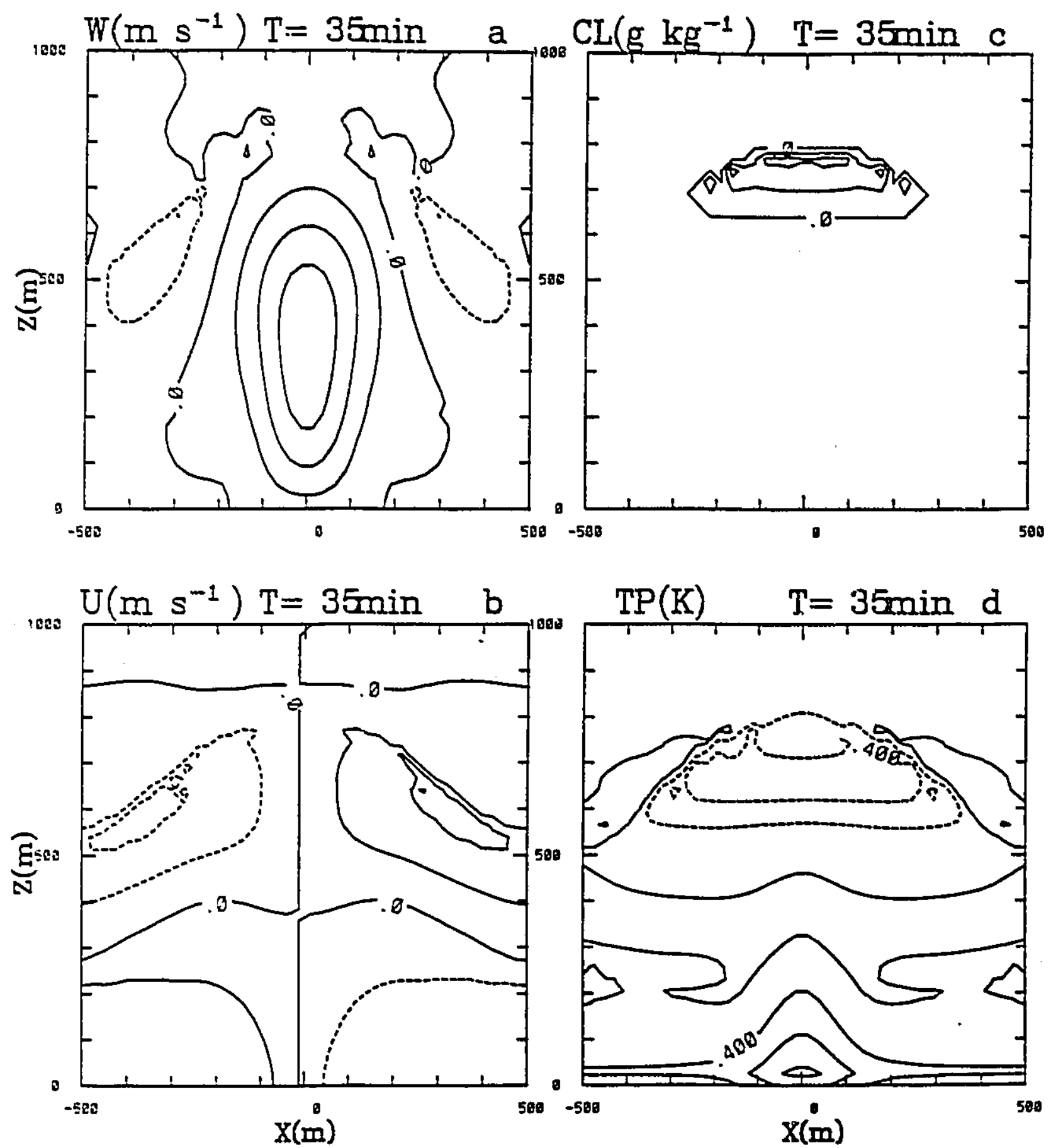

Figure 3.4: Vertical section of a) vertical velocity (W), b) horizontal velocity (U), c) cloud watcr mixing ratio (CL), and d) temperature perturbation (TP) at $35 \mathrm{~min}$. The contour intervals for $W$, $\mathrm{U}, \mathrm{CL}$. and TP are $0.5 \mathrm{~m} \mathrm{~s}^{-1}, 0.5 \mathrm{~m} \mathrm{~s}^{-1}, 0.1 \mathrm{~g} \mathrm{~kg}^{-1}, 0.2 \mathrm{~K}$ respectively. 
water content (Fig. 3.4c) shows values smaller than $0.2 \mathrm{~g} \mathrm{~kg}^{-1}$ in most regions of the cloud. Positive temperature perturbations relative to the initial state (Fig. 3.4d) are found near the center of the domain below $500 \mathrm{~m}$ as a result of surface heating. Above $500 \mathrm{~m}$, a cool pool forms because the latent heat of condensation was offset by the cooling due to adiabatic ascent. This result is consistent with that of Sommeria (1976), who found the prevalence of negative temperature perturbations in cloudy regions in a three-dimensional simulation of a small tropical cumulus.

(b) Structure at $55 \mathrm{~min}$

Fig 3.5 depicts the cloud at its mature stage. It is noted that the circulation is weaker than at $35 \mathrm{~min}$ (Fig. 3.5a,b) because the cloud shadow effect cuts off the surface heating. The undraft near the central axis below the cloud base (Fig 3.5a) decreased to a maximum of $1.3 \mathrm{~m} \mathrm{~s}^{-1}$. However, the updraft in the cloudy region increases since heat and moisture continue to be transported from the lower level to the region of the cloud. The liquid water content (Fig 3.5c) exceeds $0.2 \mathrm{~g} \mathrm{~kg}^{-1}$ in most regions and the thickness of cloud is about $300 \mathrm{~m}$ consistent with the observations of Pennell and Lemone (1974). The negative temperature perturbation (Fig. 3.5d) in the center of cloud is less negative than at the initial stage due to continuous warming by condensation.

\subsubsection{Total effect}

To examine the total effect of longwave radiation, we display the temporal evolutions of the maximum cloud water content and the total cloud water content for the CONTROL and the LW runs in Fig. 3.6 and Fig. 3.7, respectively. It can be seen that longwave radiative cooling 

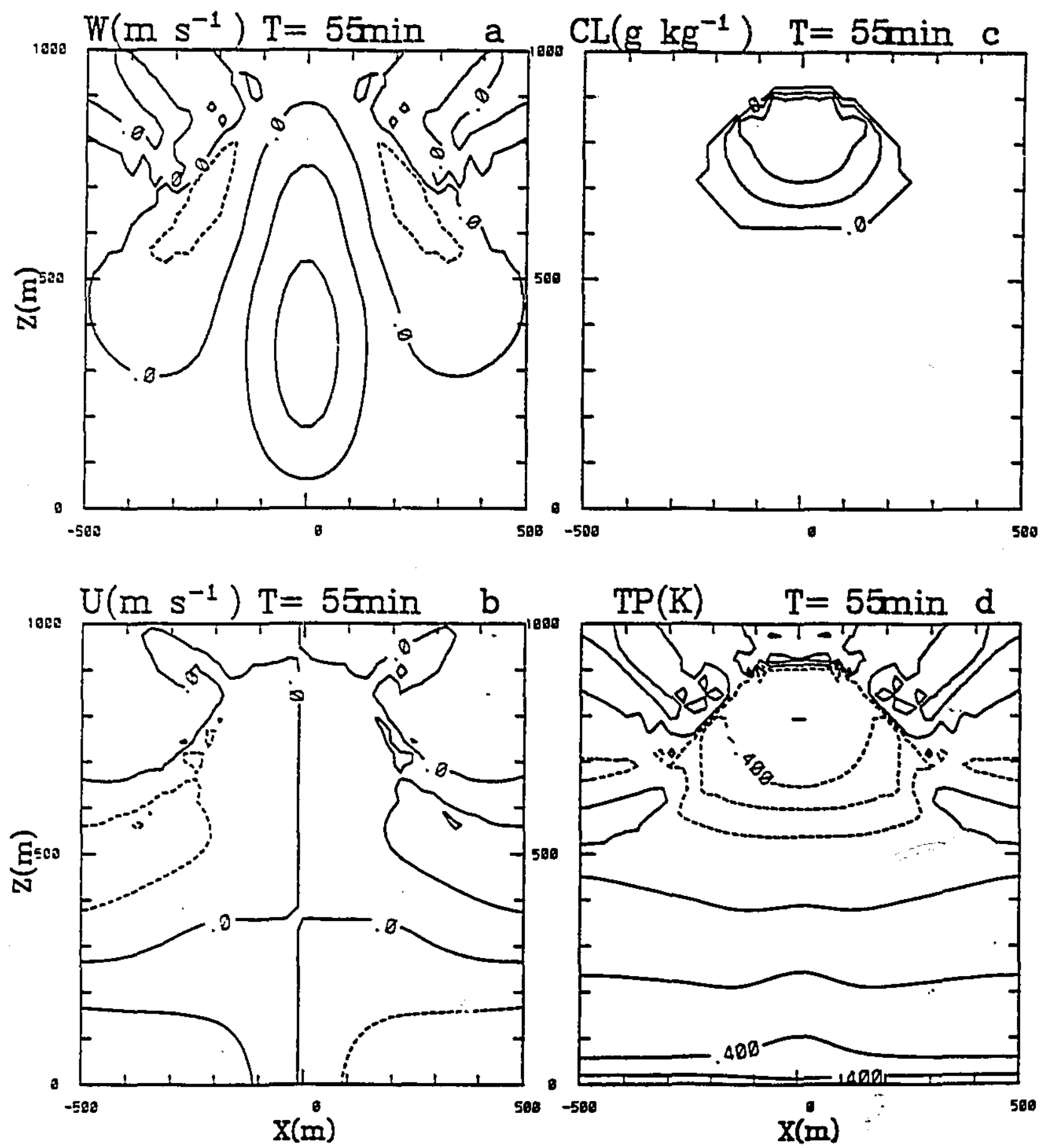

Figure 3.5: Vertical section of a) vertical velocity (W), b) horizontal velocity (U), c) cloud water mixing ratio (CL), and d) temperature perturbation (TP) at $55 \mathrm{~min}$. The contour intervals for $W$, $\mathrm{U}, \mathrm{CL}$, and TP are $0.5 \mathrm{~m} \mathrm{~s}^{-1}, 0.5 \mathrm{~m} \mathrm{~s}^{-1}, 0.1 \mathrm{~g} \mathrm{~kg}^{-1}, 0.2 \mathrm{~K}$ respectively. 
increases the maximum cloud water content through most of the simulation time. Significant differences are detected at the mature stage, when the maximum enhancement reaches $96 \%$ at $47 \mathrm{~min}$. Another feature is that the maximum cloud water content displays some oscillations particularly in the LW run. This phenomenon is related to the life cycles of individual cells in the cloud. To a lesser degree, the time series of total cloud water content also indicate corresponding increases at the growing and mature stages. The maximum increase of total cloud water content is about $20 \%$ from $50 \mathrm{~min}$ to $55 \mathrm{~min}$. Note also that the cloud decays earlier for the LW run. Thus longwave radiative cooling tends to accelerate the dissipation of the cloud.

In their study on the effect of longwave radiation on small tropical cumuli, Veyre et al. (1980) found that longwave radiation enhanced the mean cloud water content by $25 \%$. However, the dramatic increase in maximum cloud water content can be a more important result from the point of view of precipitation physics. For a given water vapour content, the effect of longwave radiation cooling on lowering the saturation water vapour pressure may enhance the growth of cloud droplets. As a result, precipitation particles may form in such a cloud which would otherwise not develop precipitation.

Fig. 3.8, Fig. 3.9, and Fig. 3.10 depict the vertical cross section of the cloud water content for the two runs at $40 \mathrm{~min}, 55 \mathrm{~min}$, and $60 \mathrm{~min}$, respectively. At $40 \mathrm{~min}$, the enhancement of condensation, as indicated by a larger LWC, is mainly concentrated near the cloud top and its sides (Fig. 3.8 a,b). The heights of cloud top are slightly lower in the LW run for all the three times.

\subsubsection{Positive feedback of longwave radiative cooling on condensation}




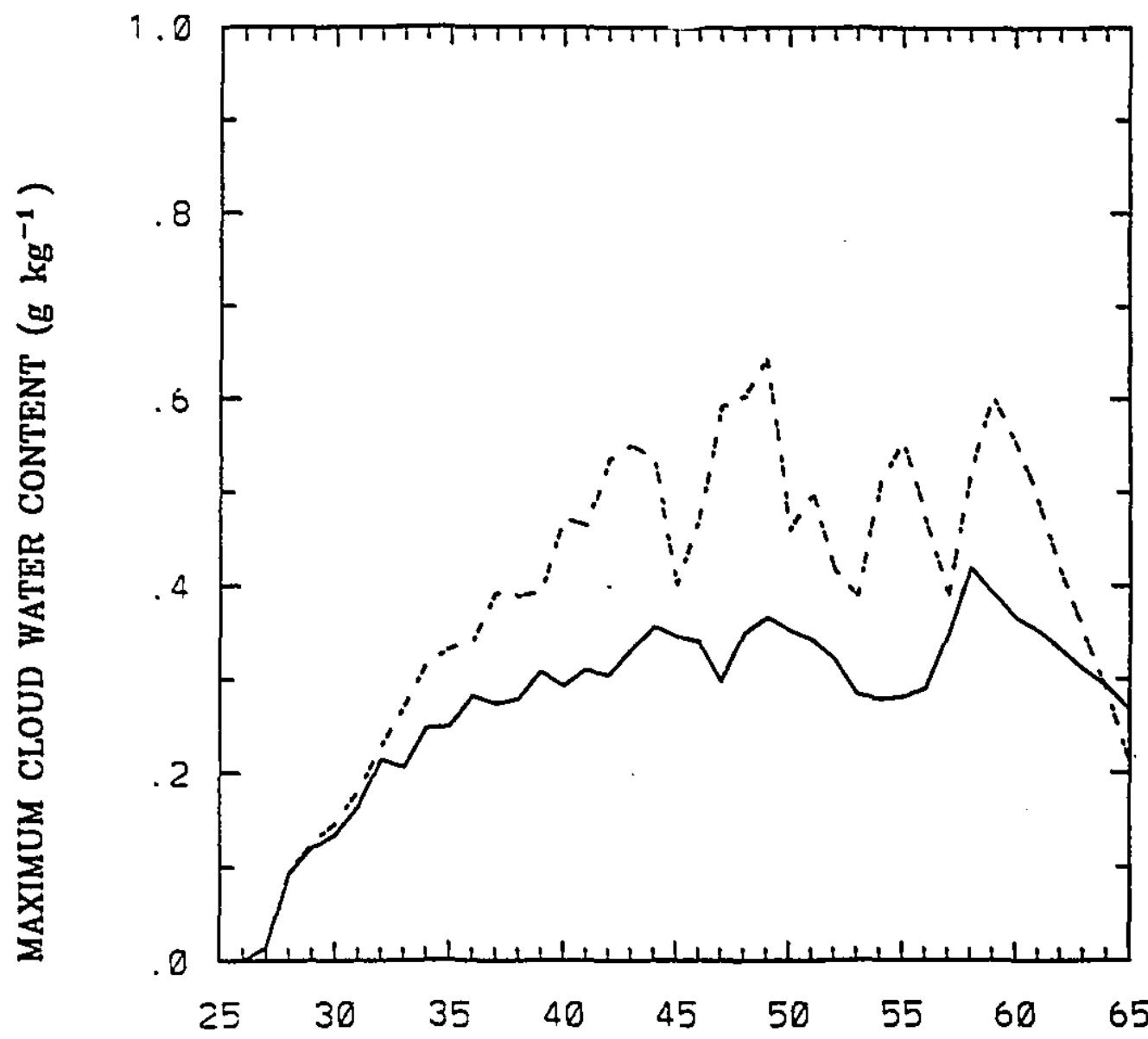

TIME (min) curve, CONTROL run. Dashed curve, LW run. 


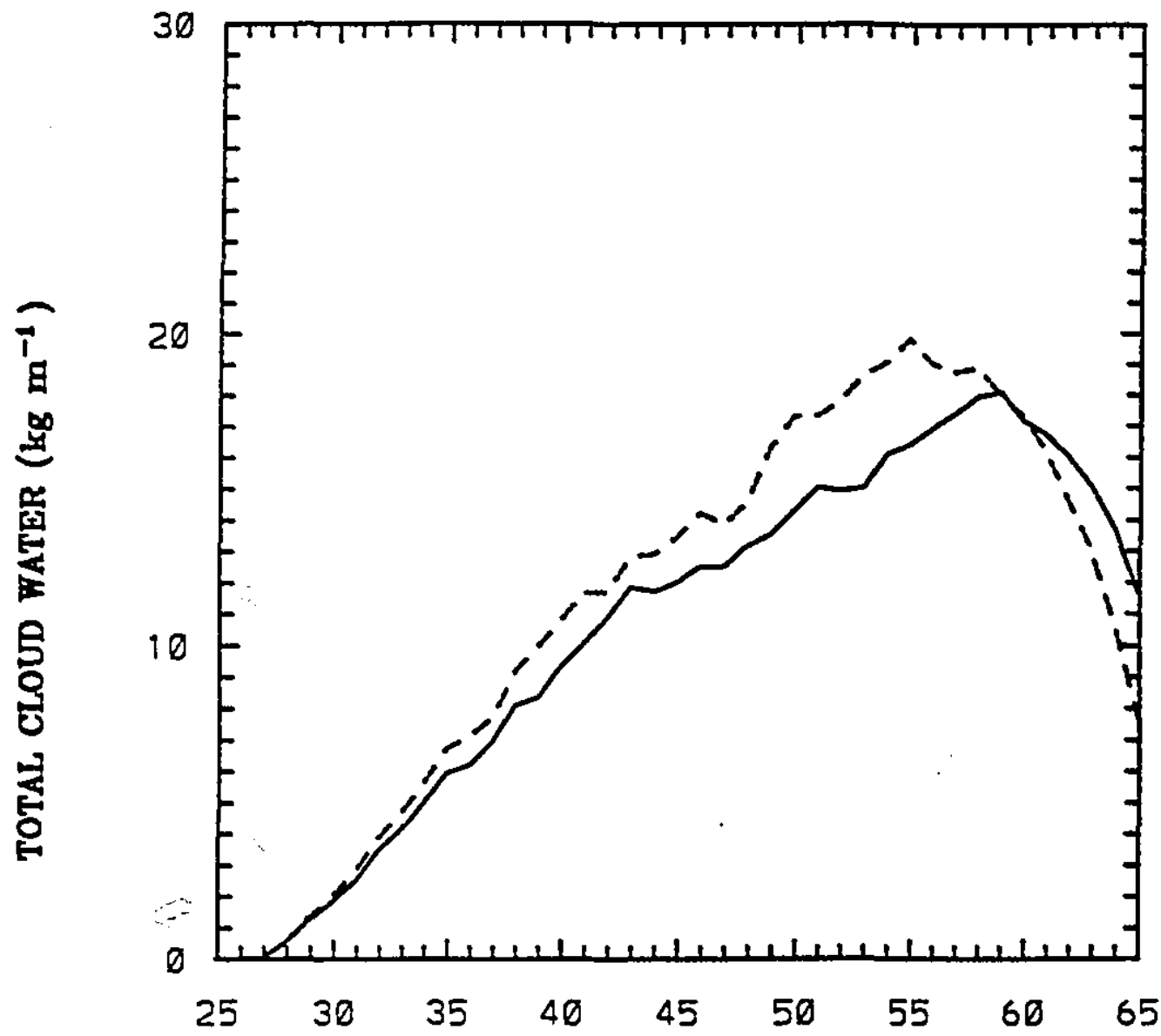

TINE (min)

Figure 3.7: Evolution of total cloud water content for the CONTROL and LW runs. Solid curve, CONTROL run. Dashed curve, LW run. 

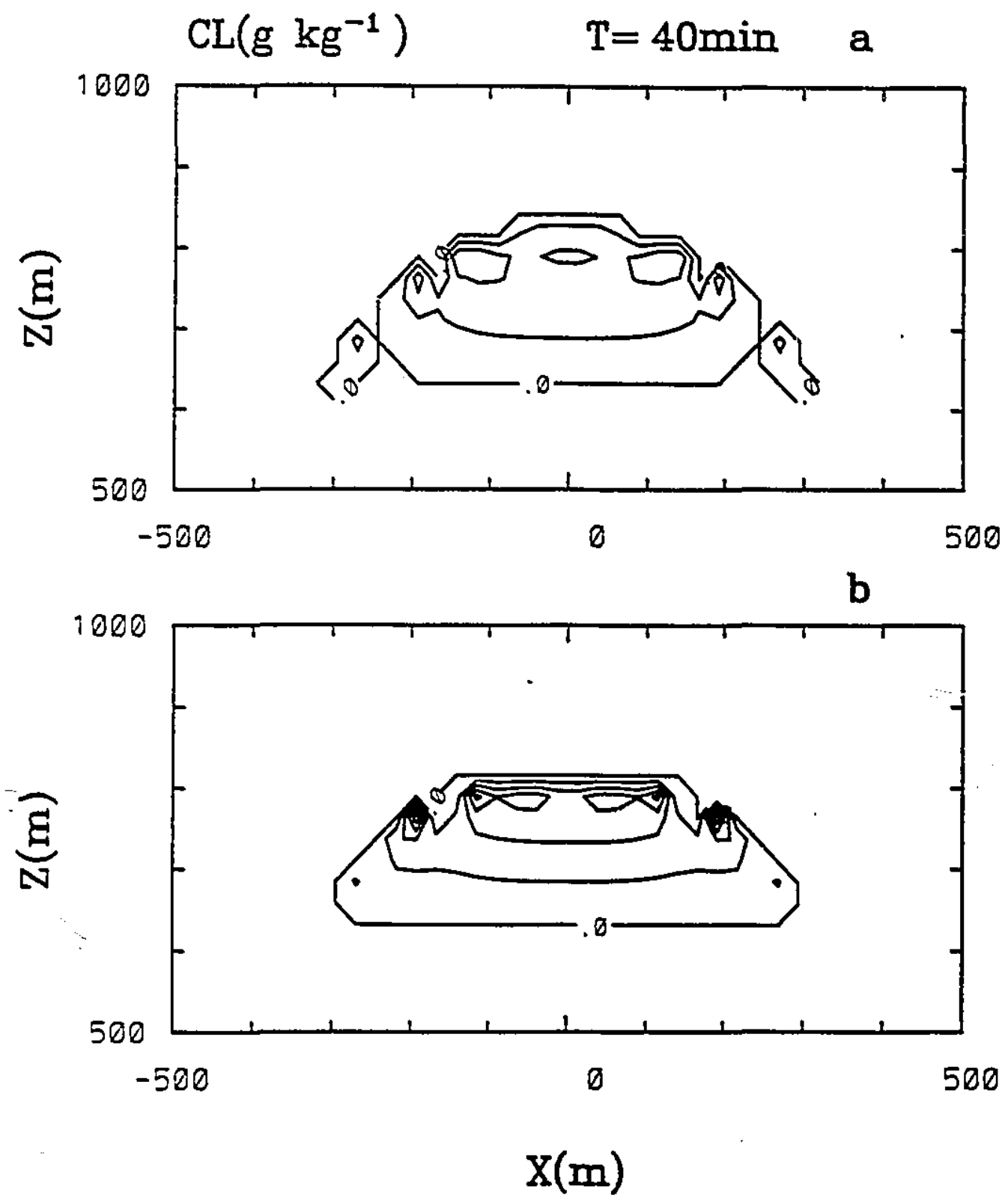

Figure 3.8: Vertical section of cloud water content at $40 \mathrm{~min}$. Contour interval is $0.1 \mathrm{~g} \mathrm{~kg}^{-1}$. a) CONTROL run. b) LW run. 

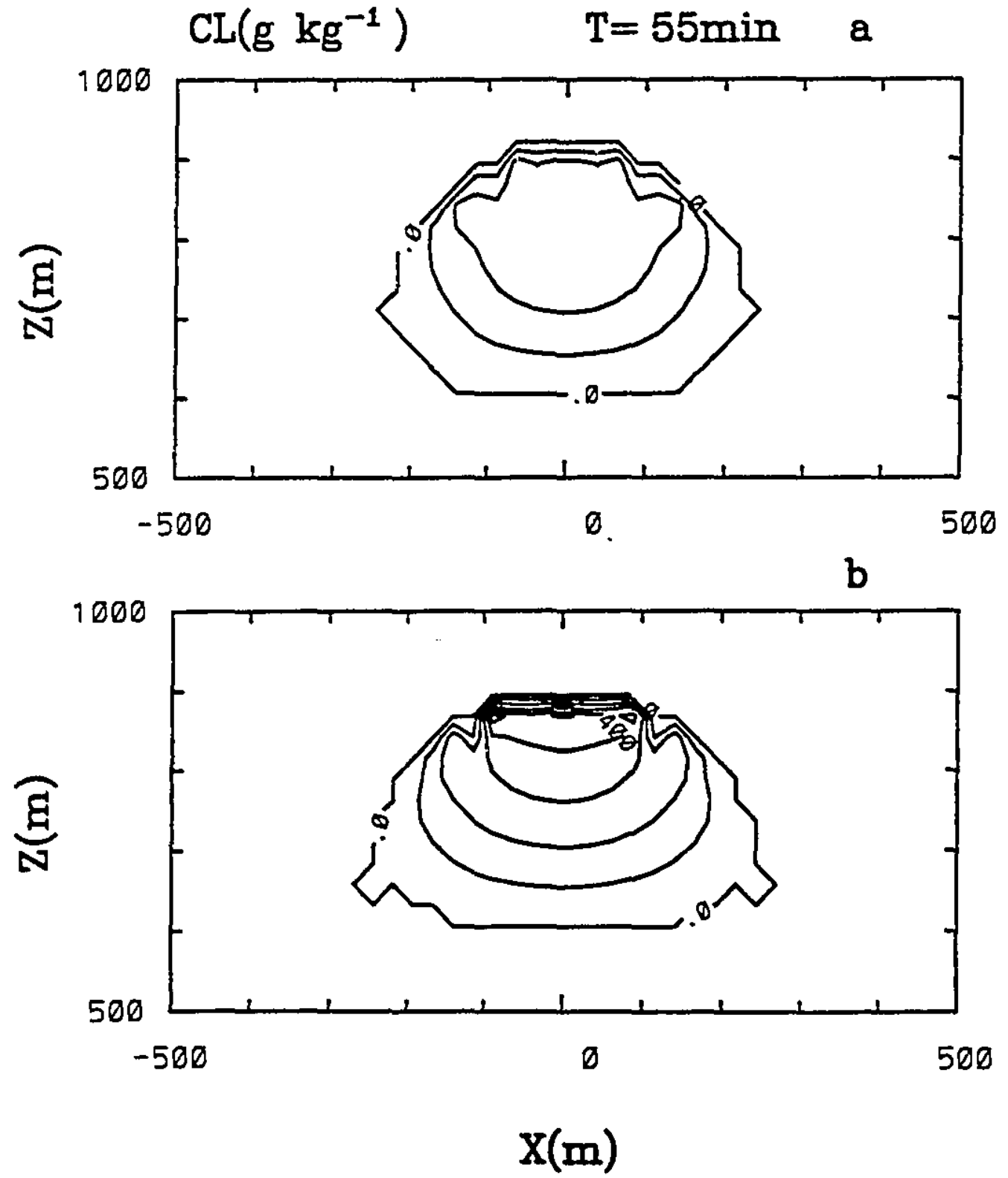

Figure 3.9: Same as Figure 3.8 but at $55 \mathrm{~min}$. 

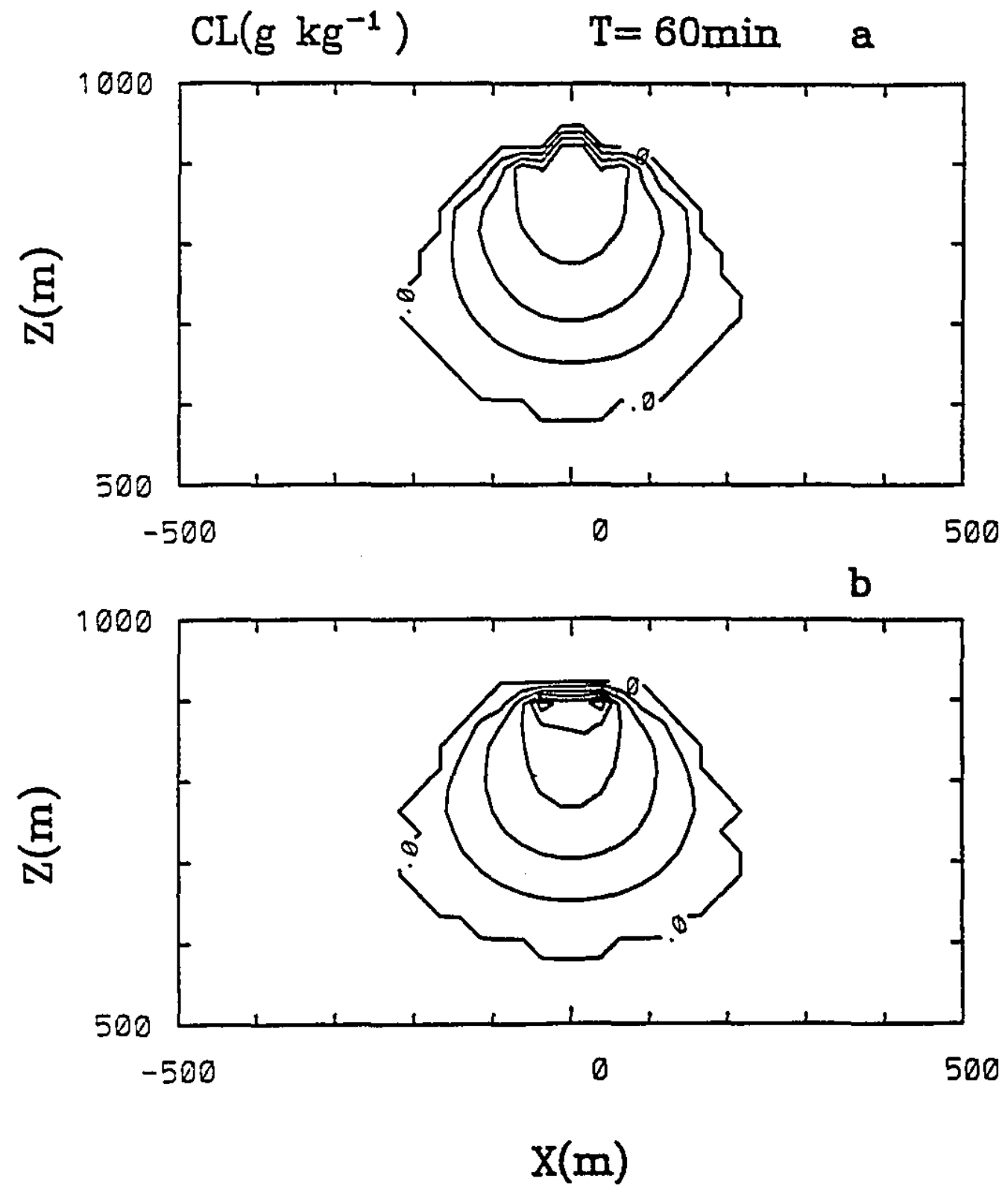

Figure 3.10: Same as Figure 3.8 but at $60 \mathrm{~min}$. 
To understand the enhancement of cloud water content mainly near the cloud top and the sides at $40 \mathrm{~min}$ (initial stage of the cloud), we plotted the distributions of vertical velocity for both runs in Fig. 3.11. The maximum downdrafts are similar and the values are $1.1 \mathrm{~m} \mathrm{~s}^{-1}$. The area of the downdraft is slightly larger in the LW run. The ratio of the area where the downdraft magnitude exceeds $0.5 \mathrm{~m} \mathrm{~s}^{-1}$ between the two runs is 1.2. The difference in the value of the updruft is also smal! and could not account for the large difference in cloud water content shown in Fig. 3.8.

Fig. 3.12 displays the distribution of longwave radiative cooling rate in the LW run at 40 min. Significant radiative cooling rates can be detected near the cloud top and sides particularly in the regions with high LWC (maximum $6 \mathrm{~K} \mathrm{~h}^{-1}$ ). Since the variation of saturation vapour pressure with temperature is more pronounced at higher temperatures (see Rogers and Yau, 1989, Tible 2.1, p16), the effect of condensation induced by pure radiative cooling should be more significant for clouds associnted with warmer temperatures. The strong radiative cooling can lower the saturation water vapour pressure, leading to enhanced condensation. It should be pointed out that this radiation-condensation interaction is a positive feedback process, as a larger LWC produces a larger radiative cooling rate, which in turn induces more condensation. Thus at the initial stage of our simulated cloud, radiation-condensation feedback serves to increase the maximum cloud water content.

\subsubsection{Secondary circulation induced by longwave radiative cooling}

Fig. 3.13 shows the distribution of longwave radiative heating/cooling rate in the cloud at $55 \mathrm{~min}$. Similar to the situation at $40 \mathrm{~min}$, the strongest cooling rates occris near the cloud top 

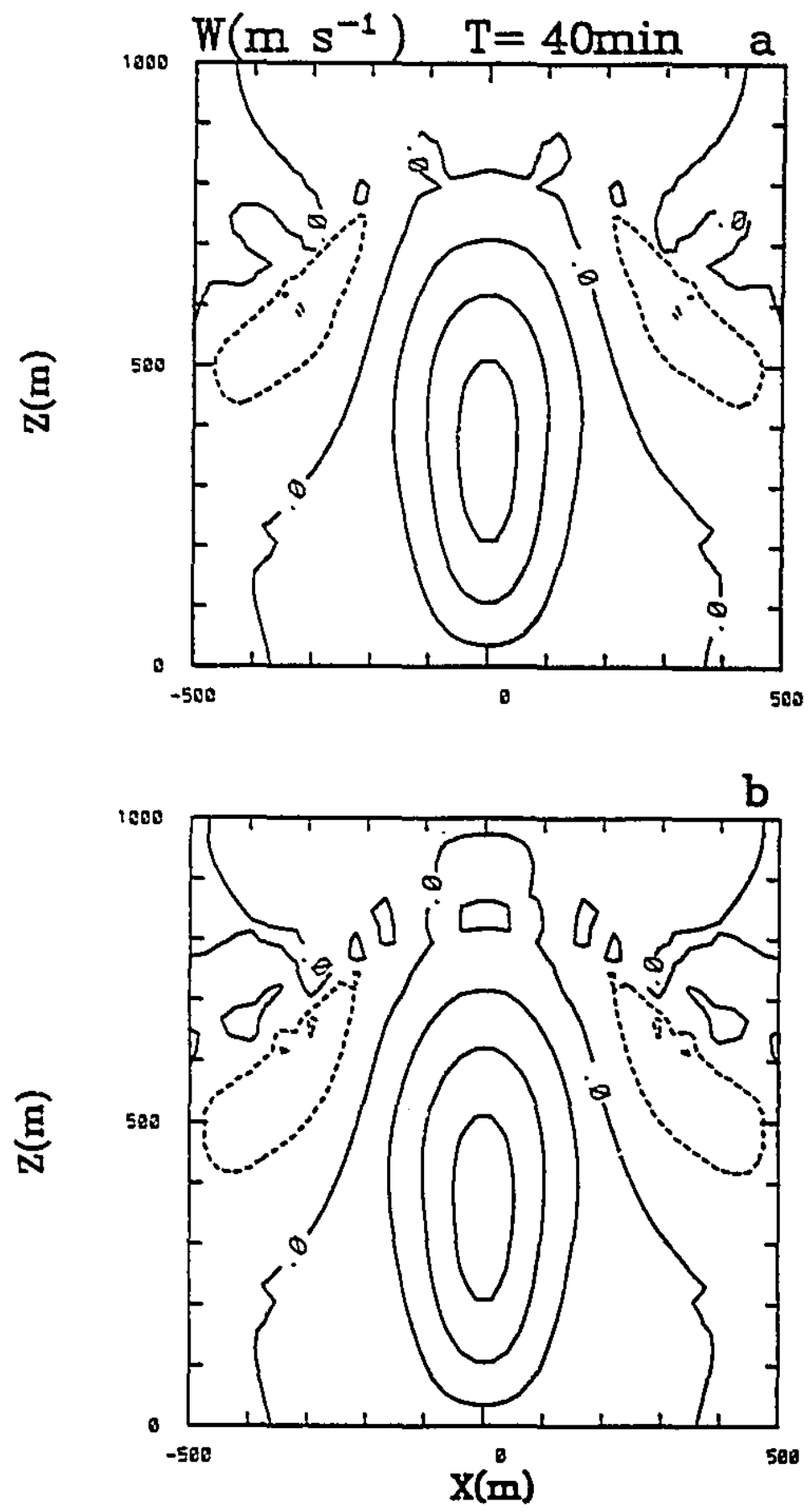

Figure 3.11: Vertical section of vertical velocity at $40 \mathrm{~min}$. Solid contours, upward motion. Dashed contours, downward motion. Contour interval is $0.5 \mathrm{~m} \mathrm{~s}^{-1}$. a) CONTROL run. b) LW run. 


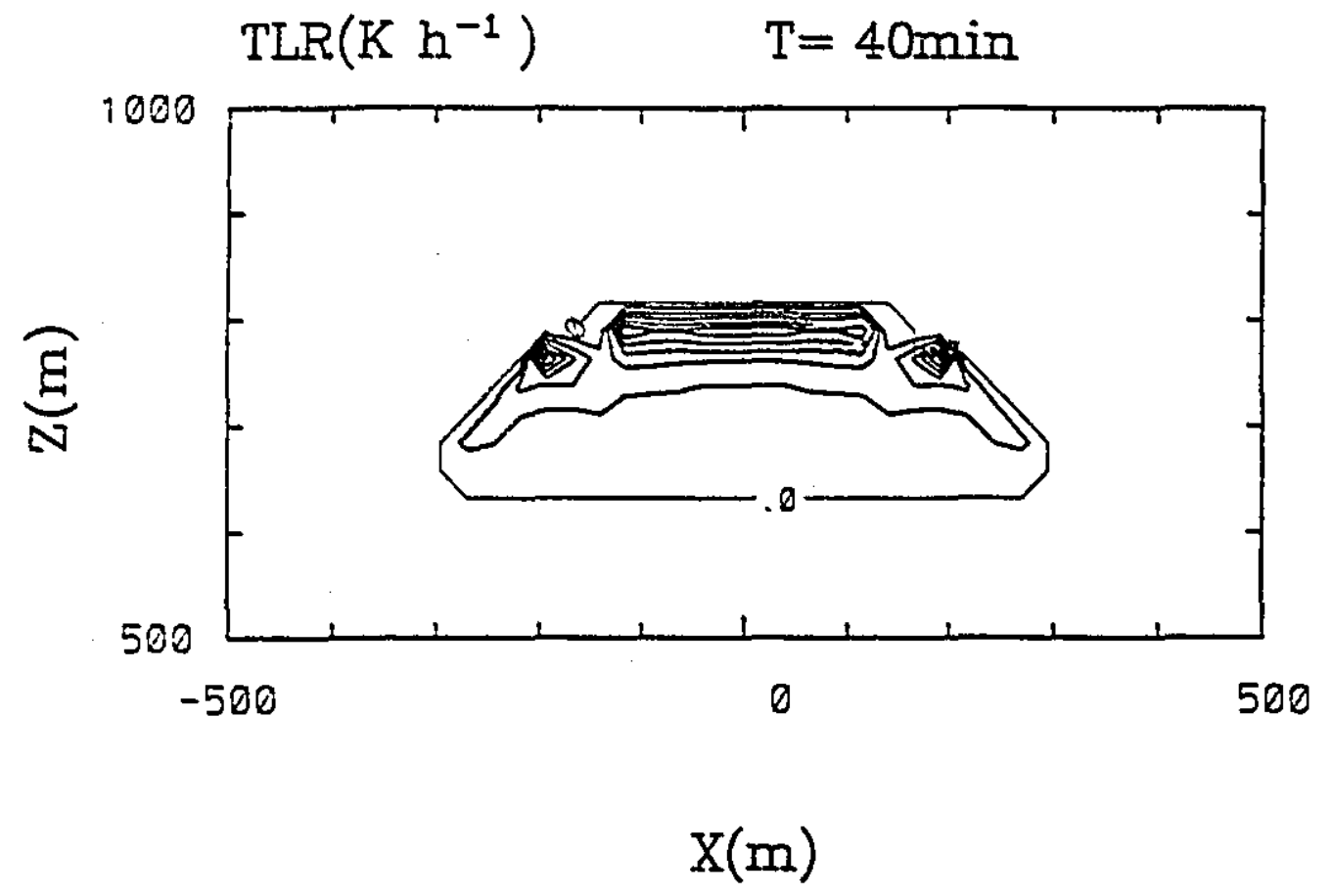

Figure 3.12: Vertical section of radiative cooling rates at $40 \mathrm{~min}$. Contour interval is $1 \mathrm{~K} \mathrm{~h}^{-1}$. The cloud boundary is shiwn in thin solid curve. 


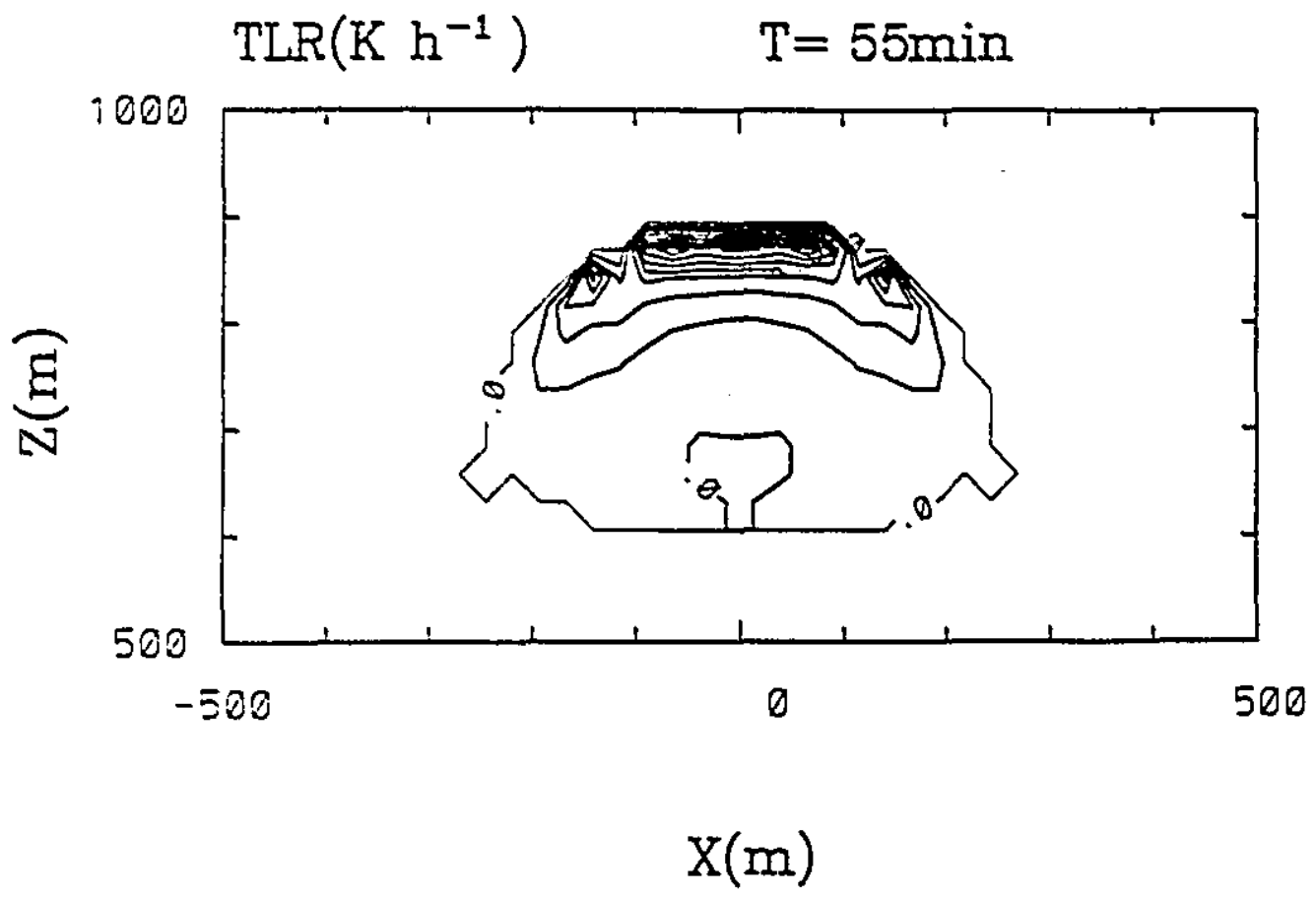

Figure 3.13: Same as Figure 3.12 but at $55 \mathrm{~min}$. 
and the upper sides of the cloud. A small region with weak heating rate (less than $1 \mathrm{~K} \mathrm{~h}^{-1}$ ) is located near the cloud's central lower portion. This heating rate is the result of longwave radiative transfer because a small positive temperature difference exists between the ground :urface and the air at the cluud base. As is shown in Figs. 3.9-3.10, for the period from $55 \mathrm{~min}$ $1060 \mathrm{~min}$, the cloud water content in the LW run exceeds that of the CONTROL run even in the interior of the cloud. Therefore the increase in total cloud water content during this period (Fig. 3.7) must arise from processes other than the direct effect of radiation-condensation feedback which acts primarily near the cloud top and the upper cloud side regions.

A clue to what happens can be obtained from the plots of temperature perturbation (Fig. 3.14) and vertical velocity (Fig. 3.15). When compared to the CONTROL, the temperature perturbation is less negative in the interior of the LW cloud but more negative at its sides. In other words, the LW cloud is warmer than the CONTROL in the interior but colder near the cloud edges. Fig. 3.15 shows that both the value and the area of the downdraft increase in the LW run. The maximum downdraft is $0.89 \mathrm{~ms}^{-1}$ in the CONTROL cloud but reaches $1.28 \mathrm{~ms}^{-1}$ in the LW run. The ratio of the areas of the downdraft with magnitude larger than $0.5 \mathrm{~m} \mathrm{~s}^{-1}$ is 1.7.

The above observation indicates that longwave radiative cooling near the cloud top and the upper cloud edges induces a dynamic response in addition to the radiation-condensation feedback process. The radiatively cooled air near the upper cloud sides subsides at the cloud edges and is continuously cooled by radiation and evaporation during descent. The air parcels at the lower cloud edges have experienced the longest duration of cooling and exhibited the largest negative temperature perturbation. 

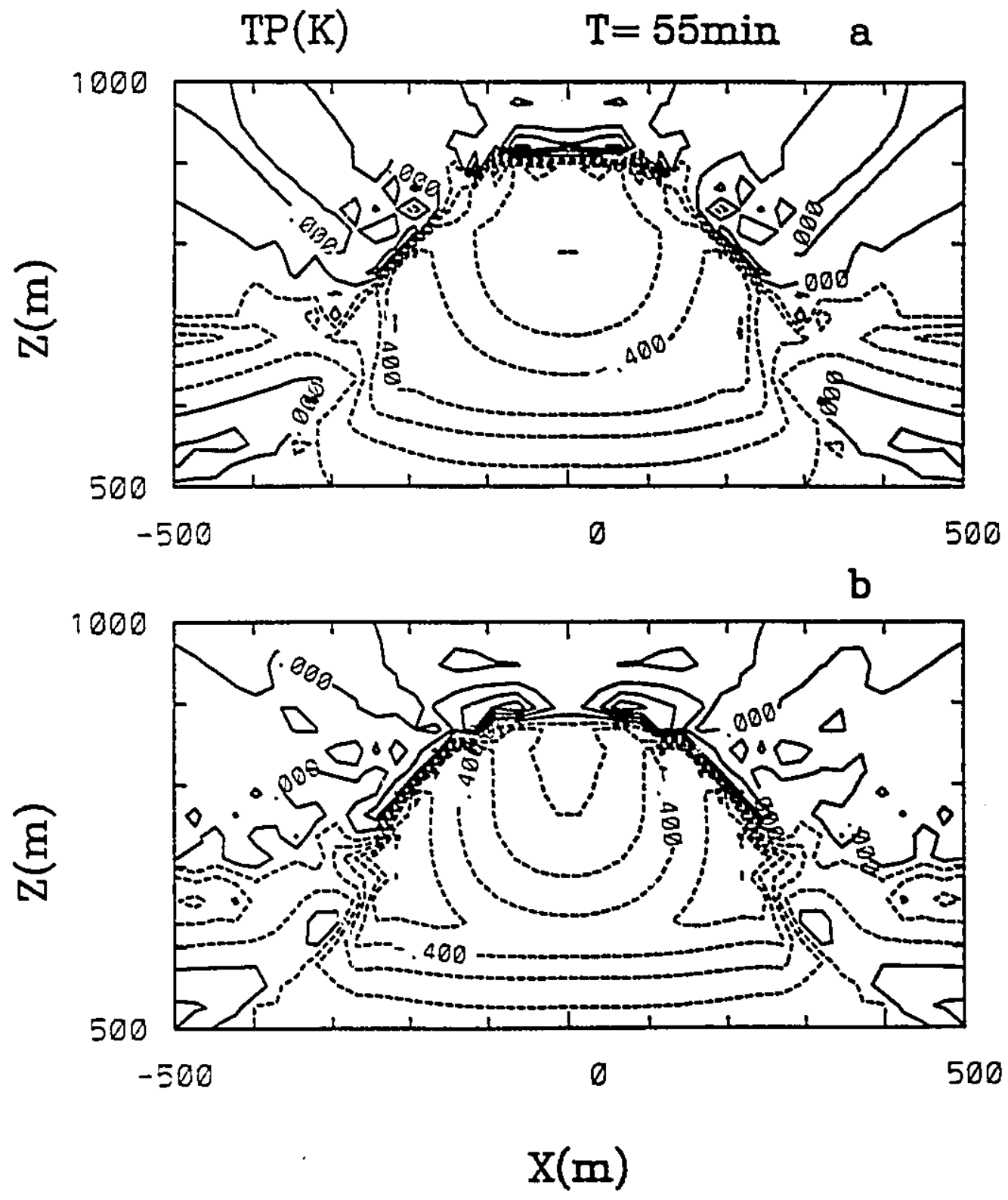

Figure 3.14: Vertical section of temperature perturbation at $55 \mathrm{~min}$. Contour interval is $0.1 \mathrm{~K}$ a) CONTROL run. b) LW run. 

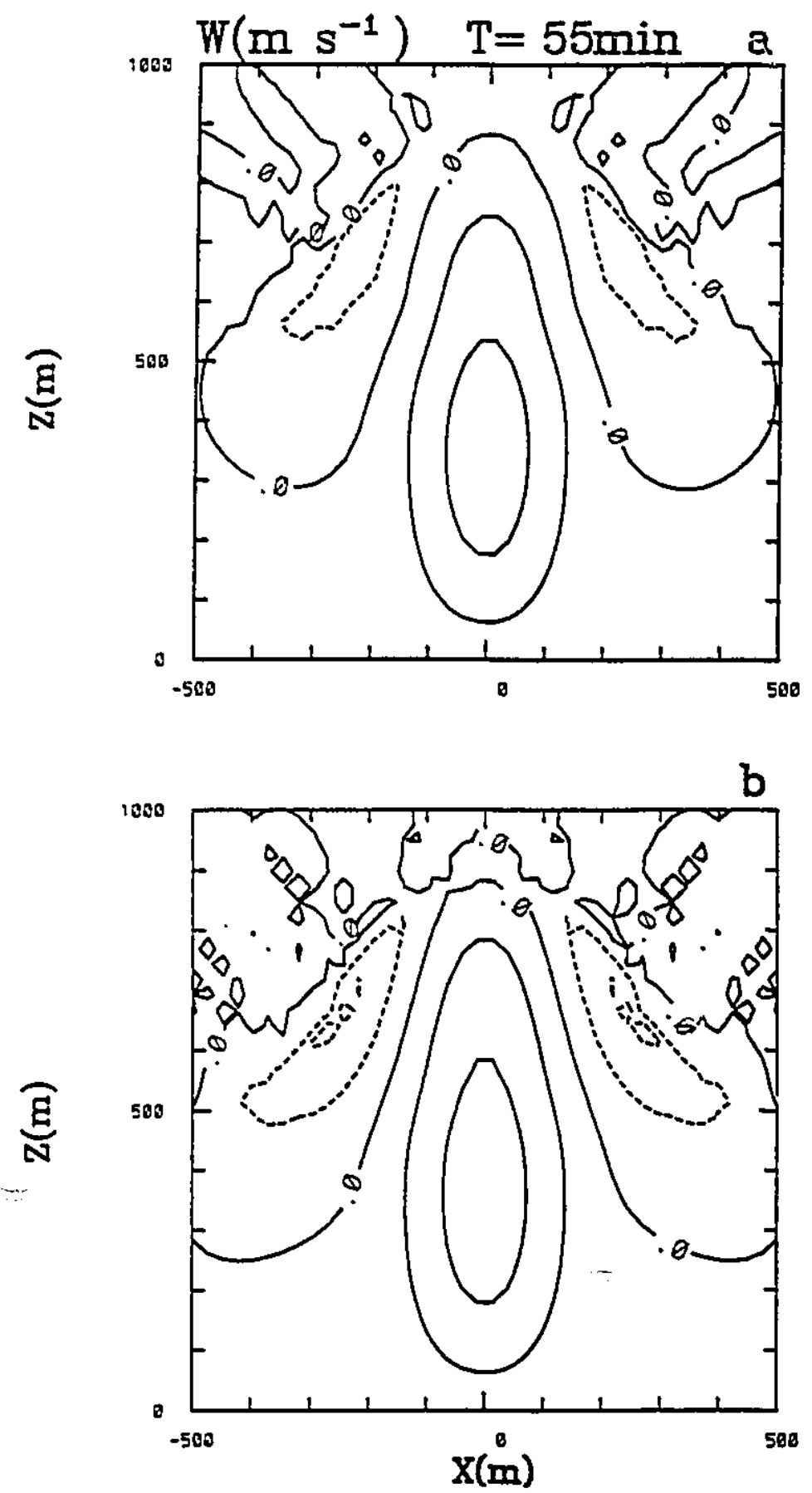

Figure 3.15: Same as Figure 3.11 but at 55 min. 
The enhanced cloud side downdraft further induces additional low-level convergence, and consequently, enhanced upward mintion near the center of the cloud. Fig. 3.16 shows the difference in horizontal velocity between the two runs. A positive (negative) value represents in increase (decrease) of horizontal motion toward the positive $\mathrm{x}$ direction. It is evident that there is a region of enhanced convergence between 250 and $600 \mathrm{~m}$ and eihanced divergence aloft. Fig. 3.17 gives a comparison of the vertical velocity at the center of the clouds. A stronger updraft is indicated between $350 \mathrm{~m}$ and $900 \mathrm{~m}$ in the LW run. The relative increases at the cloud batse $(625 \mathrm{~m})$ and at the mid-pnint of the cloud $(750 \mathrm{~m})$ are 15 and $30 \%$ respectively.

Longwave radiative cooling at the cloud edges therefore initiates a secondary circulation. The increased low-level convergence and enhanced updraft caused additional condensation and latent heat release in the cloud core. A higher cloud water content and a smaller negative temperature perturbation result near the center of the cloud.

We remark in passing that the dynamic response of longwave radiative cooling can be damped for a small warm tropical cumulus such as the one studied here. The reason is that radiative cooling lowers the saturation vapour pressure and enhanced condensation takes place. The latent heat release partially offsets the pure effect of radiative cooling and the net effect on cloud temperature decreases. Heymsfield and Miloshevich (1991) calculated the ratij of the net radiative cooling rate to the pure radiative cooling rate experienced by a saturated parcel as a function of temperature from $-80^{\circ} \mathrm{C}$ to $20^{\circ} \mathrm{C}$. He found that this ratio varies from 0.33 at a temperature of $20^{\circ} \mathrm{C}$ to about 0.9 at $-40^{\circ} \mathrm{C}$. The net raciative cooling is therefore larger for clouds at colder temperatures. 


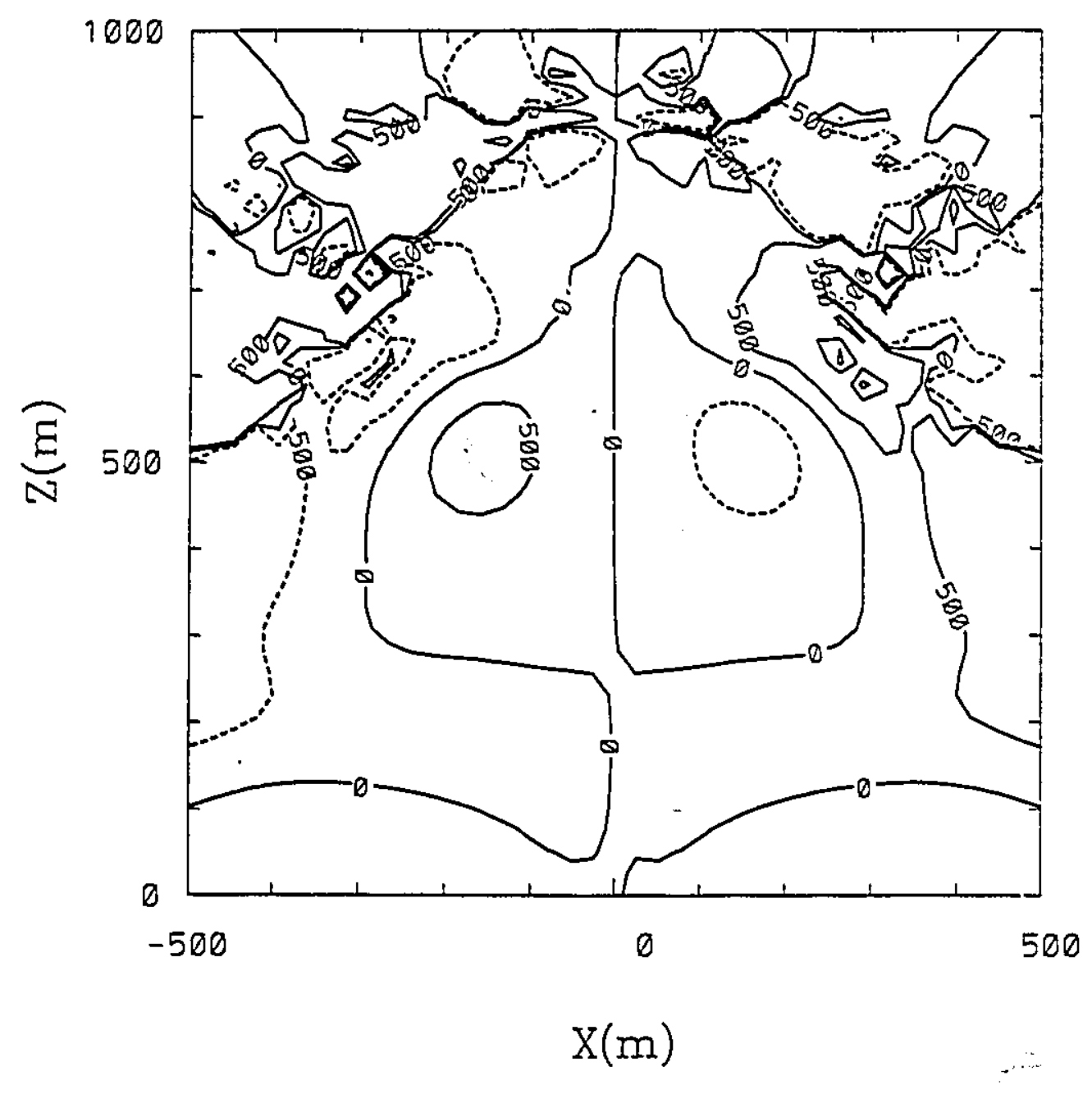

Figure 3.16: Vertical section of the difference of horizontal velocity between the LW and CONTROL runs at $55 \mathrm{~min}$. Contour lines are $-5000,-500,0,500,5000 \times 10^{-4} \mathrm{~m} \mathrm{~s}^{-1}$. 


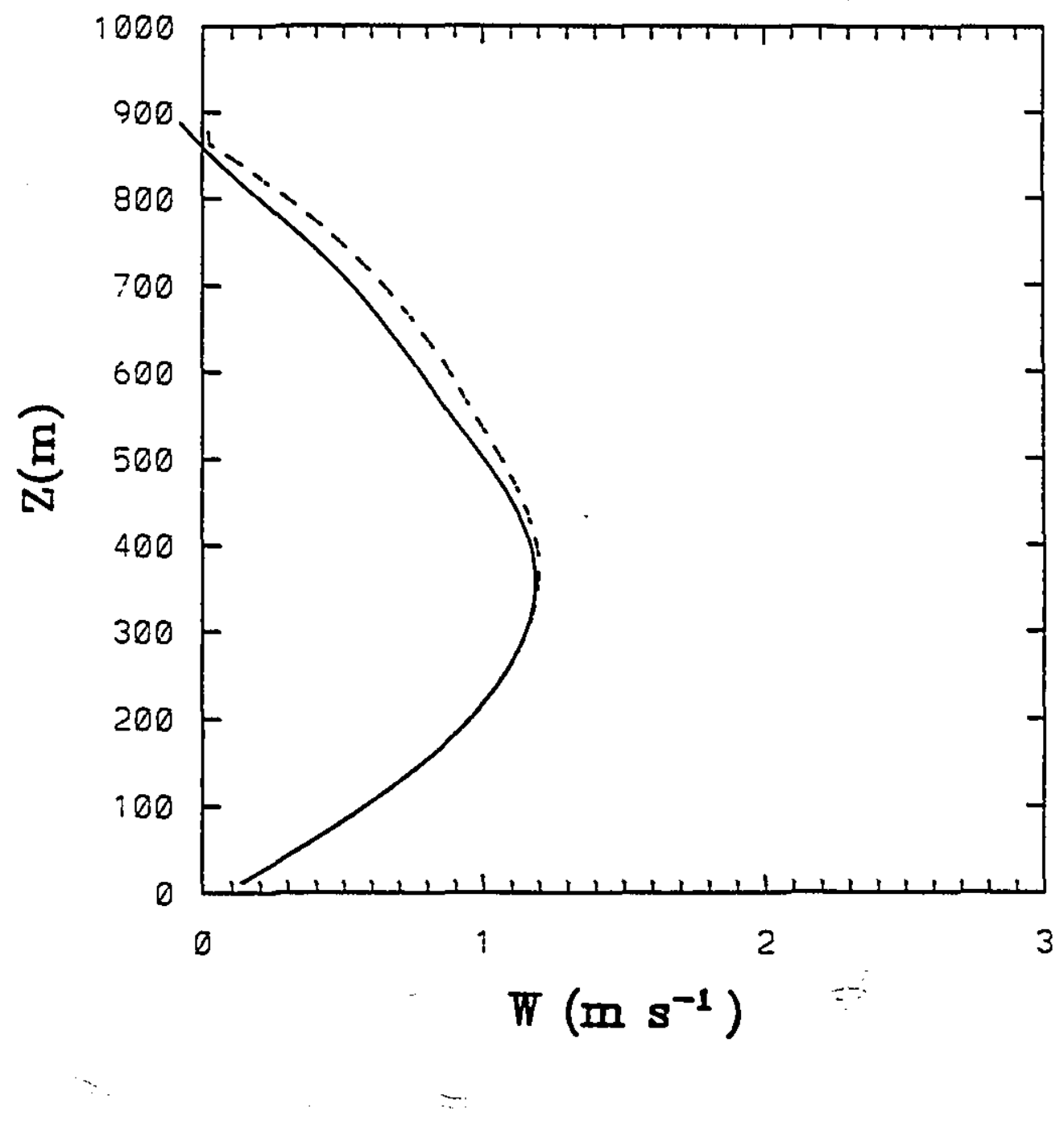

Figure 3.17: Vertical velocity at the 1st grid near the center of the domain at $55 \mathrm{~min}$. Solid curve, CONTRGL run. Dashed curve, LW run. 


\subsubsection{Rapid decay of cloud induced by longwave radiation}

Fig. 3.7 shows that the LW cloud begins its decay at $56 \mathrm{~min}$, five minutes earlier than the CONTROL. Fig. 3.9 indicates that with the inclusion of longwave radiative cooling, the total cloud water content is significantly larger prior to $56 \mathrm{~min}$. To examine the process for the faster decay, we plotted the time series of cloud water content, vertical velocity, and temperature perturbation at a central point $200 \mathrm{~m}$ above the cloud base $(X=12.5 \mathrm{~m}, \mathrm{Z}=800 \mathrm{~m})$. Note that at 56 min, the LW cloud has slightly smaller negative temperature perturbation (Fig. 3.18c) but larger cloud water content (Fig. 3.18a). Its vertical updraft is also stronger at $56 \mathrm{~min}$ and begins to weaken after 57 min.

Because the negative temperature perturbation is slightly less negative at $56 \mathrm{~min}$, the rapid decay of the LW cloud must be iritiated by the larger drag force exerted by the greater cloud water content. Once the decay process sets in, further erosion of the cloud takes place as cooling from evaporation and longwaive radiation quickly generates negative temperature perturbation and weakens further the updraft (Fig. 3.18). Our result is consistent with the effect of evaporative cooling in the decay of a cumi?us cloud simulated in Yau (1980).

\subsection{Conclusions and discussions}

In this chapter, we examined the effects of longwave radiation on cloud microphysics and dynamics in a calm environment. We first showed that the simulated clouds exhibited features, particularly cloud water content and thickness, in agreement with the observations made in small tropical cumuli. It was also shown that a resolution of $25 \mathrm{~m}$ is sufficient for our study of the effect of longwave radiative cooling. 


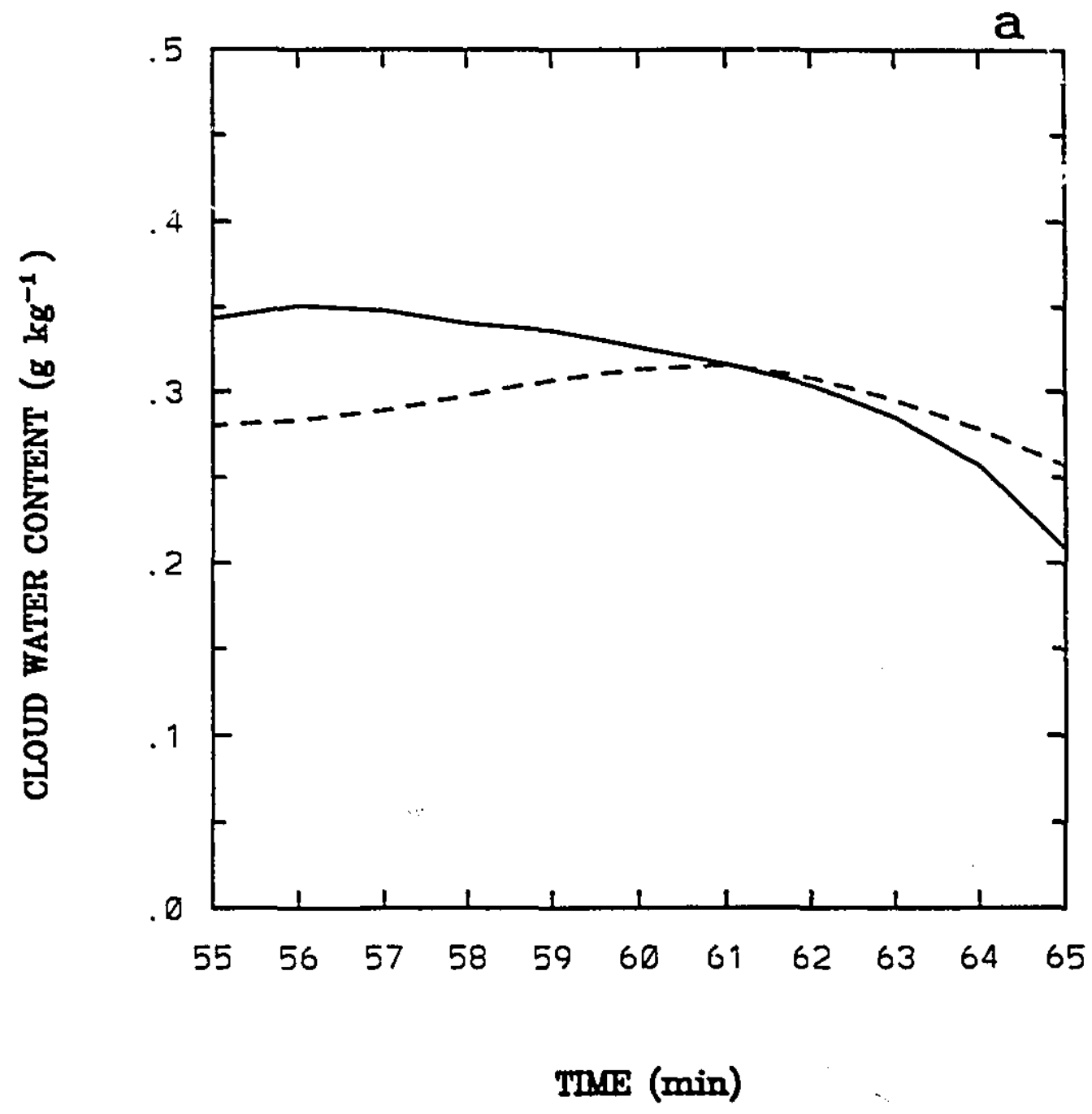

Figure 3.18a: Evolution of cloud water content. Solid curve, CONTROL run. Dashed curve, LW run. 


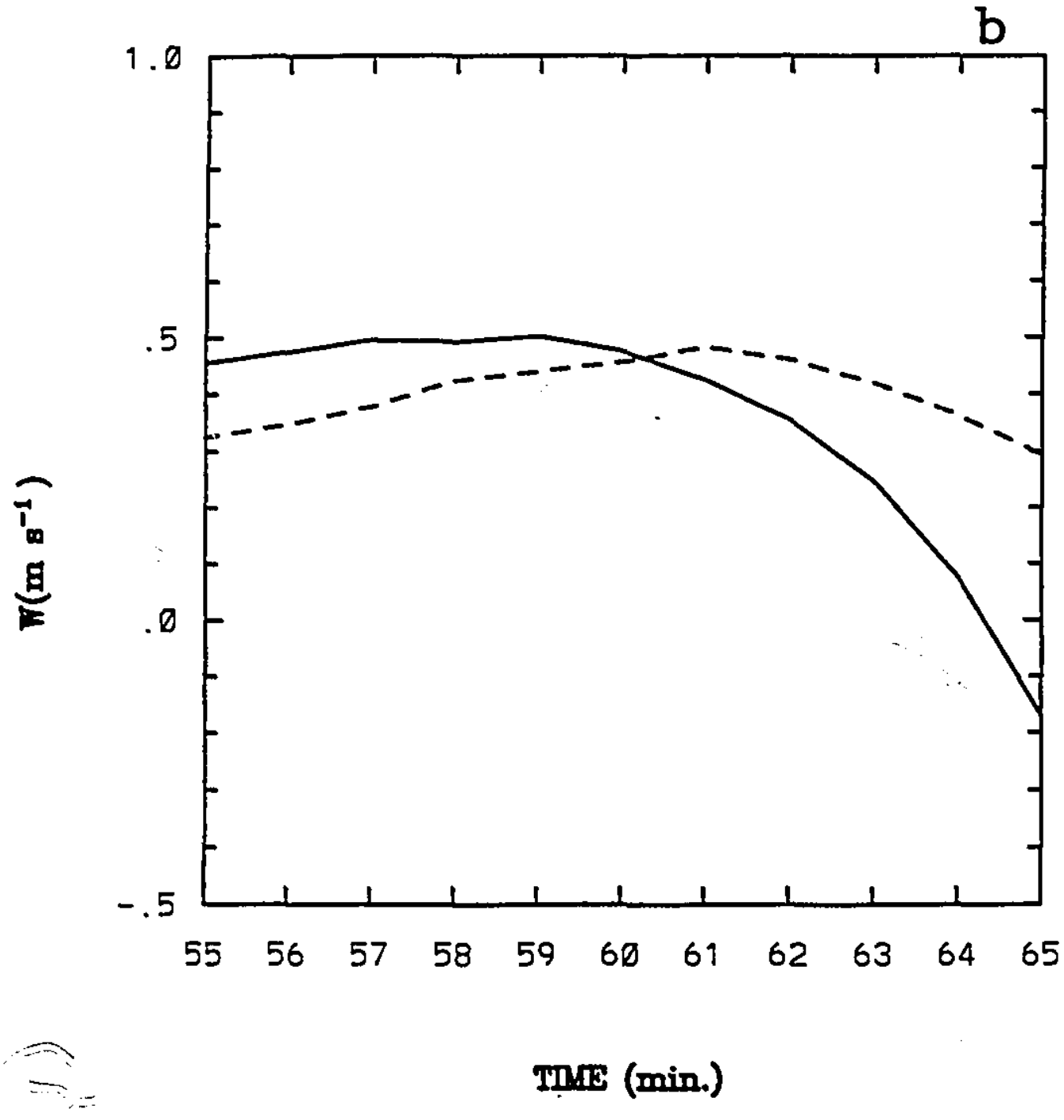

Figure 3.18b: Same as Fig.3.18a but for vertical velocity. 


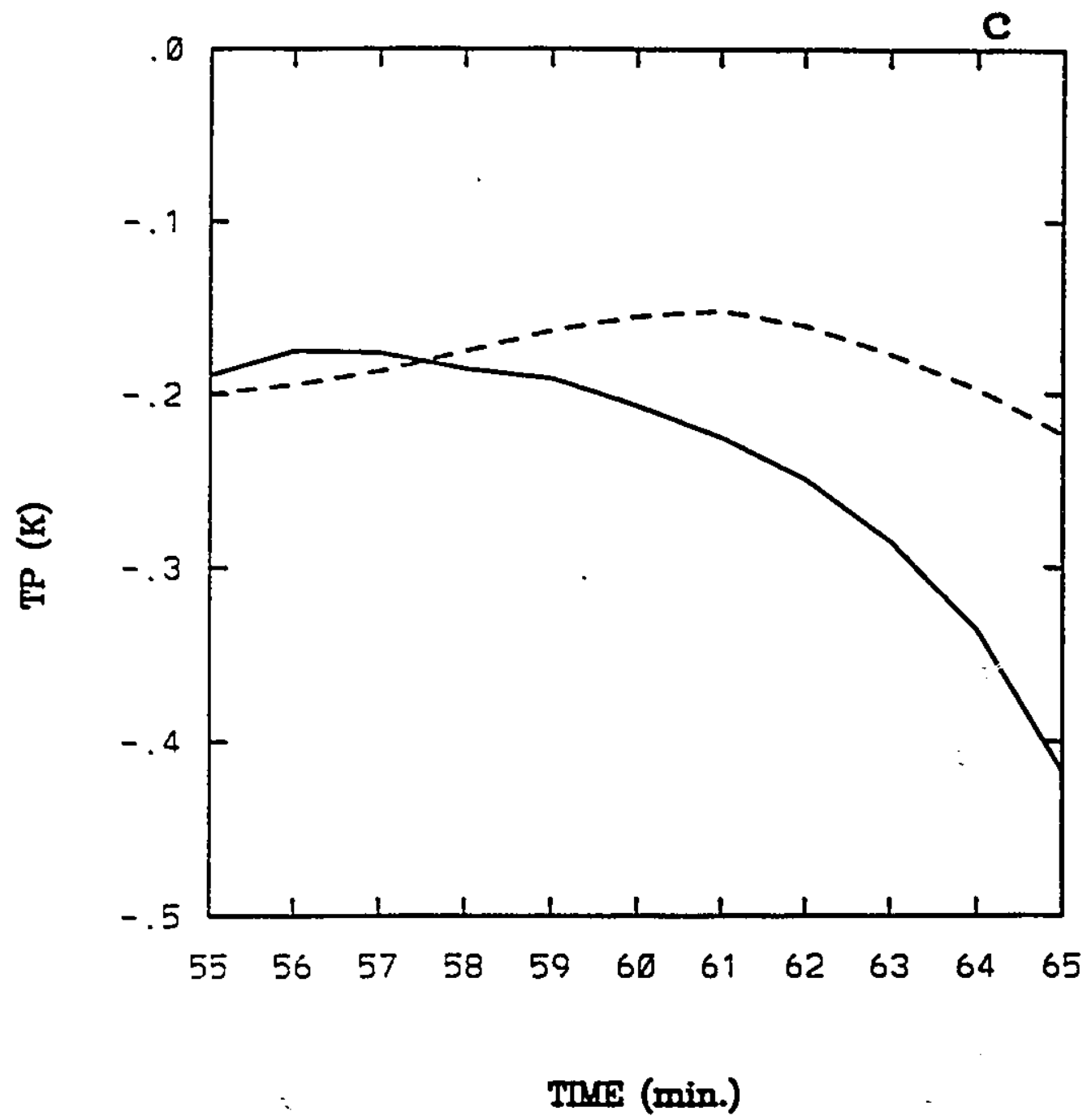

Figure 3.18c: Same as Fig.3.18a but for temperature perturbation. 
We demonstrated that longwave cooling substantially enhances the maximum cloud water content. The maximum increase reaches $96 \%$. The total cloud water content was also increased somewhat (maximum 20\%). In the initial stage of the development of the simulated cloud, the augmentation of cloud water content near the cloud top and its sides is traced mainly to the direct effect of longwave radiative cooling on cloud microphysics. In short, radiative cooling reduces the local temperature and hence the saturation water vapour pressure. The additional condensation which follows further enhances the longwave radiative cooling rate. A positive feedback process is therefore in operation.

In the mature stage of cloud, the increase of total cloud water content comes from a combination of the effects of radiation on microphysics and dynamics. The cooling from radiation and evaporation produce additional downward motion at the sides of the cloud. The enhanced low-level convergence invigorates the updraft promoting further cloud development. .

In the decaying stage, the negative buoyancy produced by cloud top radiative cooling and a higher liquid water load speeds up the decay process in the LW run.

Our study shows that longwave radiative cooling substantially enhances the maximum cloud water content. The direct effect of radiation on microphysics therefore plays a very important role in the development of a small tropical cumulus cloud. It appears that the sole effect of radiative instability, previously noted by Veyre et al. (1980), is not a sufficient explanation on the effect of longwave cooling on cloud circulations.

Using a steady-state kinematic model, Churchill and Houze (1991) showed that solar and infrared radiation did not substantially change the hydrometeor fields in the stratiform region of a tropical cloud cluster. However, recent numerical studies (Chen and Cotton, 1988; Dudhia, 
1989; Sui et al., 1991; Tao et al., 1991; 1993) clearly indicated that the circulation in the stratiform region, as well as the amount of total surface precipitation, can be enhanced by longwave radiative transfer processes. The reason of the discrepancy can be explaiiled, at least partly, by the fact that in the study of Churchill and Houze (1991), radiative cooling is limited to a shallow layer near the top of the cloud cluster where the temperature and water vapour mixing ratio are low. The direct effect of radiative cooling on condensation is therefore quite small. The enhancement of precipitation may come from the effect of radiation on dynamics. The use of a steady state kinematic model precludes an investigation of such a mechanism. 


\section{Chapter 4}

\section{The effect of wind shear}

\subsection{Introduction}

In the last chapter, the effect of longwave radiation on the development of a small cumulus in a calm environment was investigated. However, it is well-known that vertica wind shear is frequently present and can influence the development of clouds. Therefore, it becomes important to study the interaction of longwave cooling with clouds in the presence of wind shear. To set the stage, we will first review briefly earlier results on the effect of wind shear on small and moderate size cumuli. The interaction involving large and severe convective storms with the environmental wind will not be reviewed, as it falls outside the scope of the present investigation.

Observational (Malkus, 1954; Reuter and Yau, 1987a) and numerical modeling (Asai, 1964: Steiner, 1973; Yau, 1980; and Reuter and Yau, 1987b) results indicated that wind shear 
suppresses the growth of small and moderate size cumuli. These studies suggested that at leatst for non-precipitating clouds developing in a sheared environment, the center of maximum buoyancy is displaced relative to the center of maximum updraft. This contiguration reduces the conversion of potential energy to kinetic energy and slows down the development of the clond.

It is also known that clouds in a sheared environment exhibit asymmetric organization. Strong subsiding motion and colder air are found at the downshear edge of the clouds (Steiner. 1973; Yau, 1980; and Reuter and Yau, 1987a;b). Consistent with this. Telford and Wagner (1980) found ascending motion in the upshear regions of small cumuli while the downshear portions were usually subsiding and decaying.

The mechanism responsible for the asymmetric effects of wind shear on the thermodynamic and dynamic fields were studied by a number of researchers. Heymstield et all. (1978) suggested that the cloud updraft acts as an obstacle to the horizontal wind. Air is forced to flow around the upshear portion of the cloud, thereby protecting that region from entrainment. They further argued that a turbulent wake would be formed in the downshear portion, producing a high level of turbulence and mixing. Using a 2-D slab-symmetric cloud model, Reuter and Yau (1987b) explored the mixing mechanism of South African cumulus congestus clouds in a sheared environment. Their results show that mixing at the cloud top increases the horizontal momentum of the mixed air relative to the momentum of the undiluted cloud core. This extends the period of mixing on the downshear side to yield cooler temperatures and stronger downdrafts.

In this chapter, we will investigate the effects of longwave radiation on a small cumulus in a sheared environment using the same model described in the last chapter. Our analysis will focus on two experiments, designated by the symbols S0.5C and S0.5LW, which represent 
respectively the control run and the longwave radiation run in an environment with a vertical wind shear of $0.5 \mathrm{~m} \mathrm{~s}^{-1} \mathrm{~km}^{-1}$. Before discussing the differences between S0.5C and SO.5LW, we first compare the results between experiment $\mathrm{S} 0.5 \mathrm{C}$ and the CONTROL run in Chapter 3 to benchmark the sole effect of wind shear on a small cumulus cloud.

\subsection{Initial condition}

The atmospheric sounding and initial conditions are the same as in Chapter 3. The ambient wind is of constant direction (parallel to the $\mathrm{x}$-axis) with a shear of $0.5 \mathrm{~m} \mathrm{~s}^{-1} \mathrm{~km}^{-1}$ between the height of cloud base $(600 \mathrm{~m})$ and the top of the domain $(3000 \mathrm{~m})$. Below the cloud base, the wind is set to zero to keep the circulation and the simulated cloud within the simulation domain and to prevent fictitious advection over the lower boundary where surface heating is being applied.

A shear of $0.5 \mathrm{~m} \mathrm{~s}^{-1} \mathrm{~km}^{-1}$ was chosen because preliminary tests with shears of $0.25 \mathrm{~m} \mathrm{~s}^{-1}$ $\mathrm{km}^{-1}$ (experiment $\mathrm{S} 0.25 \mathrm{C}$ ) and $0.75 \mathrm{~m} \mathrm{~s}^{-1} \mathrm{~km}^{-1}$ (experiment $\mathrm{S} 0.75 \mathrm{C}$ ) showed similar behaviour in the simulated clouds. However, for the stronger shear case $\left(0.75 \mathrm{~m} \mathrm{~s}^{-1} \mathrm{~km}^{-1}\right)$, the cloud is strongly stretched in the horizontal direction and its development is quite weak. The thickness of the cloud never reaches the observed depth of $300 \mathrm{~m}$. For the weaker shear case $\left(0.25 \mathrm{~m} \mathrm{~s}^{-1} \mathrm{~km}^{-1}\right)$, the effect of the wind shear is relatively small. The cloud does not indicate important difference from the CONTROL run in Chapter 3.

\subsection{Results}




\subsubsection{The effects of wind shear on cloud development}

With the wind increasing linearly with height, the cloud tilts downshear. Fig. 4.1 displays the cloud structure in experiment S0.5C at the initial stage of the cloud $(40 \mathrm{~min})$. The cloud water content, temperature perturbation and vertical velocity fields show slight asymmetry at this carly time. The maximum downdraft is located at the downshear side. Its value of $1.34 \mathrm{~m} \mathrm{~s}^{-1}$ is $0.21 \mathrm{~m} \mathrm{~s}^{-1}$ or about $20 \%$ larger than that at the upshear flank. In the downshear portion of the cloud, the cloud water content (Fig. 4.1b) is smaller and the temperature perturbation (Fig. 4.1c) more negative.

Twenty minutes later (Fig. 4.2), the fields above the cloud base tilt significantly in the downshear direction. The asymmetry is also more pronounced. The downdraft (Fig. 4.2a) in the upshear portion of the cloud is strongly inclined, while it is more vertical in the downshear side. The cloud core (Fig. $4.2 \mathrm{~b}$ ) at a height of $800 \mathrm{~m}$ has been advected by $100 \mathrm{~m}$ from the center of the domain. The distribution of temperature perturbation (Fig. 4.2c) indicates an alignment of cooler air with the downdraft in the upshear region of the cloud. Therefore, the evaporation of cloud particles would aid in driving the downward motion along the periphery of the cloud as pointed out by Yau (1980). It is also noted that a region of warm air occurs just above the cloud top, as a result of adiabatic warming.

Fig. 4.3 shows a time series of total cloud water content for the CONTROL run in Chapter 3 and for experiment S0.5C. Up to $55 \mathrm{~min}$, the curves are very similar. Significant difference mainly occurs in the later stage when wind shear suppresses cloud development. The maximum magnitudes of the total cloud water content for the CONTROL and S0.5C experiments are 18 and $16 \mathrm{~kg} \mathrm{~m}^{-1}$ respectively (total cloud water content is calculated from the sum of liquid 

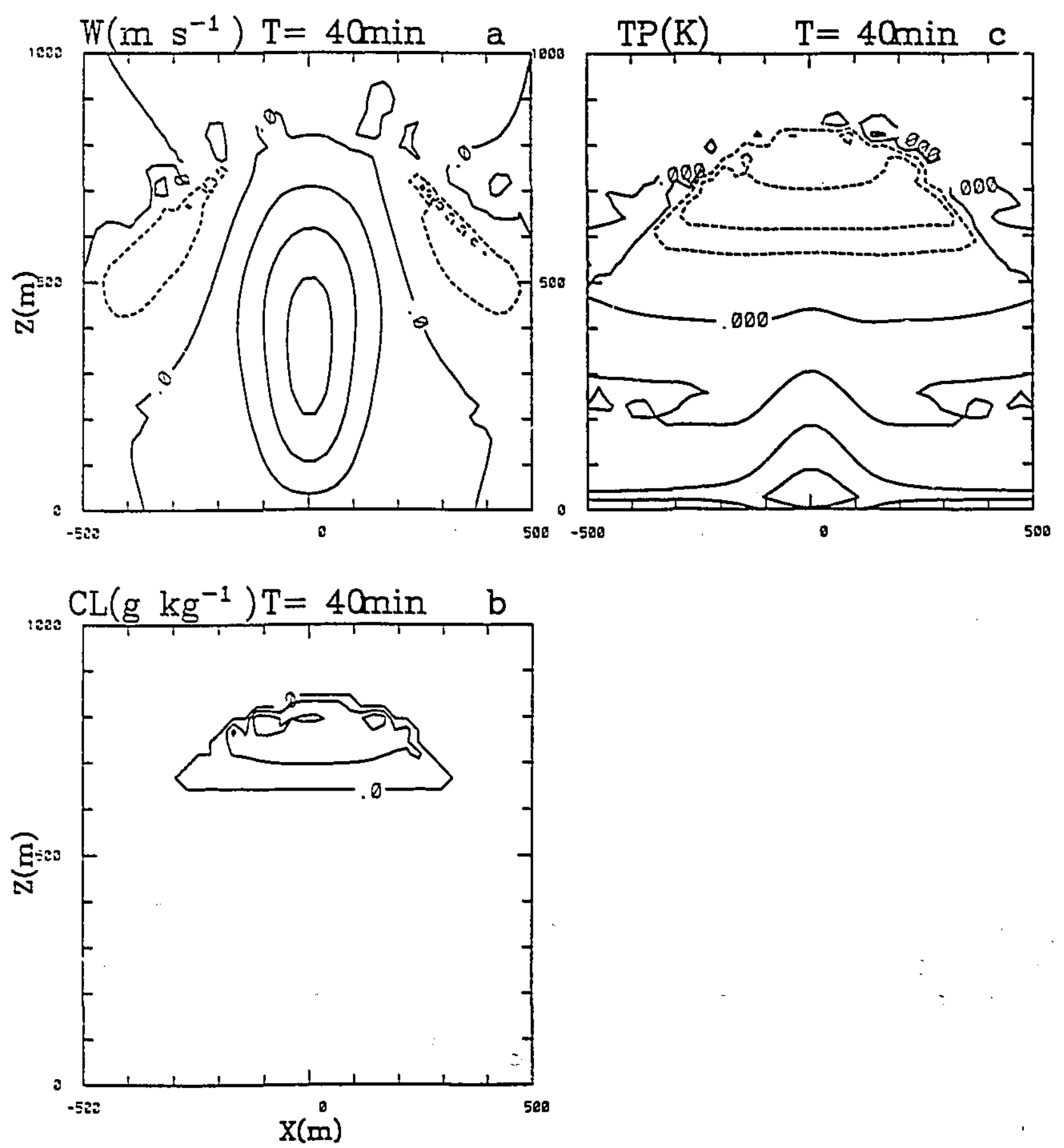

Figure 4.1: Vertical section of a) vertical velocity (W), b) cloud water mixing ratio (CL), and c) temperature perturbation (TP) at $40 \mathrm{~min}$ for experiment S0.5C. The contour iniervals for $W$, $\mathrm{CL}$, and TP are $0.5 \mathrm{~m} \mathrm{~s}^{-1}, 0.1 \mathrm{~g} \mathrm{~kg}^{-1}$, and $0.2 \mathrm{~K}$ respectively. 

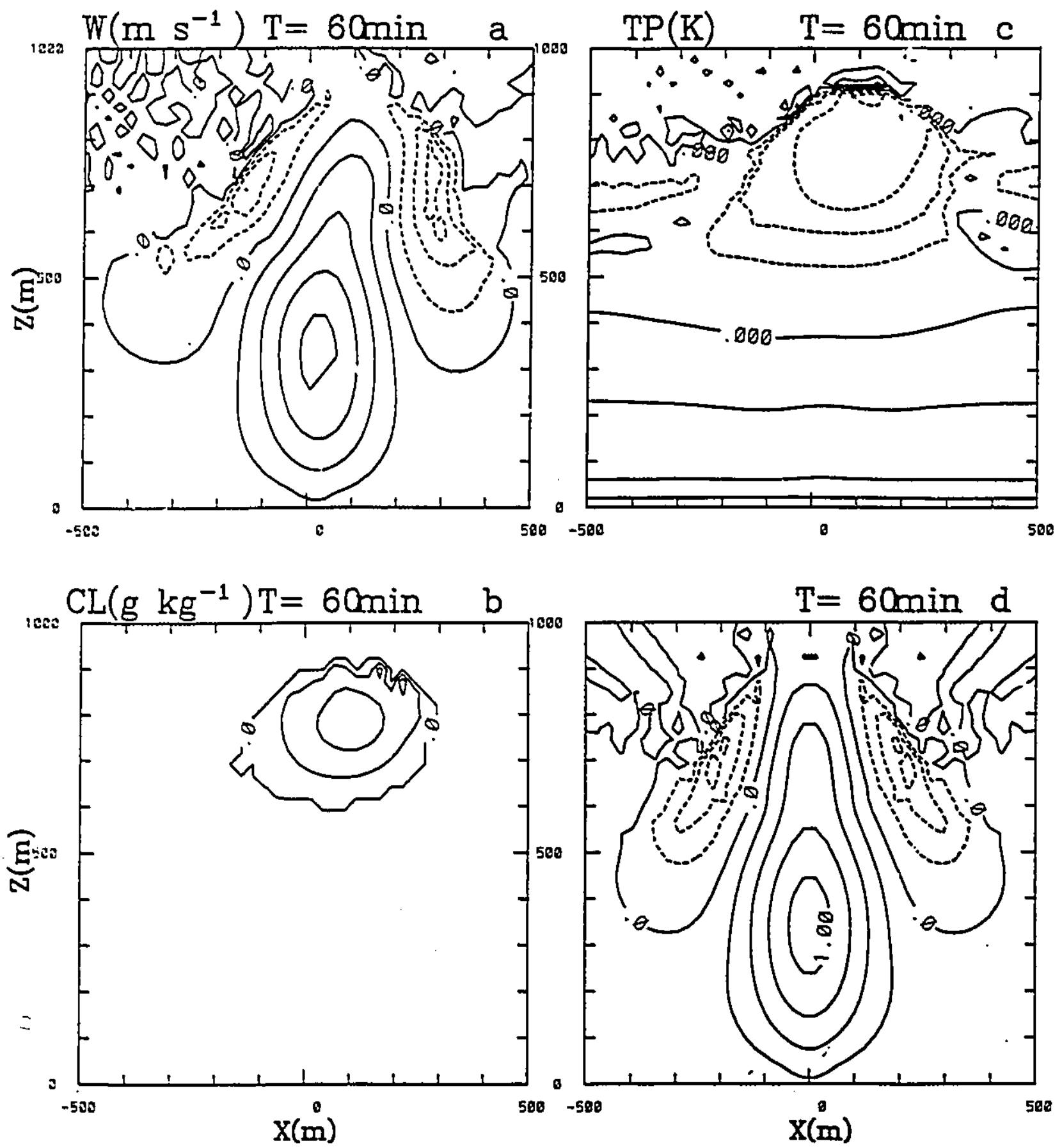

Figure 4.2: Vertical section of a) vertical velocity (W), b) cloud water mixing ratio (CL), and c) temperature perturbation (TP) at $60 \mathrm{~min}$ for experiment S0.5C. d) Vertical section of vertical velocity at $60 \mathrm{~min}$ for CONTROL run. The contour intervals for $\mathrm{W}, \mathrm{CL}$, and TP are $0.25 \mathrm{~m} \mathrm{~s}^{-1}$, $0.1 \mathrm{~g} \mathrm{~kg}^{-1}$, and $0.2 \mathrm{~K}$ respectively. 


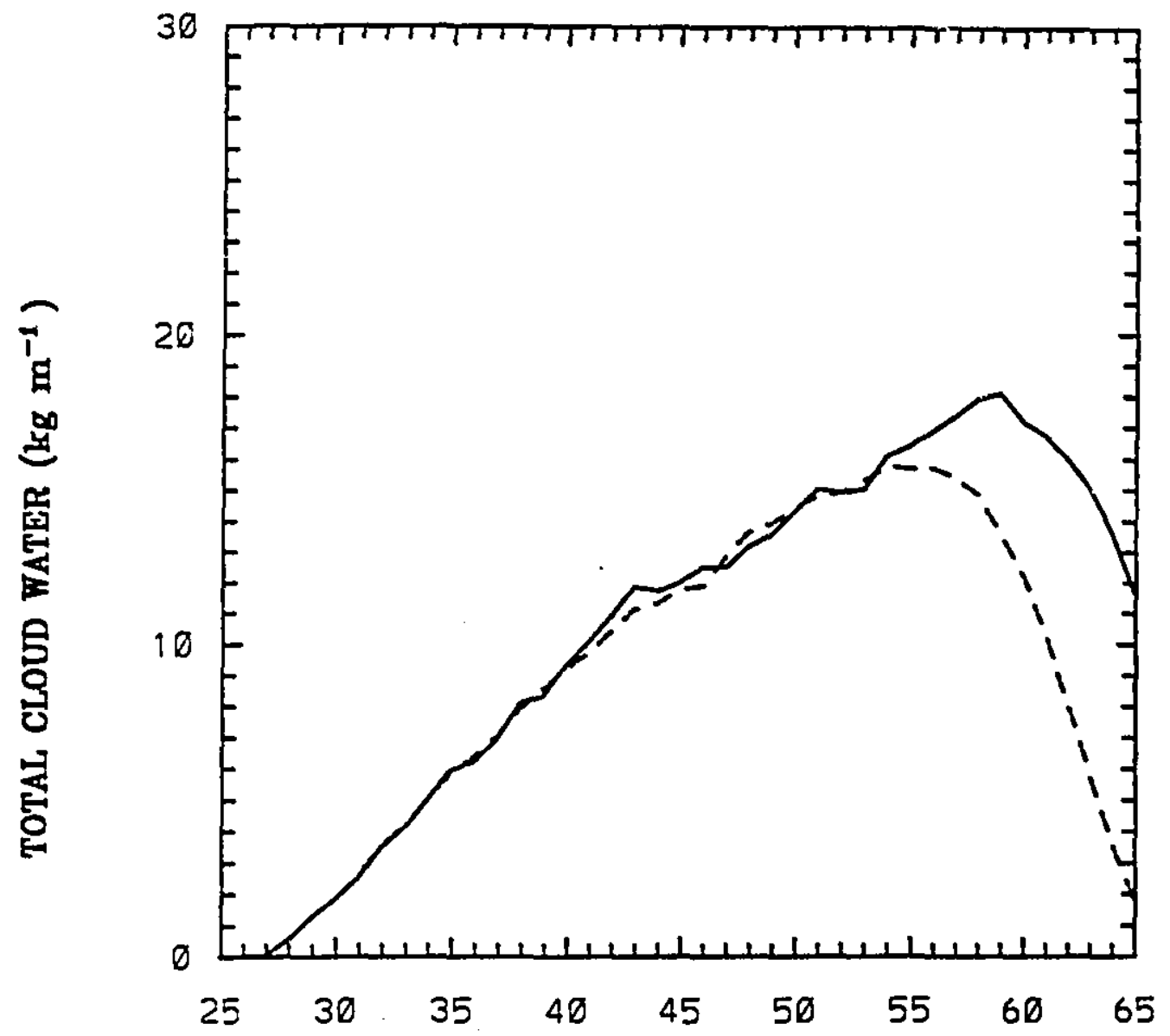

THE (min)

Figure 4.3: Evolution of total cloud water content for the CONTROL (solid) and S0.5C (dashed) runs. 
water content at each grid point for a cloud $1 \mathrm{~m}$ thick in the y direction). The life time of the cloud in shear is shortened by 3-5 minutes. The inhibiting effects of wind siear are also illustrated from a comparison of the fields of vertical velocity (W) at $60 \mathrm{~min}$ (Figs. 4.2a, d). The maximum updraft at a height of $800 \mathrm{~m}$ is $0.15 \mathrm{~m} \mathrm{~s}^{-1}$ in experiment $\mathrm{S} 0.5 \mathrm{C}$ whereas it is $0.45 \mathrm{~m}$ $s^{-1}$ in the CONTROL run.

\subsubsection{Including the effects of longwave radiation}

The temporal evolution of the maximum cloud water content and total cloud water content for experiments $\mathrm{S} 0.5 \mathrm{C}$ and S0.5LW are shown in Fig. 4.4 and Fig. 4.5, respectively. It can be seen that the effects of radiation on cloud water content is qualitatively similar to the no shear case (i.e. the maximum cloud water contents are, in general, larger when radiative effects are present. Longwave radiation also accelerates the decay of the cloud). The maximum increase of total cloud water content is $23 \%$ at $46 \mathrm{~min}$. However, at the mature stage of cloud development, the increase of total cloud water content is much smaller than the no shear case and amounts to less than $10 \%$ between 47 and $60 \mathrm{~min}$.

Figs.4.6-4.8 depict the vertical cross sections of the cloud water content for the S0.5C and S0.5LW runs at $40 \mathrm{~min}, 55 \mathrm{~min}$, and $60 \mathrm{~min}$, respectively. At the initial stage (40 min), the effect of radiation on cloud water content is quite close to the no shear case (i.e. the increase of cloud water content is mainly concentrated near the cloud top and its sides). For the period from 55 min to $60 \mathrm{~min}$, the cloud water content in the S0.5LW-run exceeds that of the $\mathrm{S} 0.5 \mathrm{C}$ run even in the interior of the cloud. However, the cloud displays strong asymmetry and tilts toward the downshear side. This asymmetry affects quantitatively the effect of radiation. As was shown in 


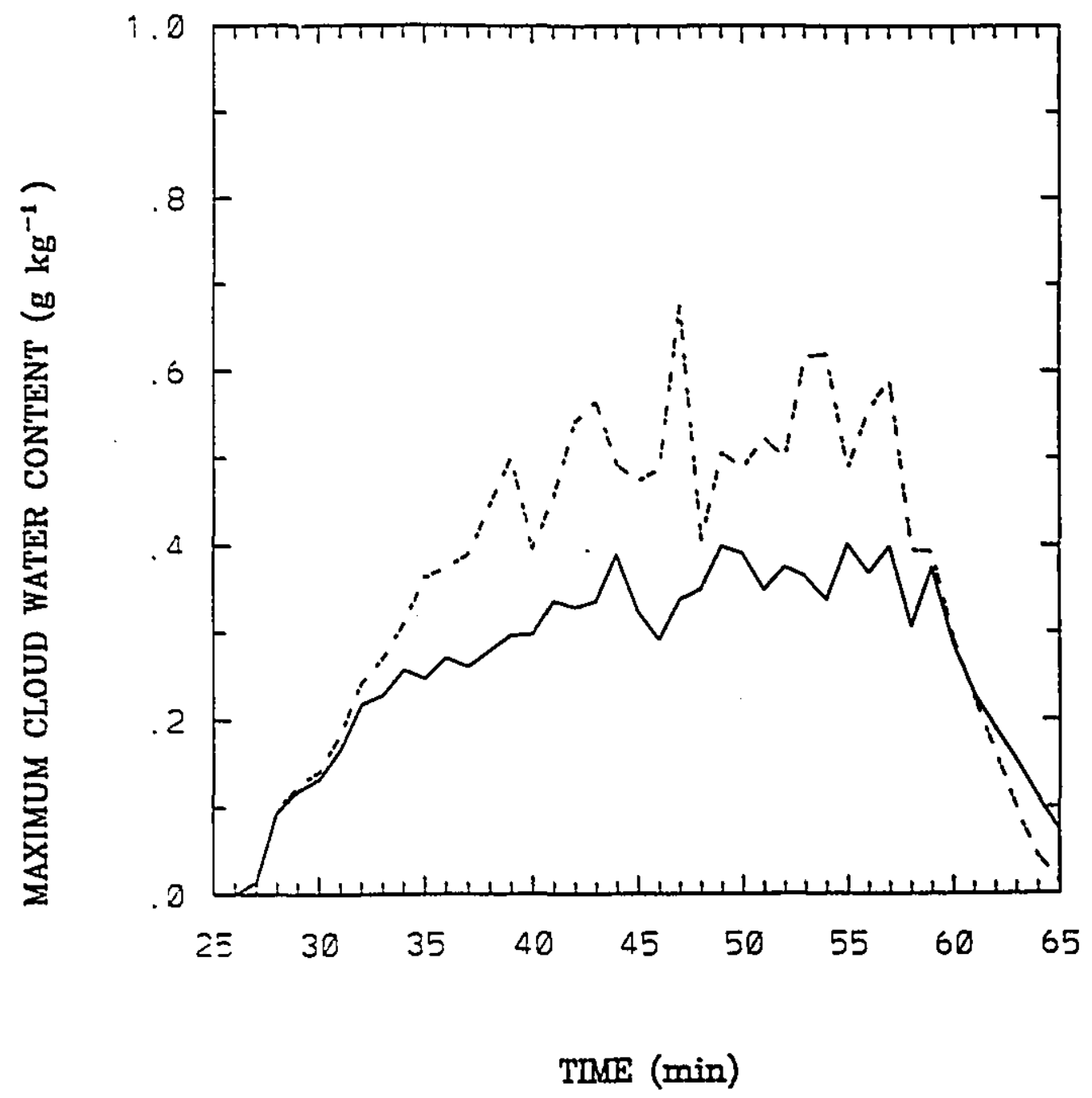

Figure 4.4: Evolution of maximum cloud water content for the S0.5C (solid) and S0.5LW (dashed) runs. 


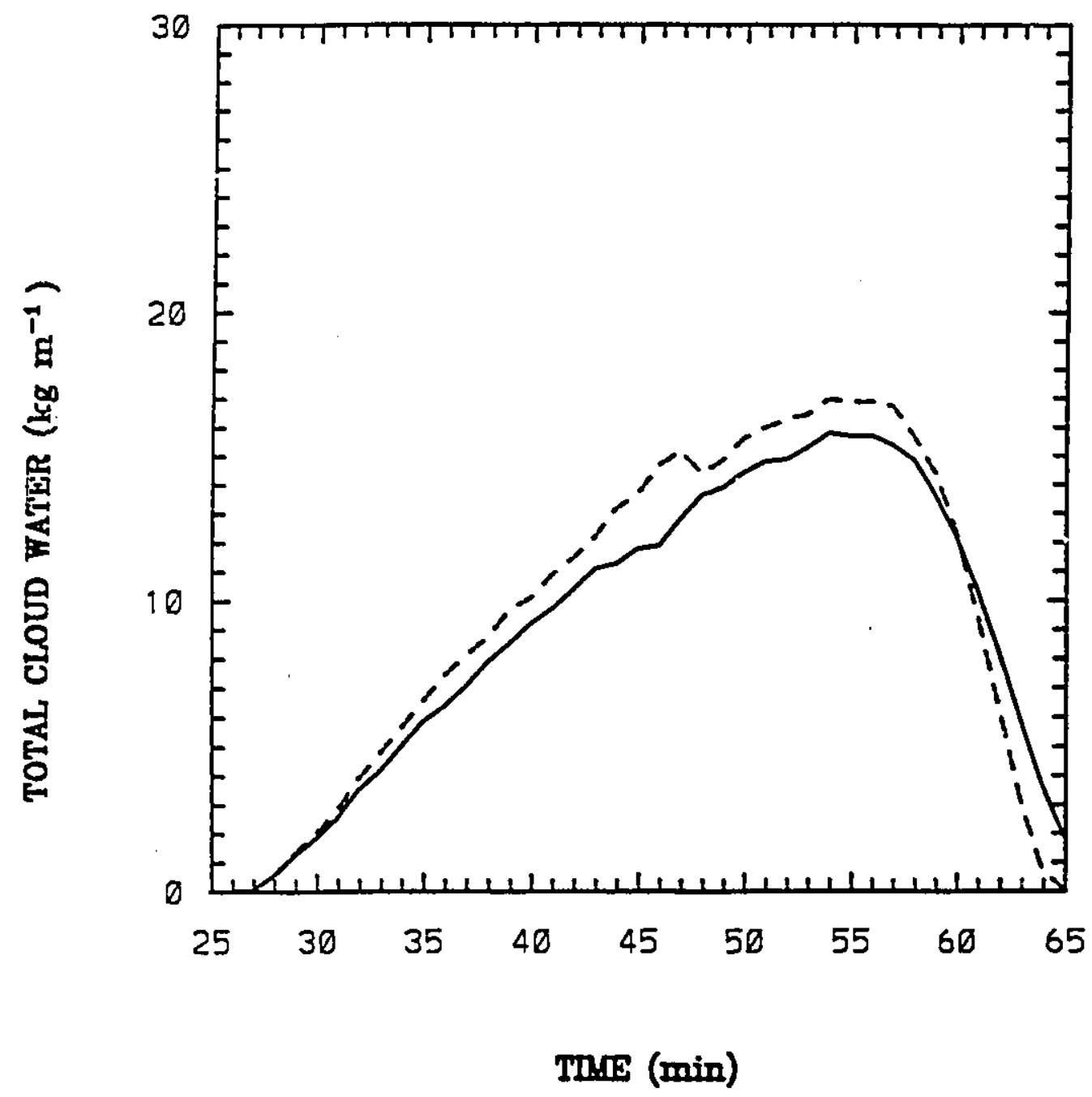

Figure 4.5: Evolution of total cloud water content for the S0.5C (solid) and S0.5LW (dashed) runs. 

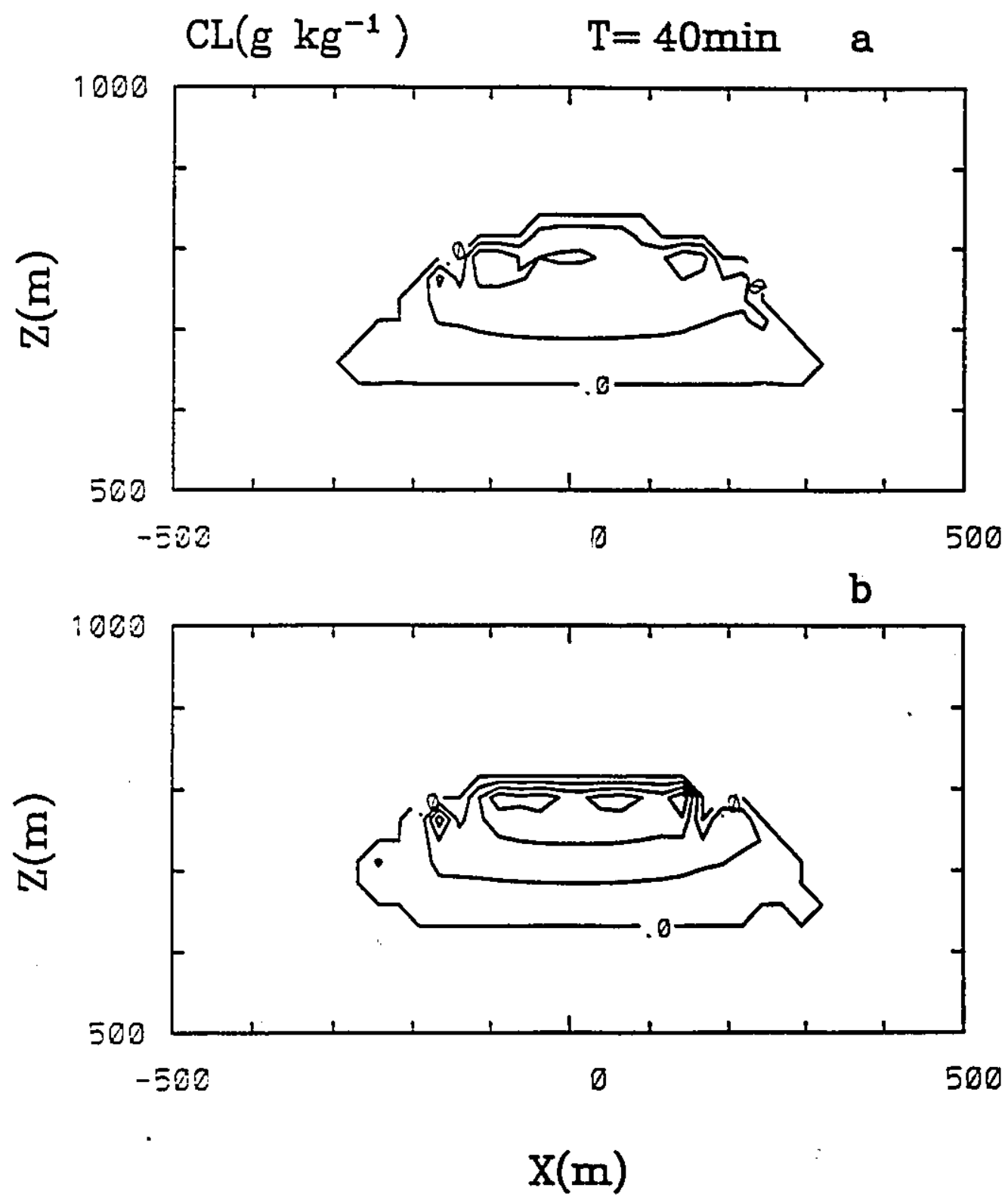

Figure 4.6: Vertical section of cloud water content at $40 \mathrm{~min}$ for a) S0.5C run, and b) S0.5LW run. Contour interval is $0.1 \mathrm{~g} \mathrm{~kg}^{-1}$. 

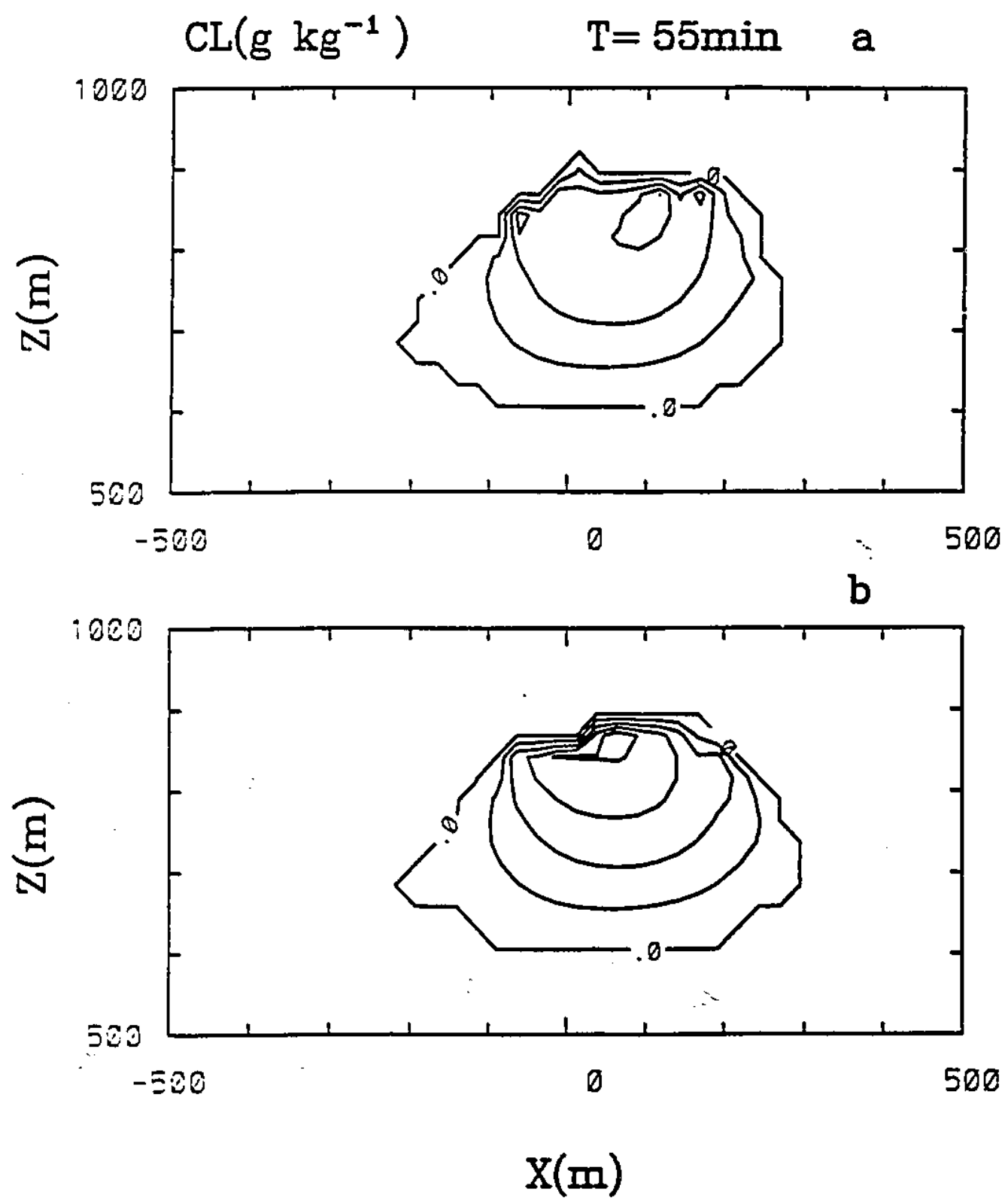

Figure 4.7: Same as Figure 4.6 but at $55 \mathrm{~min}$. 

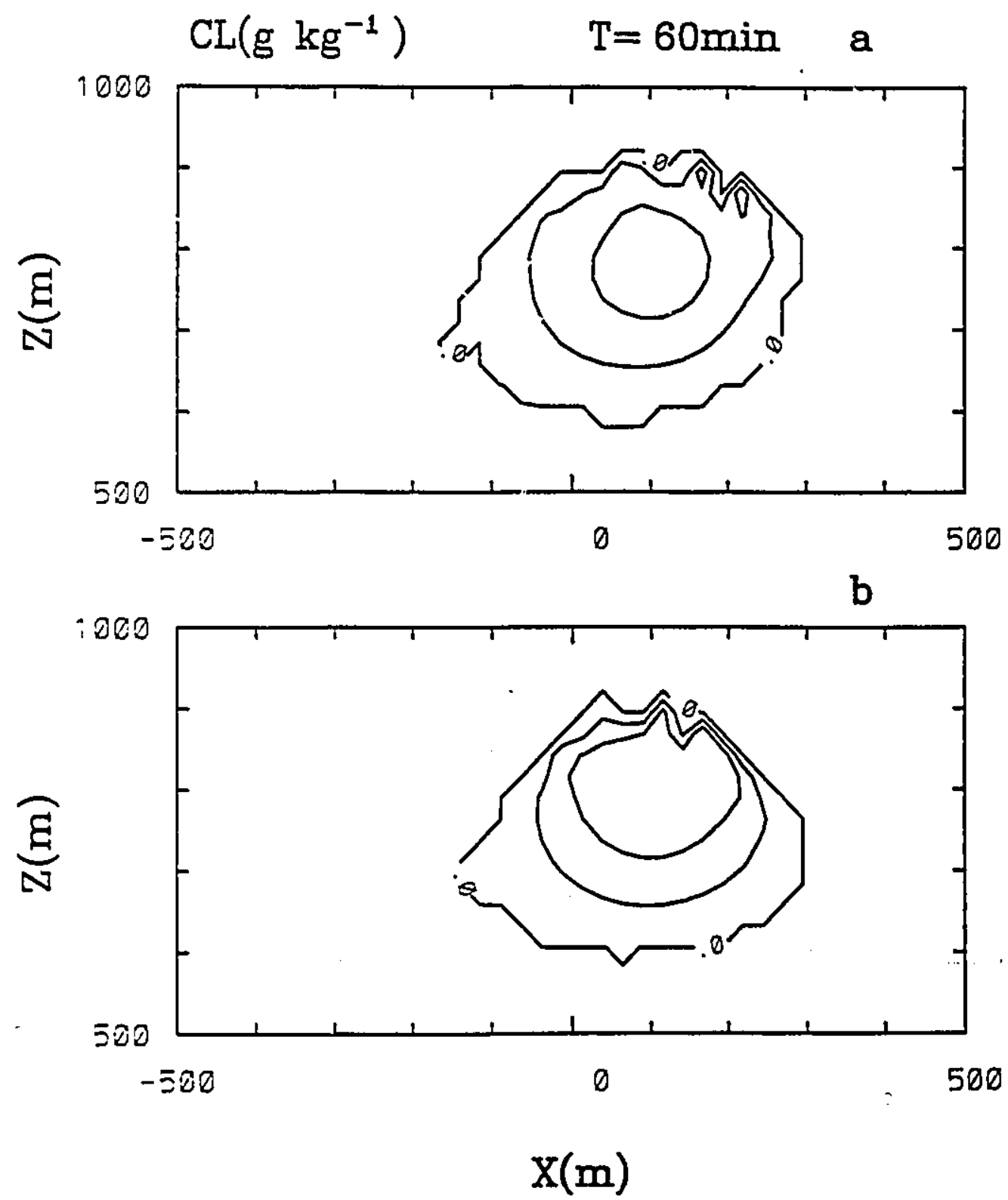

Figure 4.8: Same as Figure 4.6 but at $60 \mathrm{~min}$. 
Fig. 4.5, the increase in total cloud water content is damped in a sheared environment.

The temperature perturbation fields at $55 \mathrm{~min}$ for the two sheared simulations are shown in Fig. 4.9. Similar to the case without wind shear there are regions of enhanced cooling at the lower cloud sides. Regions with small positive temperature perturbations are found near the cloud tops in association with adiabatic warming from downward motion above the cloud top level.

To examine the effect of radiation on the dynamic fields, we display in Fig. 4.10 the vertical velocities at $55 \mathrm{~min}$. When longwave radiation is activated, the downdrafts are enhanced and they expand further downward. The stronger downdraft is associated with stronger negative temperature perturbations (see Fig. 4.9) induced by longwave radiative cooling in the vicinity $:$ : the cloud top and sides. It is noted that the changes in the downdrafts are asymmetrical. At the downshear side, the maximum downdraft is $1.5 \mathrm{~m} \mathrm{~s}^{-1}$, which is $0.4 \mathrm{~m} \mathrm{~s}^{-1}$ (or 38\%) larger than that in experiment S0.5C. At the upshear side, the maximum downdraft is $1.05 \mathrm{~m} \mathrm{~s}^{-1}$ in experiment S0.5LW, while experiment S0.5C shows maximum downdraft of $0.86 \mathrm{~m} \mathrm{~s}^{-1}$ (22\% less). Thus longwave radiation reinforces the effect of wind shear on downdrafts to yield a more asymmetric vertical velocity structure. In section 4.3 .3 , we will explore the mechanism responsible for the asymmetric behavior.

Fig. 4.11 shows the vertical distribution of maximum vertical velocity. Similar to the no shear case, the vertical velocity indicates some increase above $400 \mathrm{~m}$. However, the increases are weaker than those in the no shear CONTROL run. The percentage increases at the cloud base $(625 \mathrm{~m})$ and at the cloud center $(750 \mathrm{~m})$ are $9 \%$ and $20 \%$ respectively (for the no shear CONTROL case, they are respectively $15 \%$ and $30 \%$ ). The smaller increase is an indication of the weaker secondary circulation which develops in the sheared cloud with longwave cooling and 

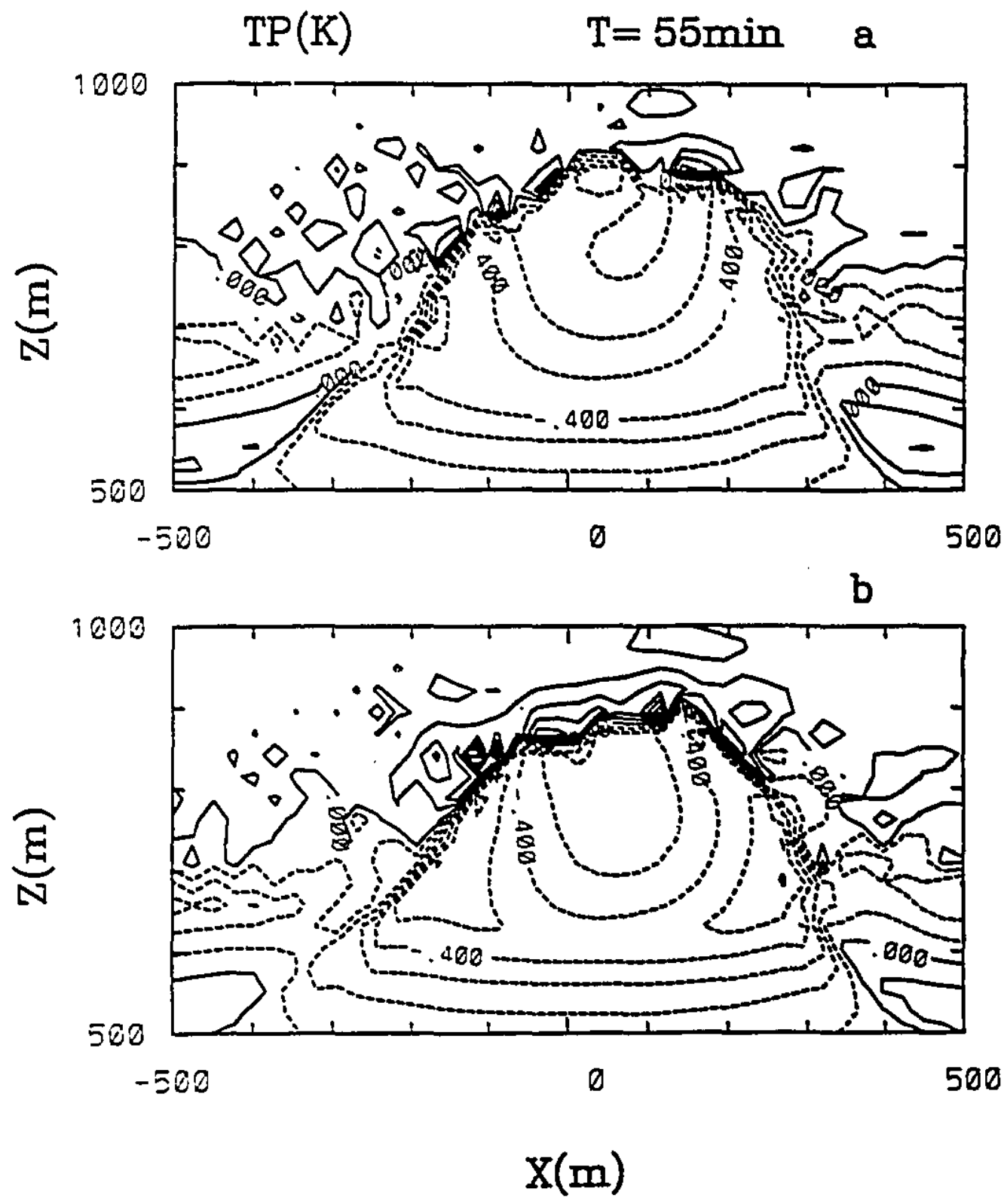

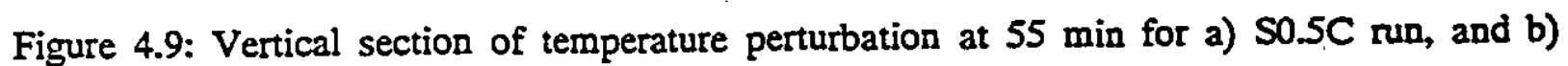
S0.5LW run. Contour interval is $0.1 \mathrm{~K}$ 

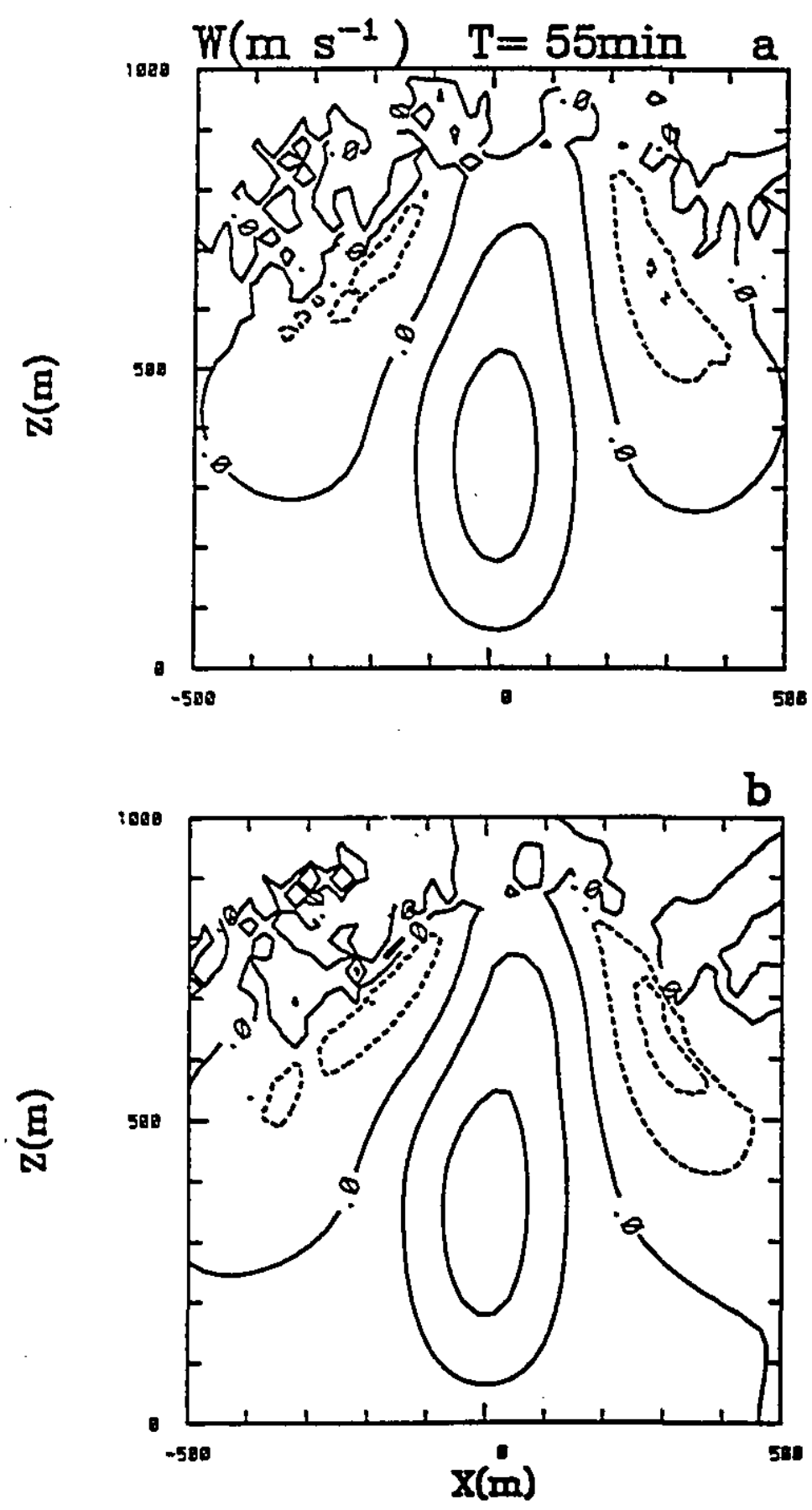

Figure 4.10: Vertical section of vertical velocity at $55 \mathrm{~min}$ for a) S0.5C run, and b) S0.5LW run.. Solid contours denote upward motion and dashed contours denote downward motion. Contour interval is $0.5 \mathrm{~m} \mathrm{~s}^{-1}$ 


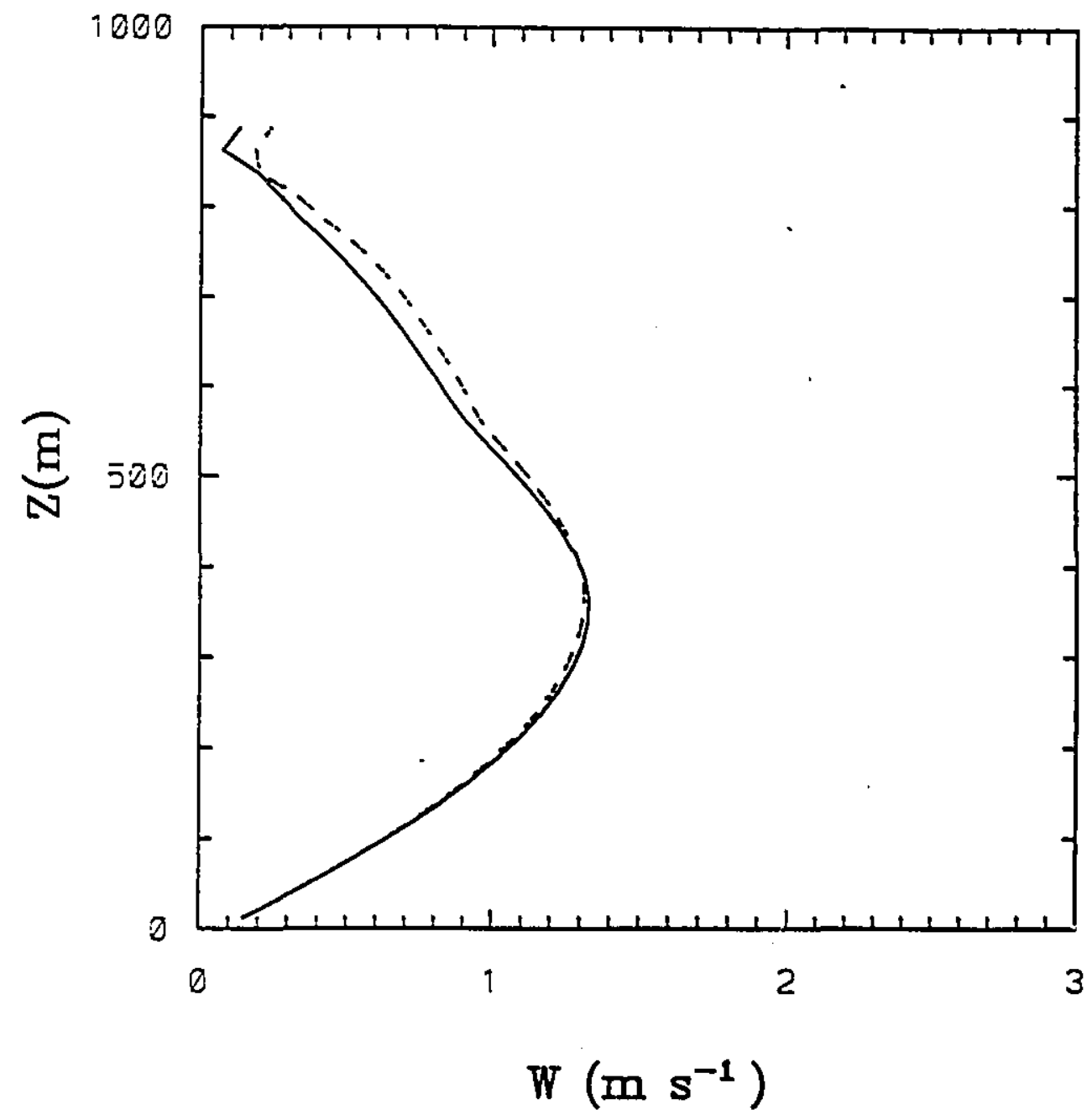

Figure 4.11: Vertical distribution of maximum vertical velocity at $55 \mathrm{~min}$ for $\mathrm{S0.5C}$ run (solid) and S0.5LW run (dashed). 
accounts for a smaller enhancement of the cloud water content in the mature stage depicted in Fig. 4.5 and Figs. 4.7-4.8. We remark that the results for experiment S0.25LW (not shown) indicate that the secoridary circulation is weaker than in the no shear CONTROL case, but stronger than in experiment SG.5LW. Thus, we conclude that in a sheared environment, the strength of the secondary circulation may depend strongly on the magnitude of the vertical wind shear.

\subsubsection{The asymmetric effects of longwave radiation on downdrafts}

To explain the asymmetric effect of longwave radiative cooling on downdrafts, we display in Fig. 4.12 the distribution of horizontal velocity and longwave radiative cooling rate (thin solid lines in intervals of $2 \mathrm{~K} \mathrm{hr}{ }^{\circ}$ ) for experiment S0.5LW at $55 \mathrm{~min}$. Note that the strongest horizontal velocity is on the downshear side. The explanation for this is that the environmental wind blows along the positive $\mathrm{x}$-direction, the transport of horizontal momentum on the upper downshear (upshear) side of the cloud is in (against) the direction of the horizontal outflow relative to the cloud. It can be seen that above $700 \mathrm{~m}$, the $u$ contour of $0.5 \mathrm{~m} \mathrm{~s}^{-1}$ extends to the right side of the cloudy region, whereas on the upshear side, the values for $\mathrm{u}$ is less than $0.5 \mathrm{~m} \mathrm{~s}^{-1}$. The distribution of longwave radiative cooling rate indicates that the strongest cooling is located in the regions where the horizontal velocity is positive (towards the right). Since the negative temperature perturbation would be advected downwind, radiative cooling enhances the development of negative buoyancy on the right flank of the cloud.

Fig. 4.13 depicts the difference in temperature perturbation (DTP) between experiments S0.5LW and S0.5C. Negative DTP values denote regions where the tsmperature perturbation (or 


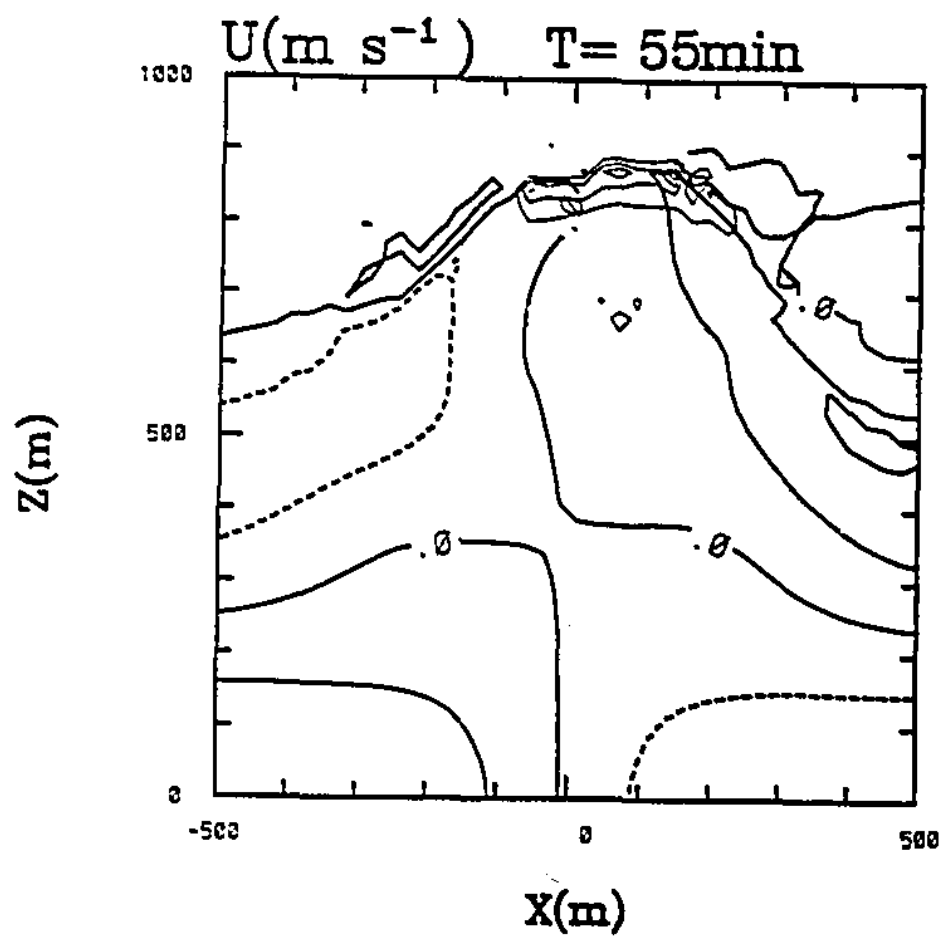

Figure 4.12: Vertical section of horizontal velocity for S0.5LW run at $55 \mathrm{~min}$. Contour interval is $0.5 \mathrm{~m} \mathrm{~s}^{-1}$. Solid lines denote the motion along the positive $\mathbf{x}$-direction. Dashed lines represent the motion along the negative $x$-direction. Thin solid lines denote the longwave radiative cooling rate. 


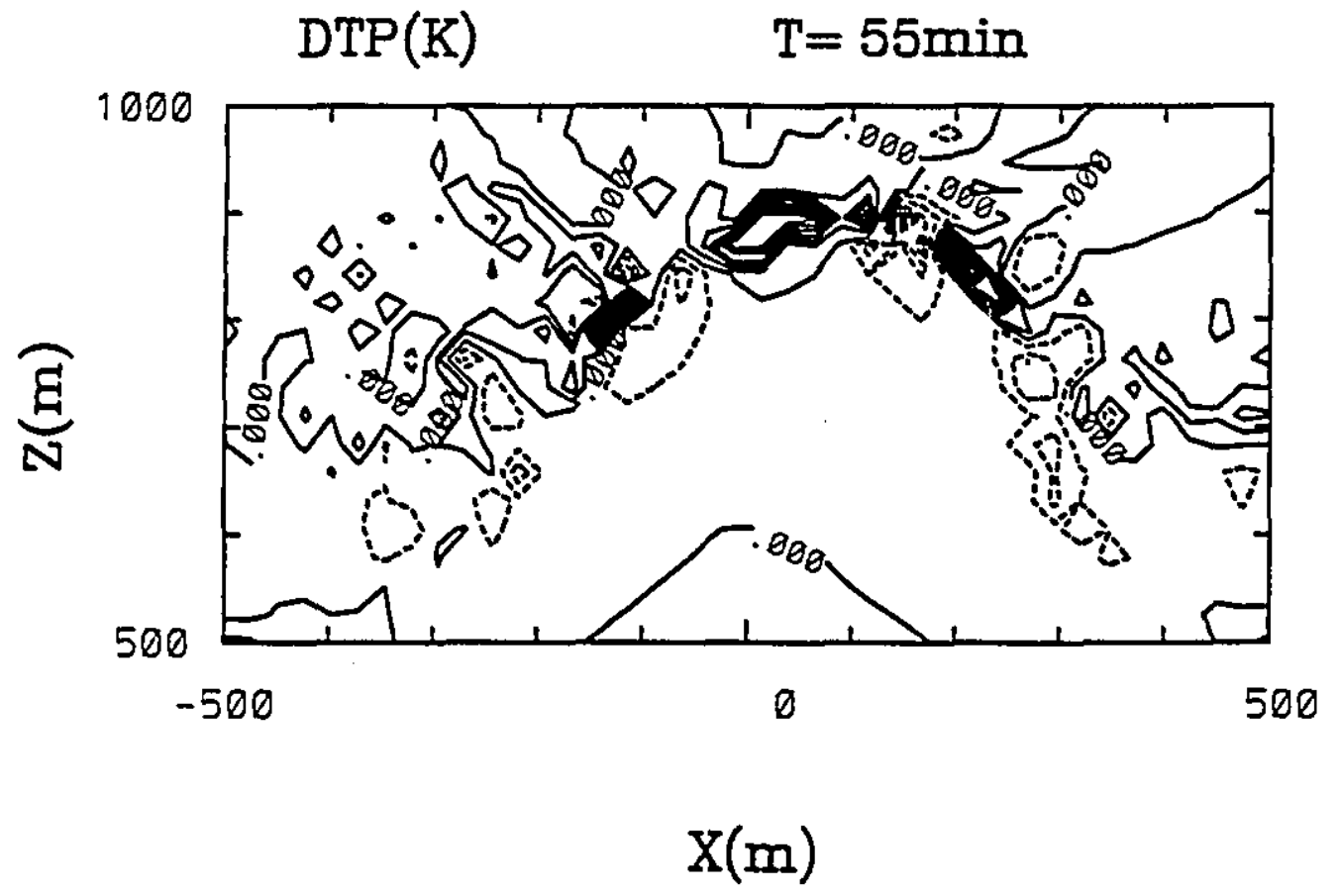

Figure 4.13: Vertical section of difference of temperature perturbation between the S0.5LW and S0.5C runs. Contour interval is $0.1 \mathrm{~K}$. 
temperature) in S0.5LW is colder than that in S0.5C. It is evident that there is enhanced cooling in S0.5LW on the upshear and downshear flanks at $(X=-75 \mathrm{~m}, \mathrm{Z}=800 \mathrm{~m})$ and $(X=300 \mathrm{~m}, \mathrm{Z}=6.50 \mathrm{~m})$. Note that these locations are within zones of strong downdrafts (see Fig. 4.10) and that both the size of the negative area and its magnitude are larger on the downshear side. Thus radiative cooling and horizontal momentum transport in a sheared environment enhance the negative temperature perturbation on the downshear flank, which in turn leads to the initiation of stronger downdrafts.

The results at later times are similar to those at $55 \mathrm{~min}$ and will not be shown.

\subsection{Conclusions}

The effects of longwave radiative cooling in a small cumulus in a sheared environment was studied using a 2-D slab-symmetric model. It was found that in qualitative agreement with the no shear case, longwave cooling strengthens the secondary circulation and the cloud water content. However, shear does suppress convection and the development of the cloud becomes weaker.

Longwave cooling also enhances the asymmetric characteristics of the simulated cloud. It was shown that in conjunction with horizontal momentum transport, radiative cooling results in a more negative temperature perturbation on the downshear flank relative to the upshear side. The downshear downdrafts therefore exhibits a stronger development. 


\section{Chapter 5}

\section{The effect of Axially Symmetric geometry}

\subsection{Introduction}

In the previous two Chapters, we investigated the effects of longwave radiation on the development of a small cumulus cloud using a two-dimensional slab-symmetric model. While this framework allows us to explore the effect of wind shear, it precludes a study of the effect of the third dimension which has been shown to affect the mode of turbulent energy transfer, the intensity of vertical motion, the ratio between the maximum updraft and maximum downdraft speeds, and the magnitude of the perturbation pressure force in a convective cloud (Murray, 1970; Soong and Ogura, 1973; Steiner, 1973, 1982; Yau, 1979). Similarly, assumptions on the geometries can also affect the distribution of longwave radiative cooling rates. For this reason, we will explore the effect of the third dimension in this chapter using an axially symmetric . model, which is the simplest model for our purpose. Our focus is to compare the effects of longwave radiation on cloud development in the two geometries in a calm environment. Similar to the slab-symmetric case presented in Chapter 3, two experiments were performed. Experiment 
$A C$ denotes the axially symmetric control run, and experiment ALW represents the axially symmetric run including longwave radiative cooling. It should be mentioned that we used the same input parameters as in Chapter 3 (i.e. the initial sounding, the grid size and time steps, and the parameters describing surface heating) to allow for a comparison with the slab-symmetric case.

The cloud dynamics model is the same version reported in Reuter and Yau (1987a;b) and the equations are described therein. The longwave radiation model is also very similar to that described in Chapter 3 except that the net flux divergence is calculated in cylindrical coordinates.

\subsection{Longwave radiative cooling rate between the slab-}

\section{symmetric and axially symmetric geometries}

To obtain a rough estimate on the effect of geometry on longwave radiative cooling rates, we first present results from the radiation models for an idealized cloud. The atmospheric profiles are the same as in Fig. 3.3. A constant LWC of $0.4 \mathrm{~g} \mathrm{~kg}^{-1}$ is assumed. For the axially symmetric geometry, the radius of the cloud is raken as $200 \mathrm{~m}$. The cloud top is at $1000 \mathrm{~m}$ and the cloud base at $600 \mathrm{~m}$. Similar parameters are used for the slab-symmetric cloud except that the linear width of the cloud is $200 \mathrm{~m}$ and the cloud is infinite in the $\mathrm{y}$-direction.

The distribution of longwave radiative cooling rates in the slab-symmetric and the axially symmetric geometries are depicted in Fig. 5.1 and Fig. 5.2 respectively. The distributions are qualitatively similar with strong cooling near the cloud top (about $6 \mathrm{~K} \mathrm{~h}^{-1}$ ) and sides (about 2 


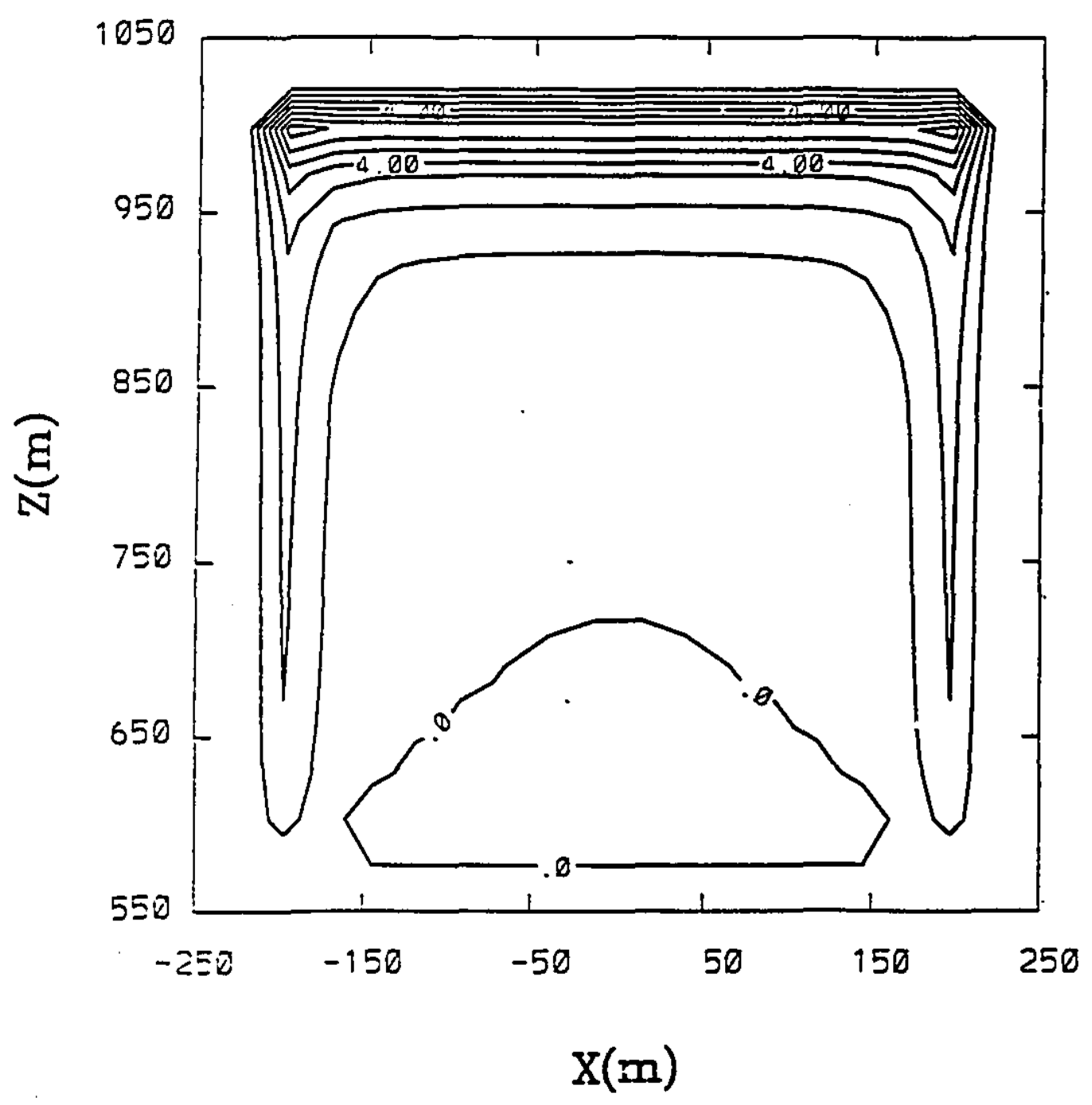

Figure 5.1: Radiative cooling rates in the idealized siab-symmetric cloud. Contour interval is 1 $\mathrm{K} \mathrm{h}^{-1}$. 


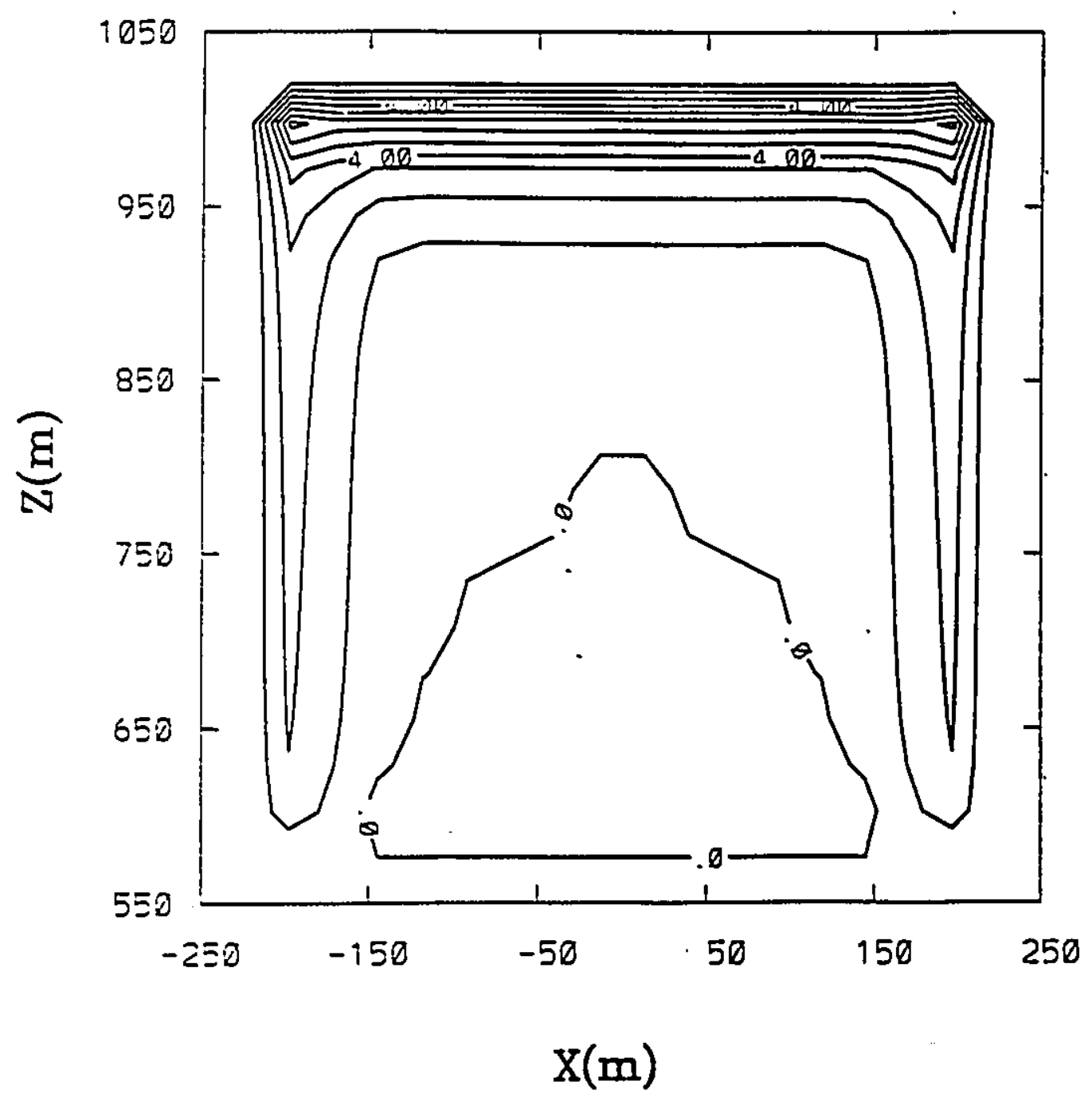

Figure 5.2: Same as Figure 5.1 except in the idealized axially symmetric cloud. 
$\mathrm{K} \mathrm{h}^{-1}$ ) but weak warming (less than $1 \mathrm{~K} \mathrm{~h}^{-1}$ ) near the cloud base. It is noteci that the cloud side cooling is slightly stronger in the axially symmetric cloud because of the effect of curvature discussed in Chaper 2. From Plate 2.1, the averaged cooling rate in the top $25 \mathrm{~m}$ of the convex perturbation is slightly stronger than the maximum from the unperturbed cloud top. On the other hand, the magnitude of the heating rate and the depth of the warming zone near the cloud base are slightly smaller in the slab-symmetric geometry because the optical thickness is larger in the $y$-direction. As a result, the radiances from the surface are more stronger attenuated in the slabsymmetric cloud than in the axially symmetric cloud.

\subsection{Comparison between the results of experiment AC}

\section{and the slab CONTROL run}

Some properties of the simulated clouds in slab-symmetric and axially symmetric gcometries are listed in table 5.1. The maximum updrafts are stronger in the axially symmetric simulation, whereas the maximum downdrafts are, in general, weaker. As a result, the ratio of the maximum downdraft speed to maximum updraft speed is larger in the slab-symmetric model.

More differences between the axially symmetric cloud and the slab-symmetric cloud are also found in the vertical cross sections of W, U, CL, and TP (Fig. 3.4 and Fig. 5.3). It can be seen that the axially symmetric cloud has a narrower downdraft region. The horizontal extent of the downdraft at a height of $500 \mathrm{~m}$ is about $175 \mathrm{~m}$ in the axially symmetric cloud, whereas it is more than $300 \mathrm{~m}$ in the slab-symmetric case. The horizontal velocity fields (Fig. 3.4b and Fig. 5.3b) indicate that both the inflow and outflow velocities are weaker in the axially symmetric 
Table 5.1. Some characteristics of the cloud evolution in experiment CONTROL and AC. Axially symmetric simulation $(\mathrm{AC})$

\begin{tabular}{|c|c|c|c|c|}
\hline Time & Cloud top & $\begin{array}{c}\text { Maximum } \\
\text { updraft } \\
(\mathrm{min})\end{array}$ & $\begin{array}{c}\text { Maximum } \\
\text { downdraft } \\
\left(\mathrm{m} \mathrm{s}^{-1}\right)\end{array}$ & $\begin{array}{c}\text { Miximum } \\
(\mathrm{CL}) \\
\left(\mathrm{g} \mathrm{kg}^{-1}\right)\end{array}$ \\
\hline 25 & 675 & 2.36 & -0.39 & 0.12 \\
\hline 30 & 825 & 2.37 & -0.78 & 0.28 \\
\hline 35 & 875 & 2.28 & -0.87 & 0.33 \\
\hline 40 & 900 & 2.09 & -0.80 & 0.39 \\
\hline 45 & 825 & 1.87 & -1.10 & 0.07 \\
\hline
\end{tabular}

Slab-symmetric simulation (CONTROL)

\begin{tabular}{|c|c|c|c|c|}
\hline $\begin{array}{c}\text { Time } \\
(\mathrm{min})\end{array}$ & Cloud top & $\begin{array}{c}\text { Maximum } \\
\text { updraft } \\
(\mathrm{m})\end{array}$ & $\begin{array}{c}\text { Maximum } \\
\text { downdraft } \\
\left(\mathrm{m} \mathrm{s}^{-1}\right)\end{array}$ & $\begin{array}{c}\text { Maximum } \\
(\mathrm{CL}) \\
\left(\mathrm{g} \mathrm{kg}^{-1}\right)\end{array}$ \\
\hline 25 & 2.08 & -0.67 & 0.00 \\
\hline 30 & 725 & 2.05 & -0.73 & 0.13 \\
\hline 35 & 775 & 1.95 & -1.06 & 0.25 \\
\hline 40 & 825 & 1.77 & -1.11 & 0.29 \\
\hline 45 & 850 & 1.66 & -1.15 & 0.34 \\
\hline 50 & 875 & 1.53 & -0.94 & 0.35 \\
\hline 55 & 900 & 1.32 & -0.89 & 0.28 \\
\hline 60 & 925 & 1.11 & -0.87 & 0.37 \\
\hline 65 & 950 & 0.93 & -0.93 & 0.26 \\
\hline
\end{tabular}



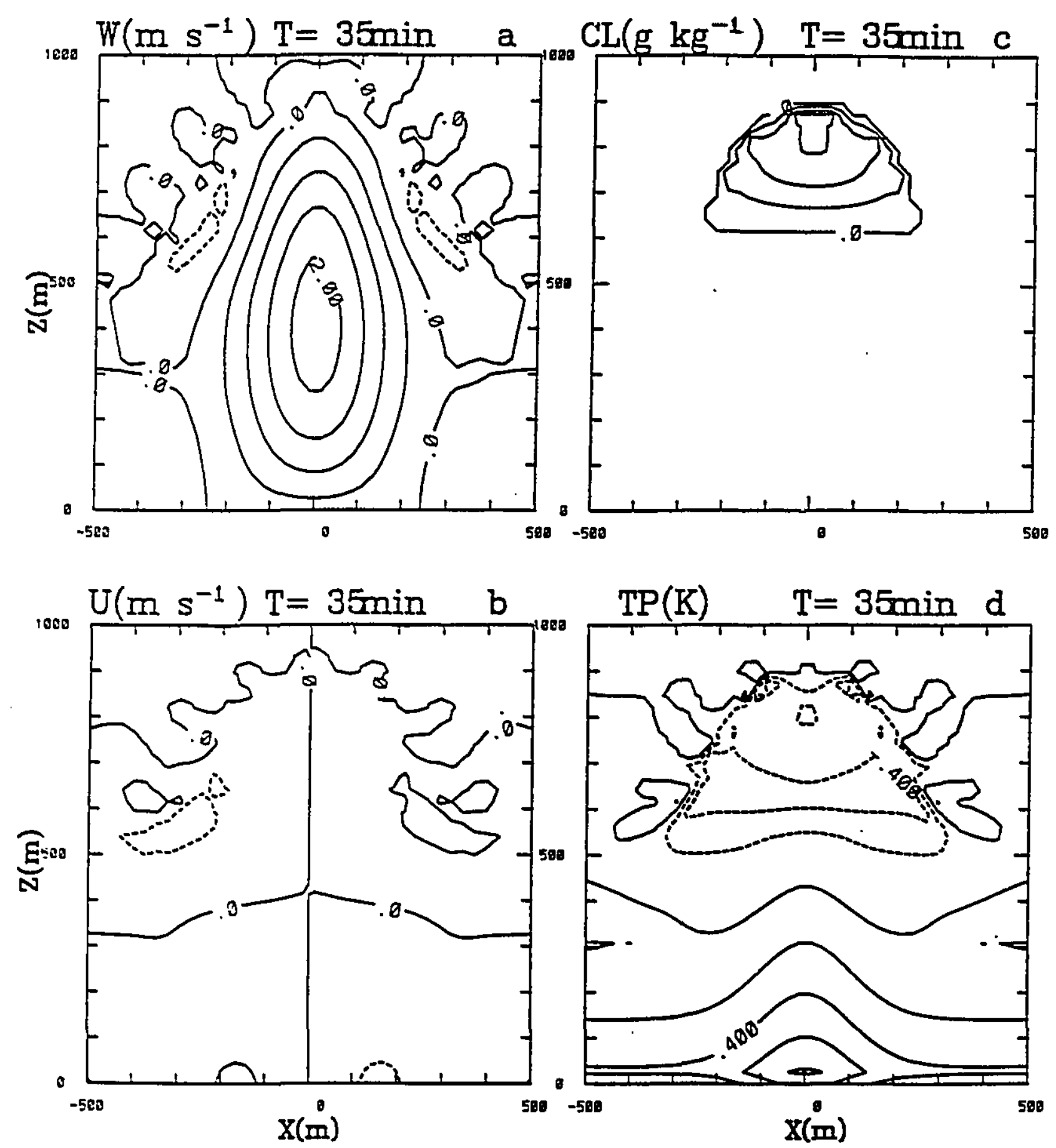

Figure 5.3: Vertical section of a) vertical velocity (W), b) horizontal velocity (U), c) cloud water mixing ratio (CL), and d) temperature perturbation (TP) at $35 \mathrm{~min}$ for the $\mathrm{AC}$ run. The contour intervals for $W, U, C L$, and TP are $0.5 \mathrm{~m} \mathrm{~s}^{-1}, 0.5 \mathrm{~m} \mathrm{~s}^{-1}, 0.1 \mathrm{~g} \mathrm{~kg}^{-1}$, and $0.2 \mathrm{~K}$ respectively. 
cloud. The magnitudes of maximum outflow for the slab-symmetric and axially symmetric clouds are 1.3 and $0.9 \mathrm{~m} \mathrm{~s}^{-1}$, respectively. As a result of the stronger updraft, more condensation (Fig. 5.3c) occurs in the axially symmetric cloud. leading to a smaller negative temperature perturbation in the cloud core (Fig. 5.3d).

It is also noted that the axially symmetric model produces a very fast cloud evolution. This is apparent from Fig. 5.4, which shows the magnitude of the maximum cloud water content as a function of time for both models. At $24 \mathrm{~min}$ the cloud forms in the axially symmetric simulation, and the maximum cloud water content continued to increase rapidly, reaching a maximum of about $0.4 \mathrm{~g} \mathrm{~kg}^{-1}$ at $41 \mathrm{~min}$. Around this time, the cloud top rises to the height of $900 \mathrm{~m}$ (Table 5.1). Because of the strong loading effect of the cloud water content, the cloud starts its decay after $41 \mathrm{~min}$. The cloud disappears completely through the evaporative process in just $5 \mathrm{~min}$. In contrast, the cloud in the slab-symmetric model develops much slower. The cloud forms at $27 \mathrm{~min}$, which is $3 \mathrm{~min}$ later than the axially symmetric case. Its subsequent evolution is also slower. The cloud starts to decay at $58 \mathrm{~min}$, which is significantly later than the axially symmetric simulation $(41 \mathrm{~min})$. It is also noted that the rate of decay is smaller. Therefore, the lifetime of the axially symmetric cloud is much shorter than that of the slabsymmetric cloud.

\subsection{Including the effects of longwave radiation}

Fig. 5.5 depicts the temporal evolution of the maximum cloud water content for experiment AC and experiment ALW. Similar to the slab-symmetric simulations, the maximum 


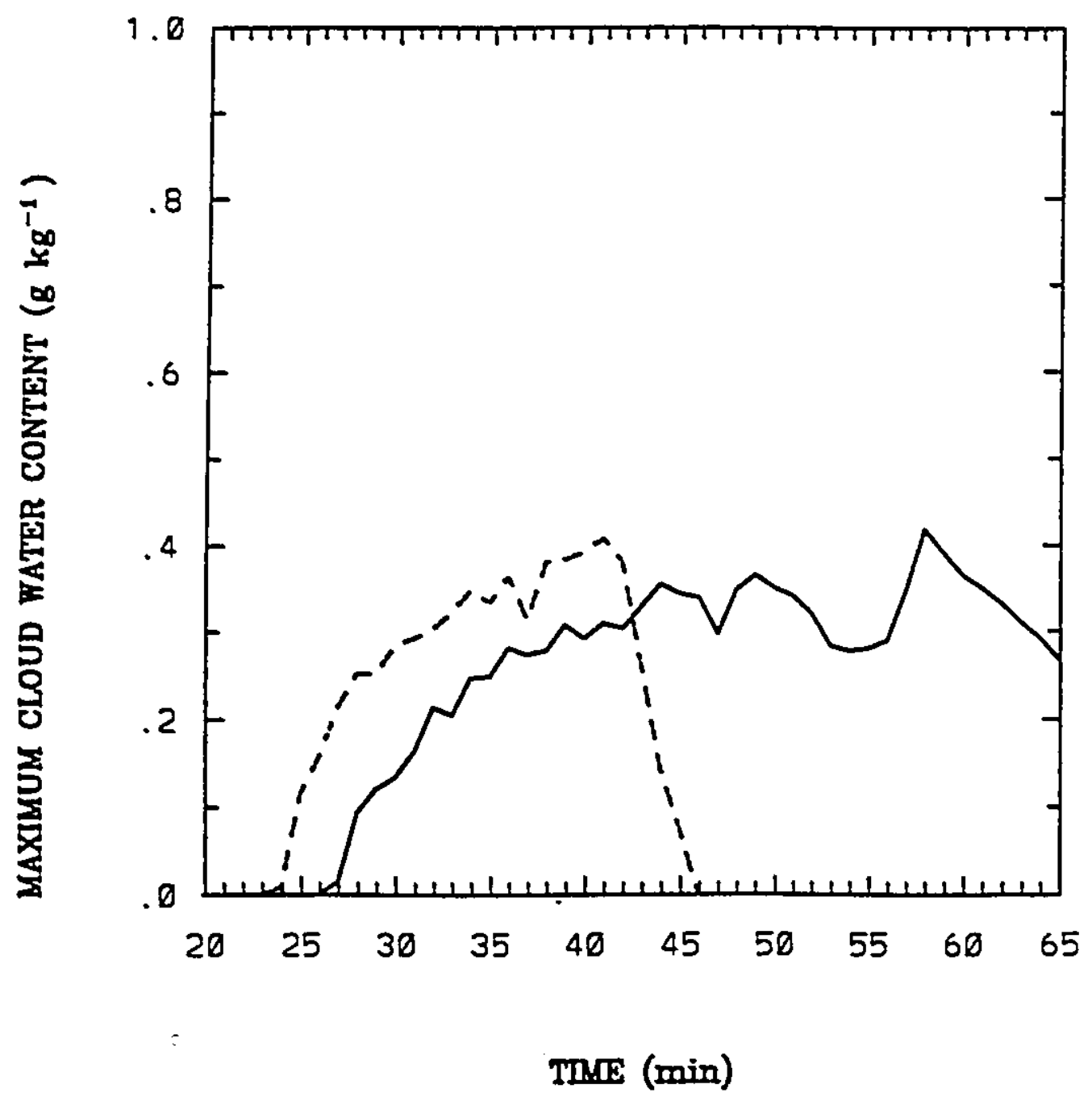

Figure 5.4: Evolution of maximum cloud water content for the CONTROL and AC runs. Solid curve denotes CONTROL run and dashed curve the AC run. 


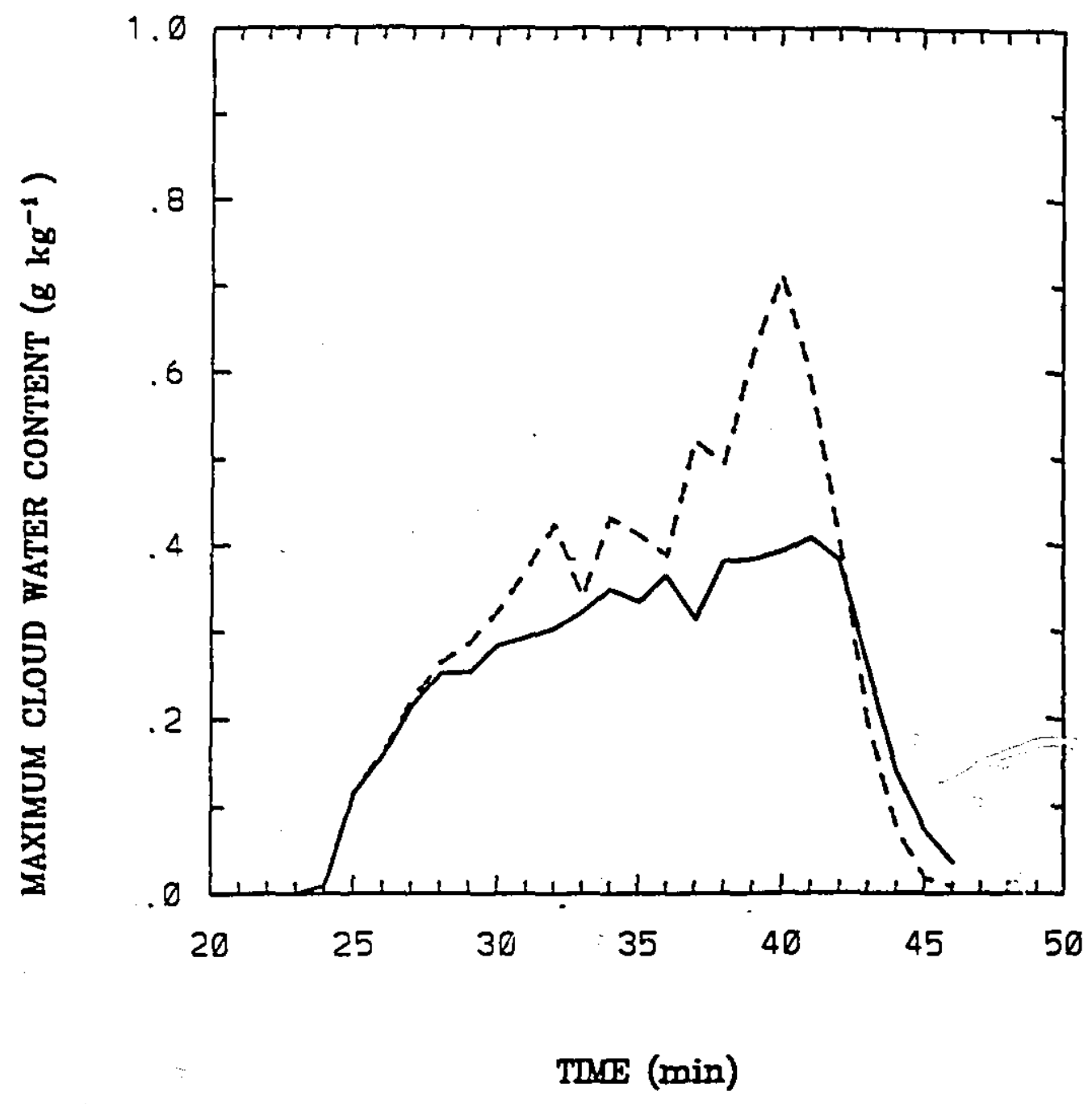

Figure 5.5: Evoiution of maximum cloud water content for the AC and ALW runs. Solid curve denotes AC run and dashed curve the ALW run. 
cloud water content displays significant increases when longwave radiation processes are included. The maximum increase is $82 \%$ at $40 \mathrm{~min}$. It can also be noted that for both simulations, the increases trecome noticeable 5-6 min after the cloud forms. Fig. 5.6 displays the vertical cross sections of cloud water content for the AC and ALW runs at the mature stage of the clouds (39 $\min$ ). The important increases in cloud water content are found mainly near the cloud top and sides. The cloud top is slightly lower in the ALW simulation.

To explore the mechanism responsible for the larger cloud water content in the ALW simulation, we first compare the vertical velocity fields for the AC and ALW runs (Fig. 5.7). It can be seen that when longwave radiation is activated, both the maximum downdraft and the area where the downdraft magnitude exceeds $0.5 \mathrm{~m} \mathrm{~s}^{-1}$ are slightly increased because of a stronger negative temperature perturbation (see Fig. 5.8) induced by longwave radiative cooling in the vicinity of the cloud top and sides. Fig. 5.9 displays the vertical velocity at the center of the cloud for the both runs. A weaker updraft is found in the ALW simulation. The results at other times (not shown) also show similar trends. We recall that in the slab-symmetric simulations, cloud side cooling produces a secondary circulation at the mature stage of the cloud ( at about $55 \mathrm{~min}$ ) to enhance the updraft. This phenomenon is however not apparent in the axially symmetric simulation. Two factors may come into play. First, it is known that the strong negative temperature perturbations near the cloud sides is a cumulative result of longwave radiative cooling. Since the lifetime of the axially symmetric cloud is shorter than the slab-symmetric cloud, the strength of the radiative cooling induced downdraft is expected to be smaller. Secondly, the airflow is not restricted to a single plane in the axially symmetric geometry. As a result, the downdrafts speed can be smaller to compensate for a given amount of upward mass 

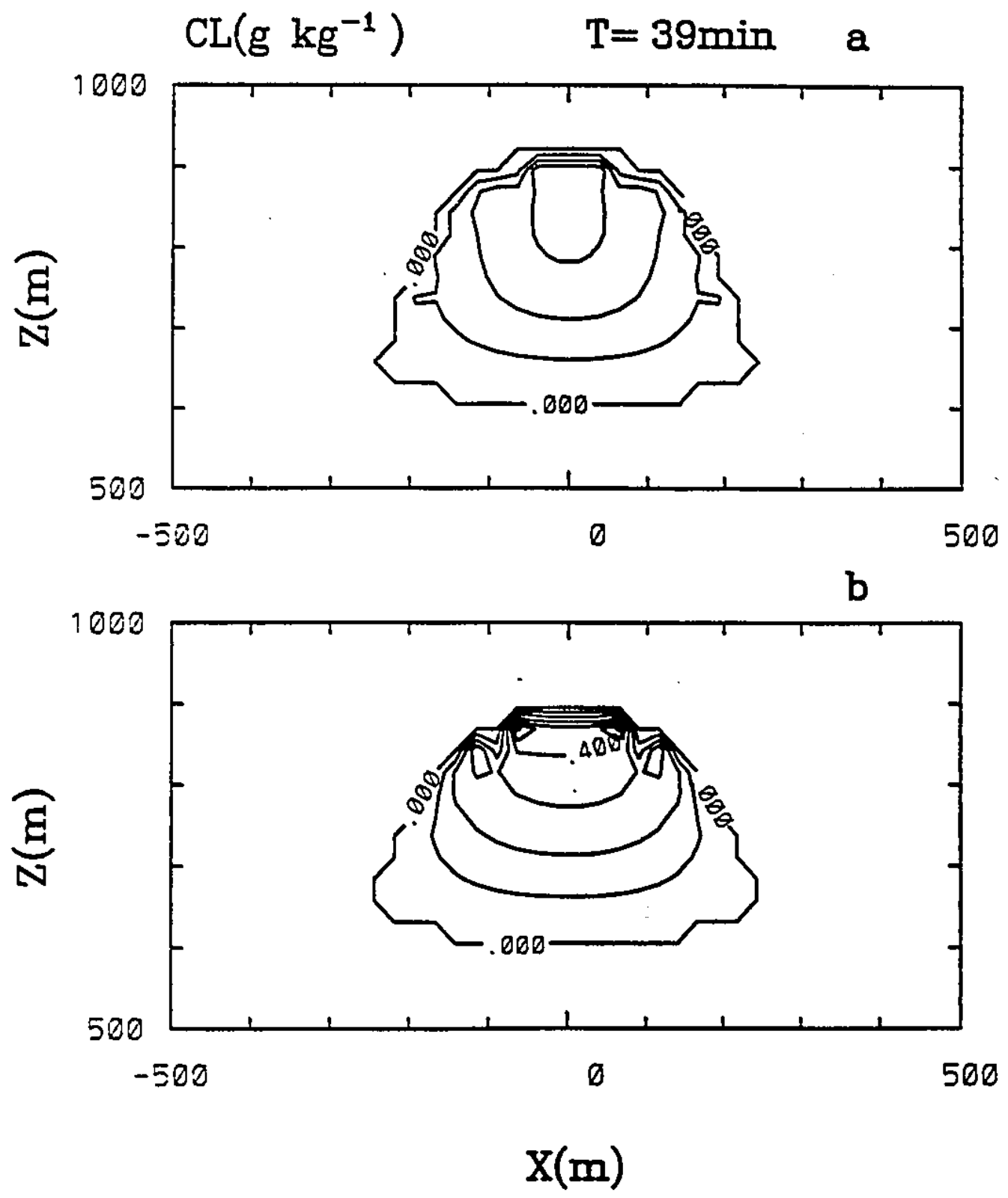

Figure 5.6: Vertical section of cloud water content at $39 \mathrm{~min}$. Contour interval is $0.1 \mathrm{~g} \mathrm{~kg}^{-1}$. a) AC run, and b) ALW run. 

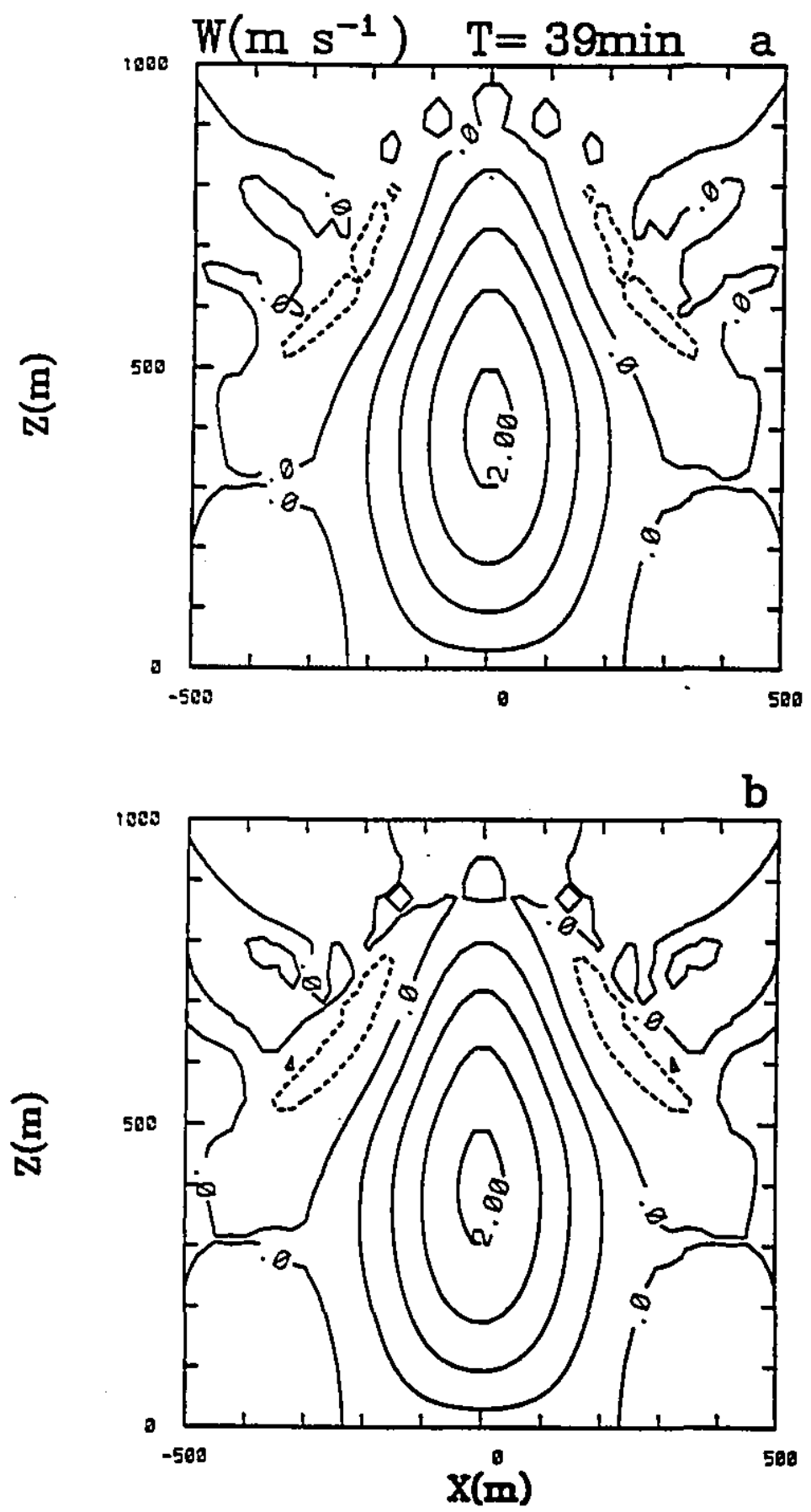

Figure 5.7: Vertical section of vertical velocity at $39 \mathrm{~min}$. Solid contours represent upward motion and dashed contours, downward motion. Contour interval is $0.5 \mathrm{~m} \mathrm{~s}^{-2}$. a) AC run. b) ALW run. 

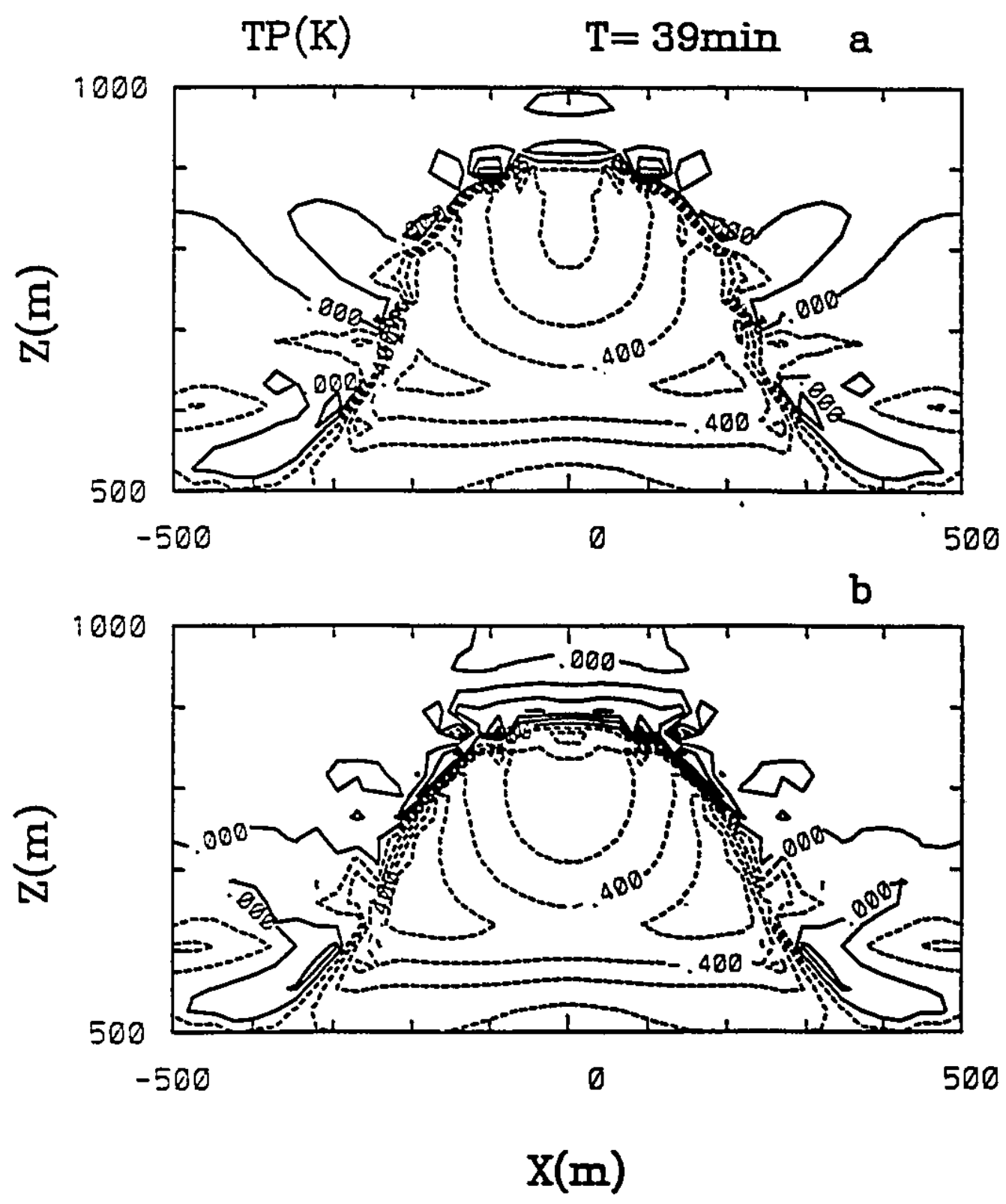

Figure 5.8: Vertical section of temperature perturbation at $39 \mathrm{~min}$. Contour interval is $0.1 \mathrm{~K}$ a) AC run. b) ALW run. 


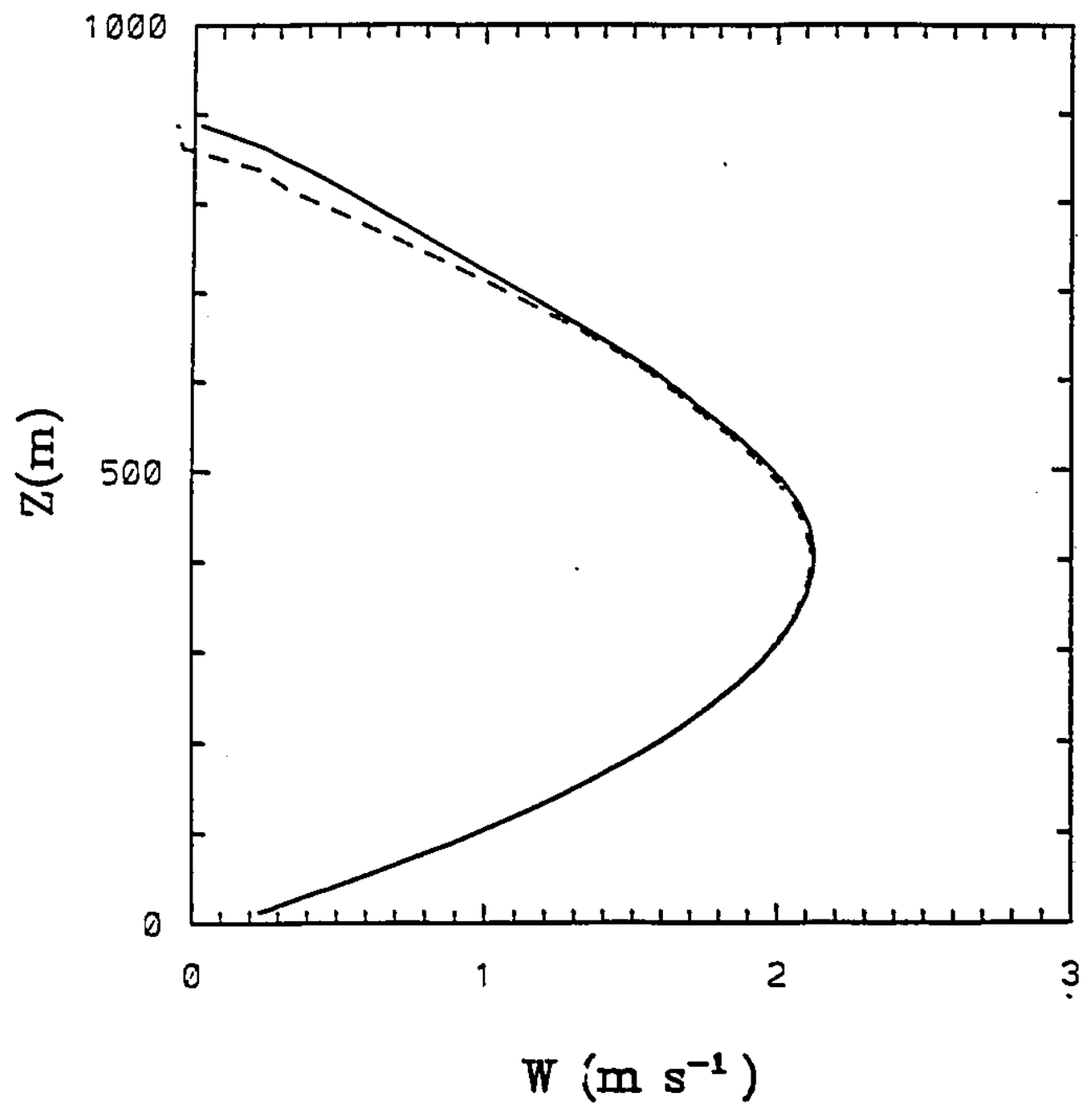

Figure 5.9: Vertical velocity at the central axis at $39 \mathrm{~min}$. Solid curve denotes AC run and dashed curve the ALW run. 
flux. For example, at the mature stage of the axially symmetric clouds ( $39 \mathrm{~min}$ ), the maximum downdraft increases from $0.82 \mathrm{~m} \mathrm{~s}^{-1}$ in experiment $\mathrm{AC}$ to $0.9 \mathrm{~m} \mathrm{~s}^{-1}$ in experiment ALW (about $10 \%$ ). On the other hand, at the mature stage of the slab-symmetric cloud (55 nin), the maximum downdraft increases from $0.89 \mathrm{~m} \mathrm{~s}^{-1}$ in experiment CONTROL to $1.28 \mathrm{~m} \mathrm{~s}^{-1}$ in experiment $\mathrm{LW}$ (about 44\%). These factors result in a weaker secondary circulation in the axially symmetric cloud so that the increase in updraft speed induced by the secondary circulation is offset by the decrease in upward motion resulting from radiative cooling (compare Fig. 5.8a, and Fig. 5.8b) and the larger cloud water loading (compare Fig. 5.6a and Fig. 5.6b) near the cloud top.

\subsection{Conclusions}

The effects of longwave radiative cooling in a small cumulus was studied using an axially symmetric model. Consistent with the slab-symmetric results, radiative cooling enhances the cloud water content and downdrafts. However, the effect of the axially symmetric geometry and the shorter cloud lifetime result in a weak secondary circulation which is offset by the decrease in upward motion induced by radiative cooling and a larger cloud water loading near the cloud top. As a result, a weaker updraft forms at the cloud core. 


\section{Chapter 6}

\section{Summary and conclusions}

In this thesis we investigated the effects of longwave radiation on the development of a small cumulus cloud by a combination of three-dimensional radiative transfer models as well as slab-symmetric and axially symmetric cloud dynamics models.

A longwave radiation model was developed to calculate the flux divergence and in-cloud radiative cooling rates. The model was first applied to the case of an isolated cumuliform cloud in the form of a cylinder. The distribution of cooling rates shows local maxima at the cloud top and sides as well as modest warming near the cloud base. The magnitude of the cooling rates depends on the temperatures of the cloud and the ground surface. For a $286 \mathrm{~K}$ cloud above a 302 $\mathrm{K}$ ground, the local cooling rates were typically $-34 \mathrm{~K} \mathrm{~h}^{-1}$ at the cloud top and $-14 \mathrm{~K} \mathrm{~h}^{-1}$ at the cloud sides. A typical local heating rate of $8 \mathrm{~K} \mathrm{~h}^{-1}$ was found at the cloud base. We proposed that the radiatively forced sinking of air at the sides of cumuliform clouds wound lead to lower-level convergence and thereby enhances the upward motion in the interior of the cloud.

Changes in cloud top cooling rates due to positive (lifting) or negative (sinking), axially symmetric perturbations to the top of horizontally extensive stratiform clouds were also 
considered. Significant effects were found that do not cancel when averaged over both positive and negative perturbations. A lifting of the cloud top does not increase the cooling rate, whereas the peak cooling rate decreases rapidly in depressions. For small perturbation, $\approx 10 \mathrm{~m}$, this may tend to inhibit the growth of negative perturbations. For larger perturbations, $\approx 100 \mathrm{~m}$. changes to the radiative cooling rates within the positive perturbations and next to the negative perturbations may act to sustain the perturbation and promote its growth.

The effect of longwave radiation on cloud microphysics and dynamics in a calm environment was then investigated. A siab-symmetric cloud was simulated which exhibited features, particularly cloud water content and thickness, in agreement with observations made in small tropical cumuli. It was also shown that a resolution of $25 \mathrm{~m}$ is sufficient for our study of the effect of longwave radiative cooling.

We demonstrated that longwave radiative cooling substantially enhances the maximum cloud water content. The maximum increase reaches $96 \%$. The total cloud water content was also increased somewhat (maximum $20 \%$ ).

The effects of longwave cooling in different stages of development of the simulated cloud were further examined and analyzed. In the initial stage of the development, the augmentation of cloud water content near the cloud top and its sides is traced mainly to the direct effect of longwave radiative cooling on cloud microphysics. In short, radiative cooling reduces the local temperature and hence the saturation water vapour pressure. The additional condensation which follows further enhances the longwave radiative cooling rate. A positive feedback process is therefore in operation.

In the mature stage of cloud, the increase of total cloud water content comes from a 
combination of the effects of radiation on microphysics and dynamics. The cooling from radiation and evaporation produce additional downward motion at the sides of the cloud. The enhanced low-level convergence invigorates the updraft promoting further cloud development.

In the decaying stage, the negative buoyancy produced by cloud top radiative cooling and a higher liquid water load speeds up the decay process in the LW run.

Similar effects were obtained in a slab-symmetric cloud in an environment with unidirectional wind shear, i.e. longwave cooling strengths the secondary circulation and the cloud water content. However, shear does suppress convection and the development of the cloud becomes weaker.

Longwave cooling also enhances the asymmetric characteristics of the simulated cloud. It was shown that in conjunction with horizontal momentum transport, radiative cooling results in a more negative temperature perturbation on the downshear flank relative to the upshear side. The downshear downdrafts therefore exhibits a stronger development.

The effect of the third dimension was then studied using an axially symmetric cloud model. Consistent with the slab-symmetric results, radiative cooling enhances the cloud water content and downdrafts. However, the shorter lifetime of the axially symmetric cloud, and the fact that the cloud side sinking motion can spread around the cloud core instead of being confined to a vertical plane, result in a weaker secondary circulation which is offset by the negative effects of cloud top radiative cooling and a higher liquid water load. As a result, a weaker updraft forms in the cloud core.

We also compared the distributions of the longwave radiative cooling rate in an idealized cloud using both the slab-symmetric and axially symmetric geometries. In general, the results for 
both models indicate qualitatively similar behavior. Small differences are detected near the cloud sides and the cloud base. The axially symmetric model produces a slightly larger heating at the cloud base and stronger cooling at the cloud sides.

Future research should be directed toward the following areas:

1) The present study shows that longwave radiation dramatically increases the maximum cloud water content. As pointed out in Chapter 3, this may have important implication to precipitation. Longwave cooling may lower the saturation water vapor pressure, and promotes the growth of cloud droplets and the formation of precipitation particles. To quantitatively investigate these effects, further study is needed using a more rigorous cloud dynamics model that includes the explicit evolution of the cloud droplet spectrum.

2) The dynamic implication to stratiform cloud mentioned in Chapter 2 is purely qualitative, and of course, requires more analysis in future studies using models with explicit dynamics. 


\section{References}

Ackerman, T. P., K.-N. Liou, F. P. J. Valero, and L. Pfister, 1988: Heating rates in tropical anvils, J. Atmos. Sci., 45, 1606-1623.

Alves, A. R., 1987: On the interaction of longwave radiation, microphysics, and turbulence in boundary layer clouds, Ph. D. thesis, 184 pp., Purdue Univ., West Lafeyette. Indiana.

Asia, T., 1964: Cumulus convection in the atmosphere with vertical wind shear: Numerical experiment, J. Meteor. Soc. Japan, 42, 245-259.

Asselin, R., 1972: Frequency filters for time integrations, Mon. Wea. Rev., 100, 487-490.

Best, A. C., 1951: Drop-size distribution in cloud and fog, Quart. J. Roy. Meteor. Soc., 77, 418426.

Carrier, L. W., G. A. Cato, and K. J. Von Essen, 1967: The backscattering and extinction of visible and infrared radiation by selected major cloud models, Appl. Opt., 6, 1209-1216.

Chen, C., and W. R. Cotton, 1983: A one-dimensional simulation of the stratus-capped mixed layer, Bound-Layer Meteor., 25, 289-321.

Chen, S., and W. R. Cotton, 1988: The sensitivity of a simulated extratropical mesoscale convective system to longwave radiation and ice-phase microphysics, J. Atmos. Sci., 45, 3897-3910.

Churchill, D. D., and R. A. Houze, Jr., 1991: Effects of radiation and turbulence on the diabatic heating and water budget of the stratiform region of a tropical cloud cluster, $J$. Atmos. Sci., 48, 903-922.

Chýlek, P., and V. Ramaswamy, 1982: Simple approximation for infrared emissivity of water clouds, J. Atmos. Sci., 39, 171-177.

P. Damiano, and E. P. Shettle, 1992: Infraed emittance of water cloud, J. Atmos. Sci., 49, 1459-1472.

Clark, T. L., and Klaassen, 1984: An examination of the penetrative downdraft mechanism in 
cumulus clouds, Proc. 9th cloud physics conference. Tallin. 523-526.

Curry, J. A., and G. F. Herman, 1985: Infrared radiative properties of summertime Aretic stratus clouds, J. Clim. Appl. Meteorol., 24. 525-538.

Davies, R., 1978: The effect of finite geometry on the :hree-dimensional transtier of solar irradiance in clouds, J. Atmos. Sci., 35, 1712-1725.

Davies, R., and A. R. Alves, 1989: Flux divergence of thermal radiation within stritiform clouds, J. Geophys. Res., 94, 16,277-16,286.

Deirmendjian, D., 1964: Scattering and polarization properties of water clouds and hazes in the visible and infrared, Appl. Opt., 3, 187-196.

Driedonks, A. G. M., and P. G. Duynkerke, 1989: Current problens in the stratocumulustopped atmospheric boundary layer, Bound.-Layer Meteor., 46, 275-303.

Dudhia, J., 1989: Numerical study of convection observed during the winter monsoon experiment using a mesoscale two-dimensional model, J. Atmos. Sci., 46, 30773107.

Duynkerke, P. G., 1989: The diunal variation of a marine stratocumulus cloud: A model sensitivity study, Mon. Wea. Rev., 117, 1710-1725.

Fu, Q., S. K. Krueger, and K.-N. Liou, 1995: Interactions of radiation and convection in simulated tropical cloud clusters, I. Atmos. Sci., 52, 1310-1328.

Gedzelman, S., 1988: In praise of altocumulus. Weatherwise, 41, 143-149.

Goody, R. M., 1964: Atmospheric Radiation, 436 pp., Clarendon Press, Oxford.

Goody, R. M., and Y. L. Yang, 1989: Atmospheric Radiation, 519 pp., Oxford University Press, New York.

Gray, W. M., and R. W. Jacobson Jr., 1977: Diumal variation of deep cumulus convection, Mon. Wea. Rev., 105, 1171-1188.

Guan, H., R. Davies, and M. K. Yau, 1995: Longwave radiative cooling rates in axially symmetric clouds, J. Geophys. Res., 100, 3213-3220.

Hale, G. M., and M. R. Querry, 1973: Optical constants for water in the 200-nm to 200- $\mu \mathrm{m}$ wavelength region, Appl. Opt., 12, 555-563.

Harshvardhan, J. A. Weinman, and R. Davies, 1981: Transport of infrared radiation in cuboidal 
clouds, J. Atmos. Sci., 38, 2500-2513.

Hedley, M., and M. K. Yau, 1988: Radiation boundary conditions in numerical modeling, Mon. Wea. Rev., 116, 1721-1736.

Heymsfield, A. J., and L. M. Miloshevich, 1991: On radiation and latent heat feedback in clouds: implications and a parameterization, J. Atmos. Sci., 48, 493-495.

Hill, G. E., 1974: Factors controlling the size and spacing of cumulus clouds as revealed by numerical experiments, J. Atmos. Sci., 31, 646-673.

Houghton, J. T., 1977: The physics of atmospheres, 203 pp., Cambridge University Press, New York.

Irvine, W. M., and J. B. Pollack, 1968: Infrared optical properties of water and ice spheres, Icarus, 8, 324-360.

Khvorostyanov, V. I., 1981: Schematization of the atmosphere's longwave radiation spectrum for cloud and fog models on the basis of high vertical resolution spectral calculations, Izv. Acad. Sc. USSR Atmos. Oceanic Phys., Eng. Transl. 17, 758-764.

Koracin, D., and D. P. Rogers, 1990: Numerical simulations of the response of the marine atmosphere to ocean forcing, J. Atmos. Sci., 47, 592-611.

Lilly, D. K., 1988: Cirrus outflow dynamics, J. Atmos. Sci., 45, 1594-1605.

Liou, K.-N., and S. C. Ou, 1979: Infrared radiative transfer in finite cloud layers, J. Atmos. Sci., 36, 1985-1996.

Liu, J. Y., and H. D. Orville, 1969: Numerical modelling of precipiiation and cloud shadow effects on mountain included cumuli, J. Atmos. Sci., 26, 1285-1297.

Malkus, J. S., 1954: Some results of a trade-cumulus cloud investigation, J. Meteor., 11, $451-467$.

Moeng, C.-H., and U. Schumann, 1991: Composite structure of plumes in stratus-topped boundary layers, J. Atmos. Sci., 48, 2280-2291.

Moeng, C.-H., S.-H. Shen, and D. A. Randall, 1992: Physical processes within the nocturnal stratus-topped boundary layer, J. Atmos. Sci., 49, 2384-2401.

Murry, F. W., 1970: Numerical models of a tropical cumulus cloud with bilateral and axial symmetry, Mon. Wea. Rev., 98, 14-28. 
Nicholls, S., 1984: The dynamics of stratocumulus: Aircraft observations and comparisons with a mixed layer model, Quart. J. Roy. Meteor. Soc., 110, 783-\$20.

Ogura, Y., and N. A. Phillips, 1962: Scale analysis of deep and shallow convection in the atmosphere, J. Atmos. Sci., 19, 173-179.

Ogura, Y., 1963: The evolution of a moist convective element in a shallow, conditionally unstable atmosphere: A numerical calculation, J. Atmos. Sci., 20, 407-424.

Orville, H. D., 1965: A numerical study of the initiation of cumulus clouds over mountainous terrain, J. Atmos. Sci., 22, 684-699.

Pennell, W. T., and M. A. Le Mone, 1974: An experimental study of turbulence structure in the fair-weather trade wind boundary layer, J. Atmos. Sci., 31, 1308-1323.

Pinnick, R. G., S. G. Jennings, P. Chýlek, and H. J. Auvermann, 1979: Verification of a linear relationship between IR extinction, absorption and liquid water content of fogs, J. Atmos. Sci., 36, 1577-1586.

Platt, C. M. R., 1975: Infrared emissivity of cirrus----simultaneous satellite. lidar and radiometric observation, Quart. J. Roy. Meteor. Soc., 101, 119-126.

- 1976: Infrared absorption and liquid water content in stratocumulus cloud, Quart. J. Roy. Meteor. Soc., 102, 553-561.

Reuter, G. W., 1985: Observations and numerical simulations of mixing mechanisms in South African cumulus congestus clouds, Stormy Weather Group Sci. Rep. MW-95, McGill University, 286pp.

—, and M. K. Yau, 1987a: Mixing mechanisms in cumulus congestus clouds. Part II: Numerical simulations, J. Atmos. Sci., 44, 798-827.

$\longrightarrow$, and - 1987b: Numerical modeling of development in a sheared environment, Contrib. Atmos. Phys., 60, 65-80.

Roewe, D., and K.-N. Liou, 1978: Influence of cirrus clouds on the infrared cooling rate in the troposphere and lower stratosphere, J. Appl. Meteorol., 17, 92-105.

Rogers, D. P., and D. Koracin, 1992: Radiative transfer and turbulence in the Cloud-topped $\therefore$ marineatmospheric boundary layer, J. Atmos. Sci., 49, 1473-1486.

Rogers, R. R., and M. K. Yau, 198\%: A short course in cloud physics, 293 pp., Pergamon Press.

Slingo, A., S. Nicholls, and J. Schmetz, 1982: Aircraft observitions of marine stratocumulus 
during JASIN, Quart. J. Roy. Meteor. Soc., 108, 833-856.

Sommeria, G., 1976: Three-dimensional simulation of turbulent processes in an undisturbed trade wind boundary layer, J. Atmos. Sci., 33, 216-241.

Soong, S.-T., and Y. Ogura, 1973: A comparison between axisymmetric and slab-symmetric cumulius cloud models, J. Atmos. Sci., 30, 879-893.

Starr, D. O'C., and S. K. Cox, 1985: Cirrus clouius. Part II: Numerical experiments on the formation and maintenance of cirrus, J. Atmos. Sci., 42, 2682-2694.

Steiner, J. T., 1973: A three-dimensional model of cumulus cloud development, J. Atmos. Sci., $30,414-435$.

- 1982: An axially symmetric cloud model: Development and simulation, Storm Weather Grop Sci. Rep. MW-94, McGill University, Montreal, 55pp.

Stephens, G. L., 1978: Radiation properties in extended water clouds, I, Theory, J. Atmos. Sci., 35, 2111-2122.

J. Atmos. Sci., 36, 1542-1556.

—, and R. W. Preisendorfer, 1984: Multimode radiative transfer in finite optical media, II, Solutions, J. Atmos. Sc:- 41, 752-735.

Sui, C.-H., K.-M. Lau, W.-K. Tao, and J. Simpson, 1991: A study of water budget in tropical convective systems: Application to climate change, Fifth Conf. on Climate Variantions, Amer. Meteor. Soc., Denver, 291-294.

Sweet, R. A., 1973: Direci methods for the solution of Poisson's equation on a staggered grid, J. Comput. Phys., 12, 422-428.

Tao, W.-K., J. Simpson, and S. T. Soong, 1991: Numerical simulation of a subtropical squall line over Taiwan Strait, Mon. Wea. Rev., 119, 2699-2723.

-

$\longrightarrow$ - C.-H. Sui, B. Ferrier, S. Lang, J. Scala, M.-D. Chou, and K. Pickering, 1993: Heating, moisture and water budgets of tropical and midlatitude squall lines: Comparisons and sensitivity to longwave radiation, J. Atmos. Sci., 50, 673-690.

Telford, J. W., and P. B. Wagner, 1980: The dynamic and liquid water structure of the small cumulus as determined from its environment, Pure and Appl. Geophys., 118, 935952. 
Tripoli, G., and W. R. Cotton, 1989: A model of midlatitude squall lines, Quart. J. Roy: Meteor. Soc., 108, 739-762.

Twomey, S., 1983: Radiative effects in California stratus, Contrib. Atmos. Phys, 56, 429-439.

Veyre, P., G. Sommeria, and Y. Fouquart, 1980: Modélisation de leffet des hétérogénétés du champ radiatif infra-rouge sur la dynamique des nuages, J. Rech. Atmos., 14. 89-10s.

Webster, P. J., and G. L. Stephens, 1980: Tropical upper-tropospheric extended clouds: Infreneccs from winter MONEX, J. Atmos. Sci., 37, 521-1541.

Welch, R. M., S. K. Cox, and J. M. Davies, 1980: Solar radiation and clouds, Meteorol. Mon., 17, 1-96.

Wiscombe, W. J., 1979: Mie scattering calculations: Advances in technique and fast, vectorspeed computer codes, Tech. Note TN140+STR, 91 pp., Natl. Cent. for Atmos. Res., Boulder, Colo..

Xu, K.-M., and D. A. Randall, 1995: Impact of interactive radiative transfer on the macroscopic behavior of cumulus ensembles. Part I: Radiation parameterization and sensitivity tests, J. Atmos. Sci., 52, 785-799.

Xu, K.-M., and D. A. Randall, 1995: Impact of interactive radiative transfer on the macroscopic behavior of cumulus ensembles. Part II: Mechanisms for cloud-radiation interactions, J. Atmos. Sci., 52, 800-817.

Yamamoto, G., M. Tanaka, and S. Asano, 1971: Radaiative heat transfer in water clouds by infrared radiation, J. Quant. Spectrosc. Radiat. Transfer, 11, 697-708.

Yau, M. K., 1979: Perturbation pressure and cumulus convection, J. Atmos. Sci., 36, 690-694.

Yau, M. K., 1980: The effects of evaporation, water load and wind shear on cloud development in a tree-dimensional numerical model, J. Atmos. Sci., 37, 488-494. 